ALEXANDRE NASCIMENTO TOMOYOSE

COMPARAÇÃO E CLASSIFICAÇÃO DE TÉCNICAS DE ESTEREOSCOPIA PARA REALIDADE AUMENTADA E JOGOS

São Paulo

2010 


\section{COMPARAÇÃO E CLASSIFICAÇÃO DE TÉCNICAS DE ESTEREOSCOPIA PARA REALIDADE AUMENTADA E JOGOS}

Dissertação apresentada à Escola Politécnica da Universidade de São Paulo para obtenção do título de Mestre em Engenharia

São Paulo

2010 


\section{COMPARAÇÃO E CLASSIFICAÇÃO DE TÉCNICAS DE ESTEREOSCOPIA PARA REALIDADE AUMENTADA E JOGOS}

Dissertação apresentada à Escola Politécnica da Universidade de São Paulo para obtenção do título de Mestre em Engenharia

Área de Concentração:

Sistemas Digitais

Orientador:

Prof. Livre-Docente Romero Tori

São Paulo 


\section{FICHA CATALOGRÁFICA}

Tomoyose, Alexandre Nascimento

Comparação e classificação de técnicas de estereoscopia para realidade aumentada e jogos / A.N. Tomoyose. -- São Paulo, 2010.

p.

Dissertação (Mestrado) - Escola Politécnica da Universidade de São Paulo. Departamento de Engenharia de Computação e Sistemas Digitais.

1. Estereoscopia 2. Renderização 3. Realidade virtual 4. Jo gos de computador I. Universidade de São Paulo. Escola Politéc- nica. Departamento de Engenharia de Computação e Sistemas Digitais II. t. 


\section{DEDICATÓRIA}

Dedico este trabalho à meus familiares. 


\section{AGRADECIMENTOS}

Ao orientador, colega e amigo Romero Tori pelo estímulo e confiança depositada.

Aos colegas de laboratório e amigos em tempo integral: Cleber Gimenez Correa, Daniel Calife, Daniel Makoto Tokunaga, Fabio Carmo, Fernando Tsuda, João Luiz Bernardes Jr., Mariza Ushijima Leone, Lucas Padovani Trias, Ricardo Nakamura, Roberto Cezar Bianchini, Silvio Ricardo Sanches, Valdinei Silva e tantos outros que conheci nesses anos de Interlab.

Aos estudantes de design: Carina Missae Costa e Pedro Gardel Câmara pela animação e suporte sempre que precisei de um toque artístico mais requintado.

A minha esposa: Juliana Saltini de Mattos Tomoyose pelo apoio incondicional. 


\section{RESUMO}

A estereoscopia é a área do conhecimento que aborda a visão em três dimensões, mas se limita, por definição, apenas às técnicas que possibilitam a reconstituição de uma cena tridimensional observada através de pelo menos dois pontos de vista distintos, que no caso dos seres humanos é a cena reconstituída no cérebro a partir das imagens obtidas pelos olhos. Inicialmente, o presente trabalho consolida os principais conceitos e técnicas desta área abrangente, para em seguida propor formas de análise, comparação e classificação de técnicas de estereoscopia através de conceitos teóricos e métricas qualitativas e quantitativas. Complementando esta proposta, com base na revisão da literatura e nos resultados experimentais, a pesquisa busca avaliar vantagens e desvantagens entre as técnicas estereoscópicas e na estereoscopia como um todo, para alimentar discussões, tendências e desafios encontrados na aplicação da estereoscopia a sistemas de Realidade Aumentada (RA), em particular sistemas de tele-presença com vídeo-avatar, e na área de jogos.

Palavras-chave: Estereoscopia. Renderização. Realidade virtual. Jogos de computador. 


\begin{abstract}
Stereoscopy is the area of knowledge that addresses three dimensional vision, but its restricted to, by definition, the techniques that allows the reconstruction of a three dimensional scene observed from two different points of view at least, in the case of human beings it is the scene reconstructed in the brain from the images obtained by the eyes. Initially, the present work consolidates the main concepts and techniques of this extended area, considering, after that, ways of analysis, comparison and classification of stereoscopy techniques through qualitative and quantitative metrics and theorical data. Additionally, based on literature review and in experimental results, the research trys to evaluate advantages and disadvantages between stereoscopy techniques and in stereoscopy as a whole, to stimulate discusson, trends and challenges found when merging stereoscopy to Augmented Reality (AR) systems, in particular tele-presence systems with video-avatar, and computer games.
\end{abstract}

Keywords: Stereoscopy. Rendering. Virtual reality. Computer games. 


\section{LISTA DE ILUSTRAÇÕES}

Figura 1 - Imagens conceituais do AVTC. Ambiente virtual (a), Vídeo da pessoa (b) e o resultado da composição (c) (SISCOUTTO, 2003).

Figura 2 - Real-Virtual Continuum 20

Figura 3 - Cenas dos filmes "Who Framed Roger Rabbit" (esquerda) e "Space Jam" (direita) (AWN SHOWCASE, 2005; ADOROCINEMA.COM, 2007).

Figura 4 - Imagens do FootBot AR (esquerda) e TanSpace(direita) por Daniel Calife.

Figura 5 - Anatomia do olho humano (WIKIPEDIA, 2008). 25

Figura 6 - Da esquerda para a direita: (a) o inseto move a cabeça para determinar a distância do objeto; (b) o objeto é movido simultaneamente no sentido oposto, parecendo estar mais próximo; (c) o objeto é movido no mesmo sentido, parecendo estar mais longe (COLLETT, 2004).

Figura 7 - Exemplo de efeito da perspectiva (baseado em SISCOUTTO et al., 2006)

Figura 8 - Exemplo de efeito da iluminação. (a) Sem iluminação. (b) lluminação com sombra na superfície do próprio objeto. (c) Idem a (b) adicionando as sombras sobre outras superfícies. (SISCOUTTO et al., 2006) .29

Figura 9 - Exemplo de oclusão parcial (SISCOUTTO et al., 2006). .30

Figura 10 - Imagem de gramado ilustrando o efeito do gradiente da textura (PHOENIX TROPICALS, 2008).

Figura 11 - Exemplo de distorção do meio, causado pela névoa suspensa no ar (O'BRIEN, 2008).

Figura 12 - Exemplo de distorção quando o meio é a água em imagem obtida por mergulhador (DAVY JONES LOCKER, 2007)...

Figura 13 - Diagrama básico de um estereoscópio e um exemplo deste equipamento (SISCOUTTO et al., 2006). 
Figura 14 - Exemplos de visualizadores de slides estéreo (REEL 3D, 2008).

Figura 15 - O par estéreo superior está preparado para visão paralela e o inferior para visão cruzada (KLEIN, 2008)

Figura 16 - A esquerda um estereograma de pontos aleatórios com o texto "3D" e a direita um estereograma de textura com um ponto de interrogação (BEENE, 2008; BWH VENTURES, 2008).

Figura 17 - Imagem do jogo Magic Carpet em estereograma. A cena é uma visão área de um morro com vegetação esparsa e uma estrutura na forma de " $\pi$ " ao centro.

Figura 18 - A esquerda óculos com filtro para criar efeito Pulfrich e a direita quadros de uma animação, enquanto o olho sem filtro percebe o quadro atual 20 olho com filtro ainda visualiza o quadro 1 (SISCOUTTO et al., 2006).

Figura 19 - Óculos com filtro ChromaDepth e diferença na distância percebida para diferentes cores (SISCOUTTO et al., 2006).

Figura 20 - Anaglifo clássico com imagem em escala de cinza quando visto a olho nú e óculos para visualização de anaglifos, com filtros vermelho e azul (3D EXPERIENCE, 2006; RAINBOW SYMPHONY, 2000)

Figura 21 - Anaglifo colorido, também chamado de colorglyph (BURDER, 2005). ...41

Figura 22 - Imagem em ColorCode 3-D e óculos com filtros ColorCode (COLORCODE, 2008).

Figura 23 - Gráficos com a sensibilidade do olho humano (cima) e a resposta dos filtros ColorCode (baixo) a diferentes comprimentos de onda da luz visível (baseado em DEEB; MOTULSKY 2005; US PATENT 6687003). .44

Figura 24 - Padrões de polarização da luz (baseado em NAVE, 2006) 45

Figura 25 - Óculos com filtros polarizados e esquema de visualização estereoscópica por polarização da luz (AMAZON, 2008; baseado em WAACK, 2004). 46

Figura 26 - Óculos obturador em versão com fio e sem fio (SISCOUTTO et al., 2006). 
Figura 27 - Imagem resultante de sistema usando HMD de vídeo e o HMD ARVision-3D com tecnologia video see-through e duas câmeras acopladas (KONDO et al., 2007; INITION, 2008).

Figura 28 - Imagem resultante de sistema usando HMD óptico e o HMD ProView XL40/50 com tecnologia optical see-through (PIEKARSKI, 2004; SILVA, 2003)......50

Figura 29 - Cartão holográfico criado por Schreck (2008). Na parte superior estão as imagens iniciais, a esquerda o esquema de funcionamento desta técnica e na direita o resultado final. 52

Figura 30 - Esquema do comportamento óptico das lentes lenticulares (ROBERTS, 2003). 53

Figura 31 - Fotografia da solução desenvolvida pelo ICT. Notar o detalhe da parte oclusa de trás da cabeça reconstruída refletida no vidro (JONES et al., 2007). 54

Figura 32 - Imagens usadas por Gasperini (2002) em uma animação de par estéreo alternado. .55

Figura 33 - Esquemas de funcionamento dos monitores autoestereoscópicos. Junção das imagens esquerda e direita (esquerda) e o que ocorre na observação do monitor (baseado em WEINAND 2005b).

Figura 34 - Esquemas do funcionamento dos monitores polarizados. Geração das imagens polarizadas (cima) e como o observador visualiza as imagens de forma estereoscópica (baseado em ZALMAN, 2008).

Figura 35 - Arquitetura conceitual do AVTC (SISCOUTTO, 2003). 60

Figura 36 - Imagens do protótipo da arquitetura AVTC. Visão esquerda (a), Visão direita (c) e o resultado estéreo para óculos obturadores (b) (SISCOUTTO 2003)...61 Figura 37 - Arquitetura das classes de visualização do CyberMED e o resultado em anaglifo colorido de uma imagem de um coração (SANTOS; MACHADO, 2008).....62 Figura 38 - Esquema de montagem do IllusionHole (baseado em KITAMURA et al., 2001). 63

Figura 39 - IllusionHole em ação e os pontos de vista dos observadores (baseado em KITAMURA et al., 2001). .64 
Figura 40 - Imagem gerada pelo protótipo em Java. Superior direito: renderização normal, inferiores: par anaglífico vermelho/ciano, superior esquerdo: anaglifo completo.

Figura 41 - Imagem renderizada em anaglifos do teste de profundidade gerada pelo protótipo em OpenGL .80

Figura 42 - Diagrama UML com principais componentes do sistema...... 81

Figura 43 - Diagrama com as implementaçoes do módulo Render. 83

Figura 44 - Diagrama ilustrando a organização das cenas 83

Figura 45 - Teste de Profundidade. Imagem sem estereoscopia (esquerda) e em anaglifos (direita) .86

Figura 46 - Teste de Proporção. Imagem sem estereoscopia (esquerda) e em anaglifos (direita) .87

Figura 47 - Teste de Interação. Imagem sem estereoscopia (esquerda) e em anaglifos (direita) .88

Figura 48 - Teste de Posição Relativa. Imagem sem estereoscopia (esquerda) e em anaglifos (direita) 89 


\section{LISTA DE TABELAS}

Tabela 1 - Classificação das características levantadas para os testes

Tabela 2 - Restrições das soluções estereoscópicas...........................................75

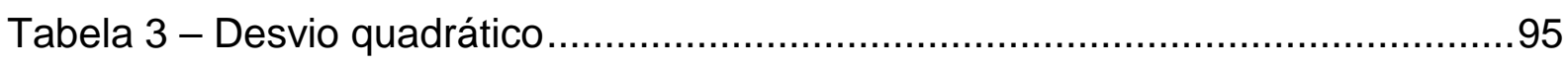

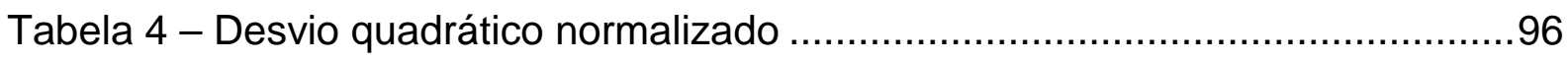

Tabela 5 - Classificação das soluções estereoscópicas através dos tipos de emissores e receptores ..................................................................................... 101 


\section{SUMÁRIO}

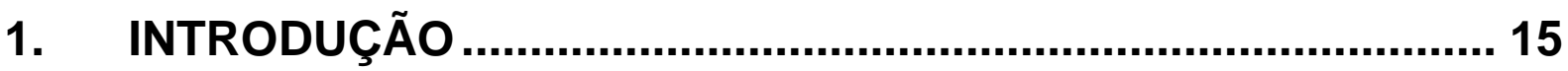

1.1 Justificativa ............................................................................ 17

1.2 Realidade Virtual e Jogos.............................................................19

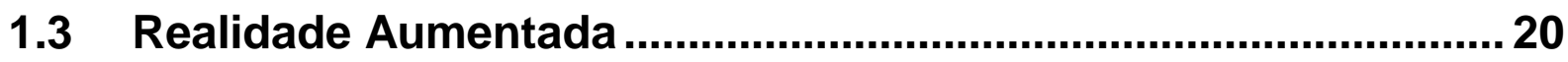

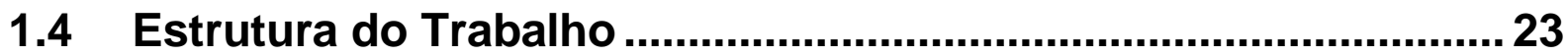

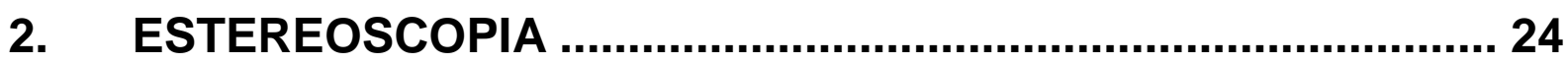

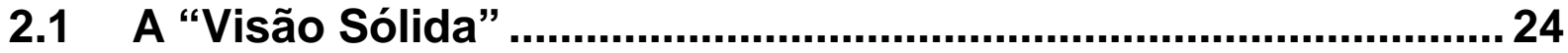

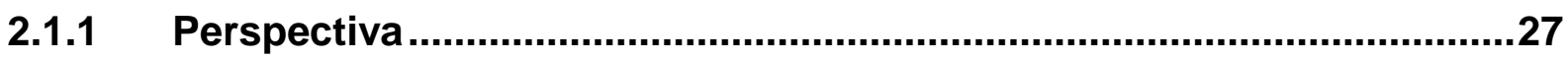

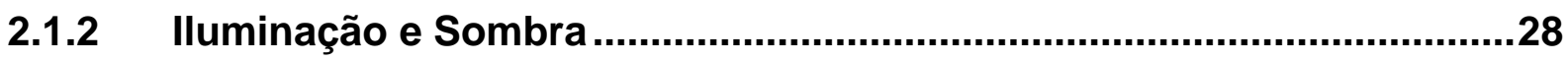

2.1.3 Oclusão

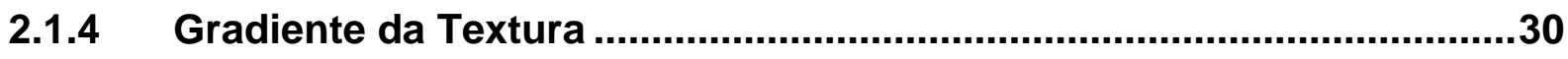

2.1.5 Distorção do Meio ..............................................................................

2.2 Soluções de estereoscopia ............................................................ 32

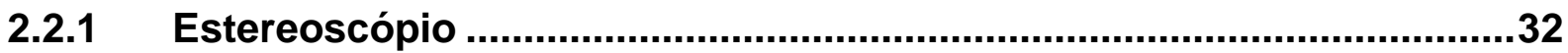

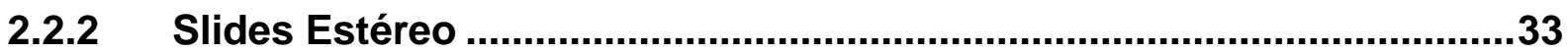

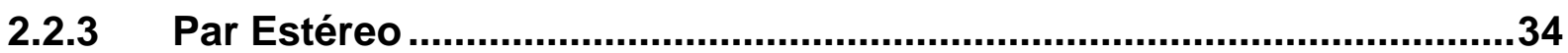

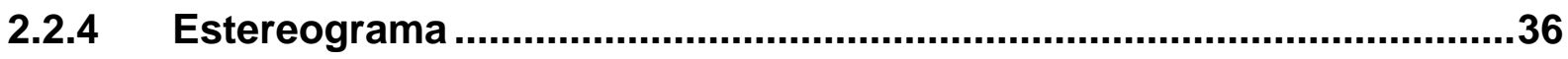

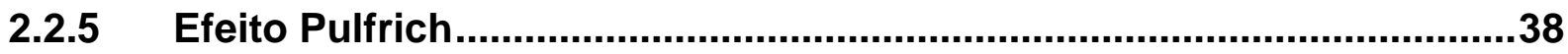

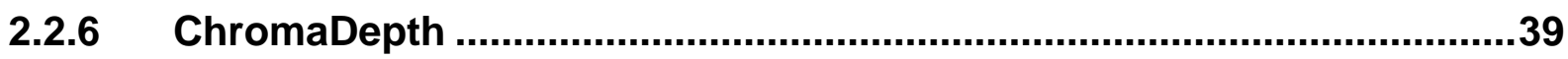

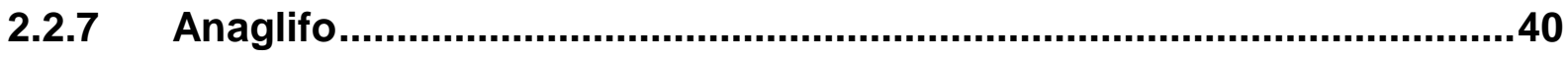

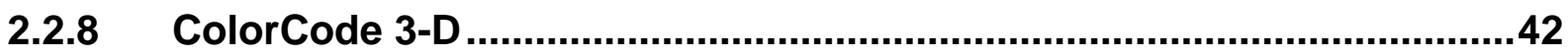

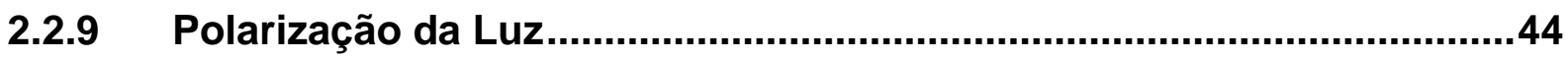


2.2.10 Óculos Obturadores (LCS/Shutter Glasses) .......................................46

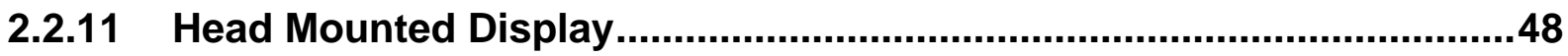

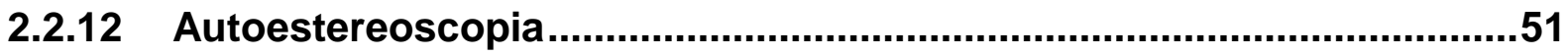

2.2.13 Par Estéreo Alternado (Wobble/Wiggle Stereo) …...............................54

2.3 Mercado de Estereoscopia ........................................................56

2.4 Trabalhos em Realidade Virtual e Aumentada ............................59

2.4.1 Augmented Virtuality Tele-Conferencing (AVTC)..................................59

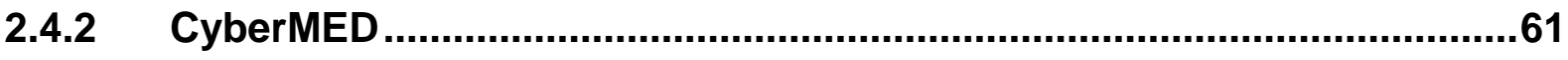

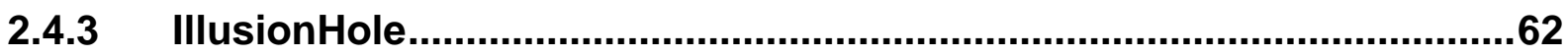

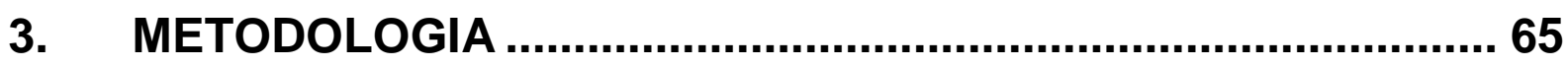

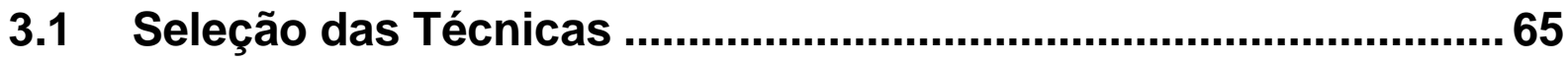

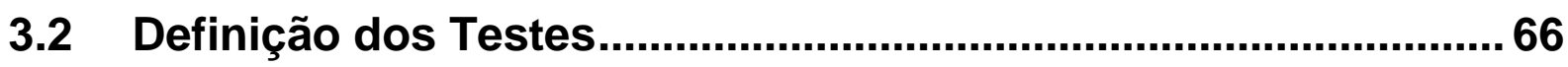

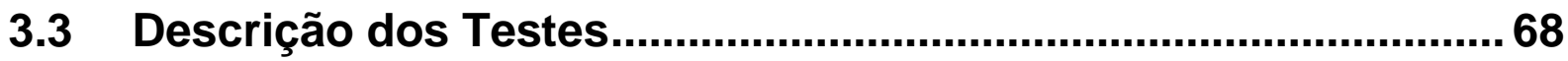

3.4 Processo de realização dos testes ............................................70

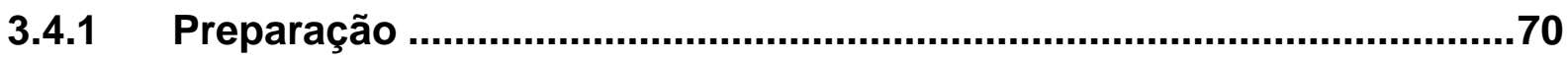

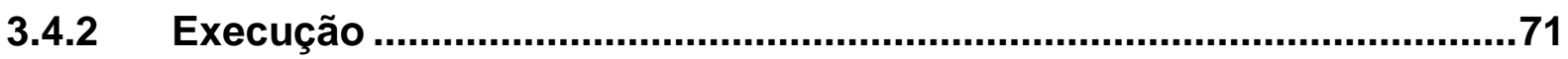

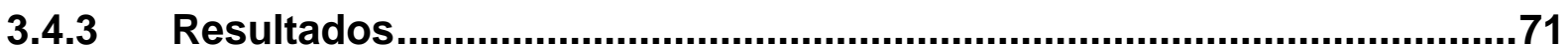

3.5 Análise de Resultados dos Testes ............................................ 72

4. EXPERIMENTOS COM AS TÉCNICAS DE ESTEREOSCOPIA 74

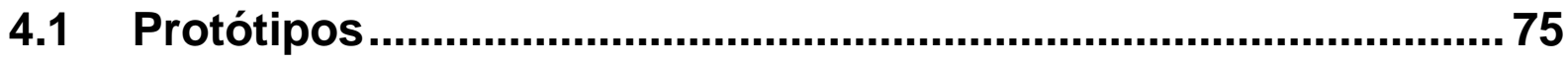

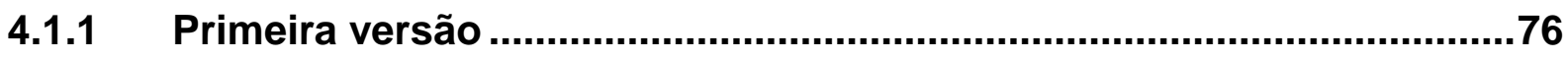

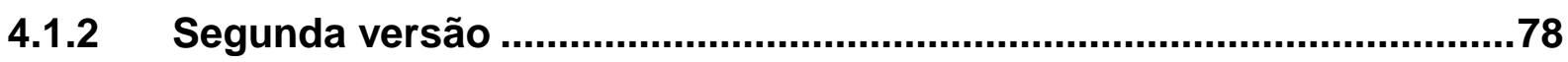

4.2 Versão final do sistema .............................................................. 80

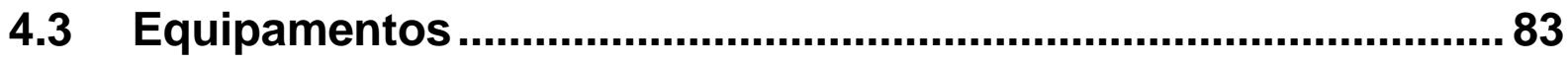

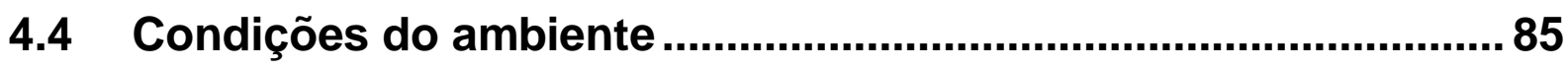




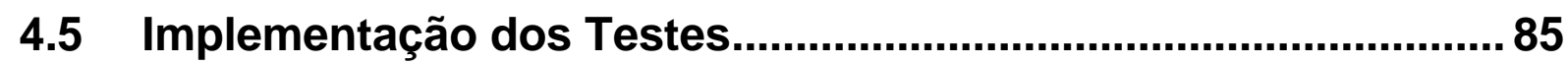

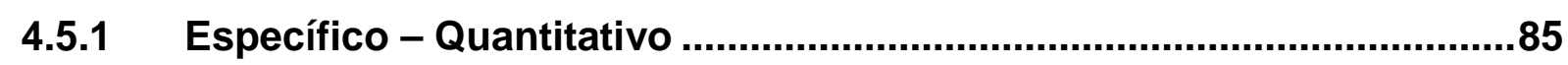

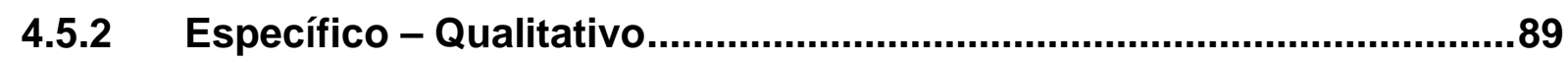

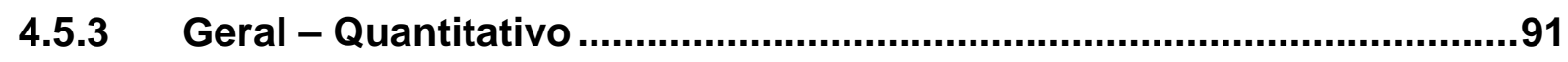

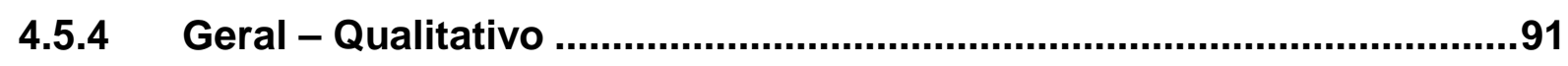

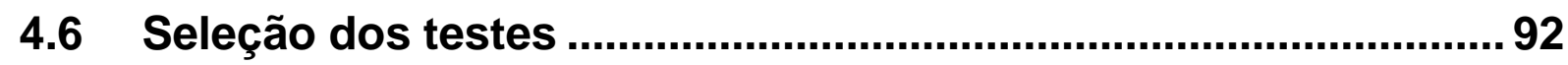

5. ANÁlise DE RESULTADOS E CLASSIFICAÇÃO DAS TÉCNICAS ................................................................................. 93

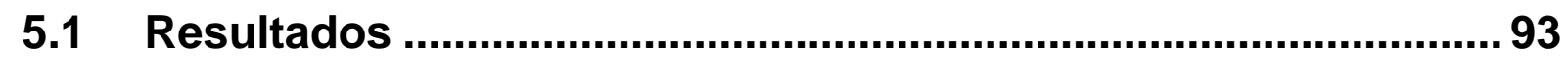

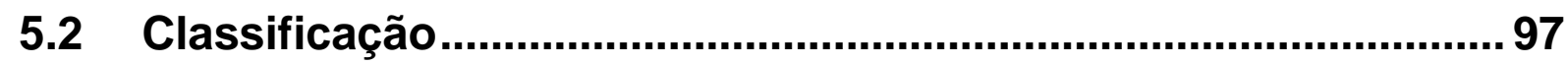

5.2.1 Receptor de Par Estéreo ……............................................................

5.2.2 Emissor de Par Estéreo ........................................................................99

6. APLICAÇÃO EM REALIDADE AUMENTADA ........................ 102

6.1 Desafios da Estereoscopia em Realidade Aumentada.............. 104

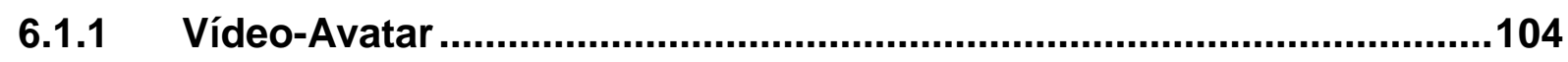

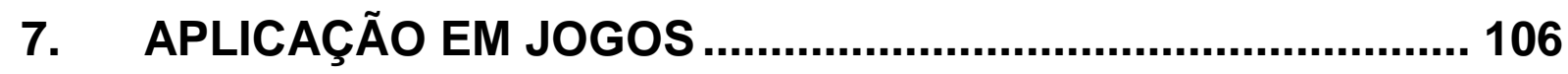

7.1 Desafios da Estereoscopia em Jogos..................................... 107

7.1.1 Conceitualização................................................................................107

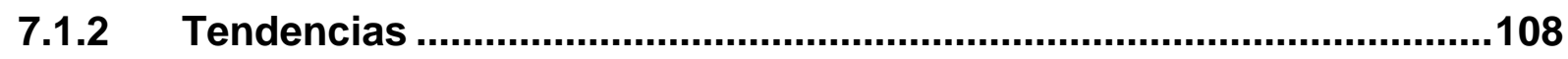

7.2 Implementação da Estereoscopia em Game Engine.................. 109

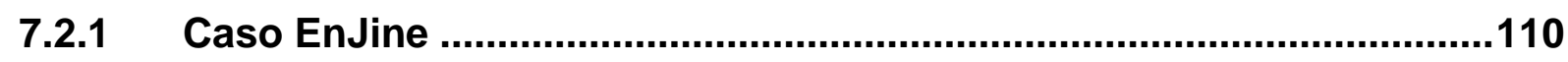

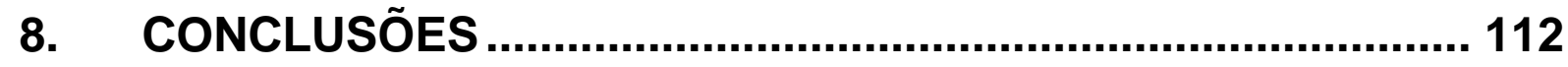

8.1 Trabalhos Futuros ....................................................................... 114 


\section{INTRODUÇÃO}

A estereoscopia é uma área do conhecimento muito abrangente, presente em textos voltados a medicina (ZYGMUNT et al., 2005), arte (ADAMS, 2003) e tecnologia (HOLLIMAN, 2002). Em geral, o termo estereoscopia é apenas pincelado nos textos que o referenciam, sem que haja um detalhamento maior em relação ao seu desenvolvimento. Trabalhos dedicados a uma pesquisa mais profunda nesta área são escassos (ADAMS, 2003).

Projetos que exploram o uso de ambientes virtuais interativos ou de ambientes aumentados, com a adição de elementos reais, não exploram todo o potencial de visualização e percepção de profundidade que a estereoscopia proporciona. Com base no conceito de tele-presença, que é a experiência de estar imerso em um ambiente através de uma mídia de comunicação (STEUER 1992), uma exploração maior da estereoscopia pode proporcionar os subsídios necessários para que esses projetos possam subir mais um degrau na experiência da tele-presença pelo usuário, adicionando a percepção de profundidade à visualização de ambientes virtuais e aumentados interativos.

Exemplificando esta proposta, alguns dos projetos desenvolvidos no Laboratório de Tecnologias Interativas (INTERLAB) voltados a área de realidade virtual e aumentada podem usufruir deste valor agregado pela estereoscopia. Um deles é o EnJine que consiste em um game engine didático implementado sobre a plataforma Java e Java 3D (JAVA3D, 2010) que se sobressai em sua organização, que segue padrões recomendados pela engenharia de software, e facilidade para ser aprendido e utilizado (TORI et al., 2006). Uma das tarefas dos alunos do curso de computação gráfica é utilizar o EnJine para desenvolver um jogo e assim fixar conceitos básicos de projeto, engenharia e computação gráfica.

No entanto, o principal projeto desenvolvido no INTERLAB que apresenta potencial para a estereoscopia é o Vídeo-Avatar, inserido no projeto TIDIA-AE da FAPESP, que trabalha na integração de avatares de pessoas reais, gerados por meio de vídeos, com um ambiente virtual tridimensional gerado por computação gráfica. Para que essa integração seja a mais realista possível é necessário aplicar soluções de 
estereoscopia que possibilitem aos participantes visualizar o ambiente e os outros avatares de forma tridimensional. Um primeiro passo nesta linha foi o Augmented Virtuality Tele-Conferencing (AVTC) desenvolvido no INTERLAB (SISCOUTTO, 2003). O sistema AVTC gera um ambiente virtual de tele-conferência com a adição de vídeo-avatar real e permite uma visualização estereoscópica limitada de imagens do vídeo-avatar em um ambiente controlado.

Considerando o leque de recursos que a estereoscopia tem o potencial de abrir nestas áreas, este trabalho visa uma pesquisa mais aprofundada das técnicas estereoscópicas e suas aplicações. Assim, o objetivo primário deste projeto é comparar vantagens e desvantagens das soluções estereoscópicas abordadas, levando em consideração fatores qualitativos e quantitativos, gerando discussões e apresentando informações comparativas que possam auxiliar na seleção de qual solução expandir ou implementar em aplicações futuras. Os objetivos secundários são realizar discussões e propor tendências de forma a indicar as soluções mais adequadas a serem implementadas em um sistema que explora a tele-presença utilizando vídeo-avatares e na aplicação da estereoscopia na área de jogos e engines gráficos.

Uma contribuição essencial do trabalho e meio de atingir o objetivo primário é a proposta de uma metodologia para mensurar e comparar a performance das técnicas estereoscópicas em diferentes cenários. Um extensa pesquisa teórica sobre técnicas que permitem a visualização estereoscópica é realizada, a qual fornece a fundação conceitual necessária para projetar e implementar os cenários de teste e selecionar quais técnicas estereoscópicas avaliar. Definido este processo teórico sobre estereoscopia, falta concretizar a realização da parte experimental. 0 caminho escolhido é a criação de um sistema de testes, que permite acoplar tanto módulos com novas soluções estereoscópicas como novos cenários de teste.

Outra contribuição que esta mais relacionada aos objetivos secundários é a discussão do uso da estereoscopia na área de jogos. A discussão visa não só apresentar limitações e soluções técnicas, mas também em termos do design dos jogos. A estereoscopia proporciona novas variáveis aos designers de jogos, que podem ser exploradas na mecânica dos jogos para proporcionar novas experiências aos jogadores. Do ponto de vista técnico, um dos principais alvos da argumentação é o EnJine, com foco na incorporação de um módulo de estereoscopia a este game 
engine. Embora a implementação do módulo não esteja no escopo do trabalho, pontos relevantes para guiar um desenvolvedor que implemente este módulo são detalhados. Além disso, limitações tanto do Java 3D como do EnJine, que restrinjam ou impeçam a implementação são descritas.

\subsection{Justificativa}

A estereoscopia é um tema que gera a curiosidade dos pesquisadores desde, no mínimo, meados do século XIX (FEHN, 2005) e seu estudo e desenvolvimento se deu em grande parte a iniciativas visando à exploração comercial. Um indício deste enfoque comercial pode ser visto pelo número de patentes e produtos exclusivos de empresas que trabalham nessa área (ROBERTS, 2003; APO, 2008).

Devido ao grande número de iniciativas comerciais isoladas, objetivando atingir o público, as soluções de estereoscopia acabaram se tornando conhecidas superficialmente, mas poucas vezes explorada a fundo, principalmente em relação à classificação e desenvolvimento das soluções. Um efeito deste conhecimento diluído é o grande número de websites pessoais e comerciais que abordam o tema da estereoscopia, fornecendo dicas e produtos. Tendo em vista estes pontos, a estereoscopia é um tema que ainda requer esforços de consolidação, para que possa atingir um estágio de maturidade que permita ser amplamente utilizada e não apenas para uso restrito ou como um diferencial exótico.

Como foi apresentado no capítulo anterior, um campo que a estereoscopia apresenta potencial é na realidade virtual e aumentada, pois permite uma sensação maior de tele-presença do usuário. Em especial para o projeto Vídeo-Avatar desenvolvido no INTERLAB, a estereoscopia é um requisito natural, já que permite ao participante uma experiência mais realista. A Figura 1 exibe algumas imagens do conceito utilizado no AVTC, um dos produtos da linha de pesquisa Vídeo-Avatar. 


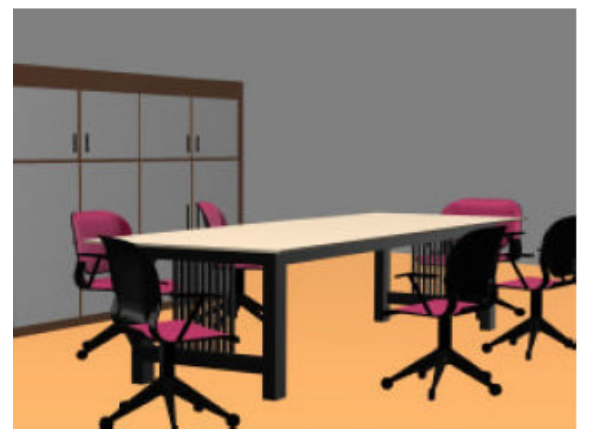

(a)

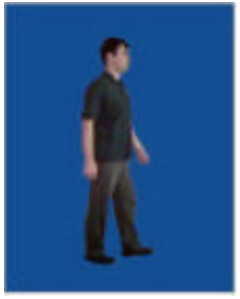

(b)

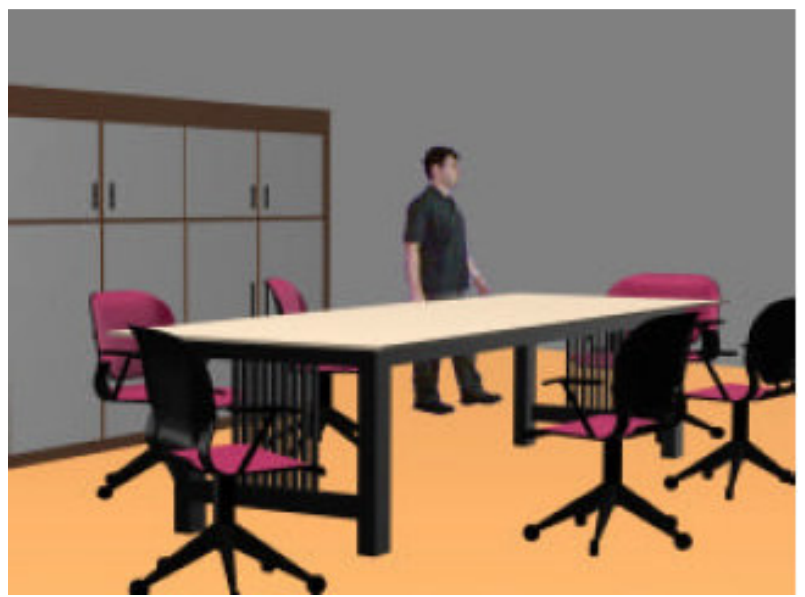

(c)

Figura 1 - Imagens conceituais do AVTC. Ambiente virtual (a), Vídeo da pessoa (b) e o resultado da composição (c) (SISCOUTTO, 2003).

Um incentivo a mais nesta área de pesquisa é o investimento cada vez maior de grandes empresas envolvidas em computação gráfica e comunicação visual. A NVidia que é uma das grandes fabricantes de placas gráficas retomou o trabalho no seu software que permite a visualização estereoscópica em anaglifos, óculos obturadores, entre outros e lançou uma nova versão do programa que suporta alguns modelos de monitores com estereoscopia por polarização (NVIDIA, 2008).

Do ponto de vista do consumidor, o custo para obter os equipamentos necessários para a visualização estereoscópica é cada vez menor e o avanço da autoestereoscopia torna possível visualizar cenas tridimensionais sem precisar de óculos especiais (WEINAND, 2005b).

A indústria do cinema investe cada vez mais nos filmes em 3D e não por acaso os cinemas estão adotando mais e mais o sistema digital, que suporta projeção estereoscópica (SCREENDIGEST, 2010). 


\subsection{Realidade Virtual e Jogos}

A Realidade Virtual (RV) é tipicamente vista como um novo tipo de mídia e definida através de equipamentos que utiliza como computadores, Head Mounted Displays, fones de ouvido e luvas com sensores de movimento (STEUER, 1992).

Esta, no entanto, é uma definição fraca de RV, pois vincula o conceito teórico as soluções tecnológicas utilizadas. Uma melhor definição de RV pode ser feita com base no conceito de tele-presença descrito por Steuer (1992), de forma a isolar o conceito de RV da tecnologia, que esta sempre em evolução. Assim, uma possível definição de Realidade Virtual, que é a adotada neste texto, é a de um ambiente real ou virtual no qual o usuário vive a experiência de tele-presença.

Paralelamente às pesquisas em RV, uma área que também usufruía da evolução dos computadores é a indústria dos jogos eletrônicos, voltada principalmente ao mercado. Os jogos partiram de animações monocromáticas em 2D, para um grande impulsionador no desenvolvimento de ambientes virtuais em três dimensões. A partir da década de 90, a comunidade dos videogames começou a ocupar espaços que pertenciam à comunidade de RV. Pesquisas na área de RV agora levam em consideração o que acontece na área dos videogames, com foco não apenas em entretenimento, mas também treinamento, simulação e educação (ZYDA, 2005).

Um recurso dos jogos que é de grande valia em outras áreas que criam ambientes virtuais são os game engines. Estes engines acumulam as principais funcionalidades necessárias para gerar um ambiente virtual, como exibição de modelos em 3D e acesso a dispositivos de entrada e saída. Essa integração de diferentes funcionalidades em um mesmo módulo permite a reusabilidade do componente em diferentes projetos e aplicações (FRITSCH; KADA, 2004). 


\subsection{Realidade Aumentada}

O conceito de Realidade Aumentada abrange uma região dentro de uma linha imaginária, na qual os extremos são o Mundo Real e a Realidade Virtual, conforme definido por Milgram (1994).

O Mundo Real nada mais é do que o ambiente em que vivemos, onde todos os objetos são físicos, enquanto a Realidade Virtual representa um ambiente completamente gerado computacionalmente, existindo somente elementos virtuais. Para ser classificado como Realidade Aumentada, um ambiente deve consistir predominantemente de elementos reais, com alguns adicionais virtuais. A Figura 2 apresenta a representação dessa linha Real-Virtual.

\section{Realidade Aumentada Virtualidade Aumentada \\ Mundo Real \\ Ambiente Virtual \\ Real-Virtual Continuum}

Figura 2 - Real-Virtual Continuum

Uma outra região, definida mais próxima do extremo virtual do que a RA é a Virtualidade Aumentada, na qual os elementos virtuais predominam no ambiente que é acrescido de algumas partes reais.

Como esta é apenas uma definição conceitual de Realidade Aumentada, fez-se necessária uma definição mais técnica, que permita classificar mais objetivamente se um sistema é ou não RA.

Azuma (1997) propõe que para um sistema ser RA, deve exibir três características:

- Combinar real e virtual

- Ser interativo em tempo-real 
- Ser registrado em 3D

A primeira característica é trivial, resultante da própria natureza da RA de estar entre o Mundo Real e a Realidade Virtual. A segunda característica permite isolar falsas aplicações que podem parecer RA a primeira vista, por exemplo os filmes "Who Framed Roger Rabbit" de 1988 e "Space Jam", nos quais desenhos animados interagem com personagens reais. Um ponto que eles não atendem para serem considerados RA é a exigência de serem interativos em tempo-real, pois espectadores não podem manipular os elementos do filme. Por último o registro em $3 \mathrm{D}$, que também filtra falsos candidatos a RA, como é o caso de uma projeção em uma tela, embora seja interativa e combine real e virtual, não é realizado o registro em três dimensões.
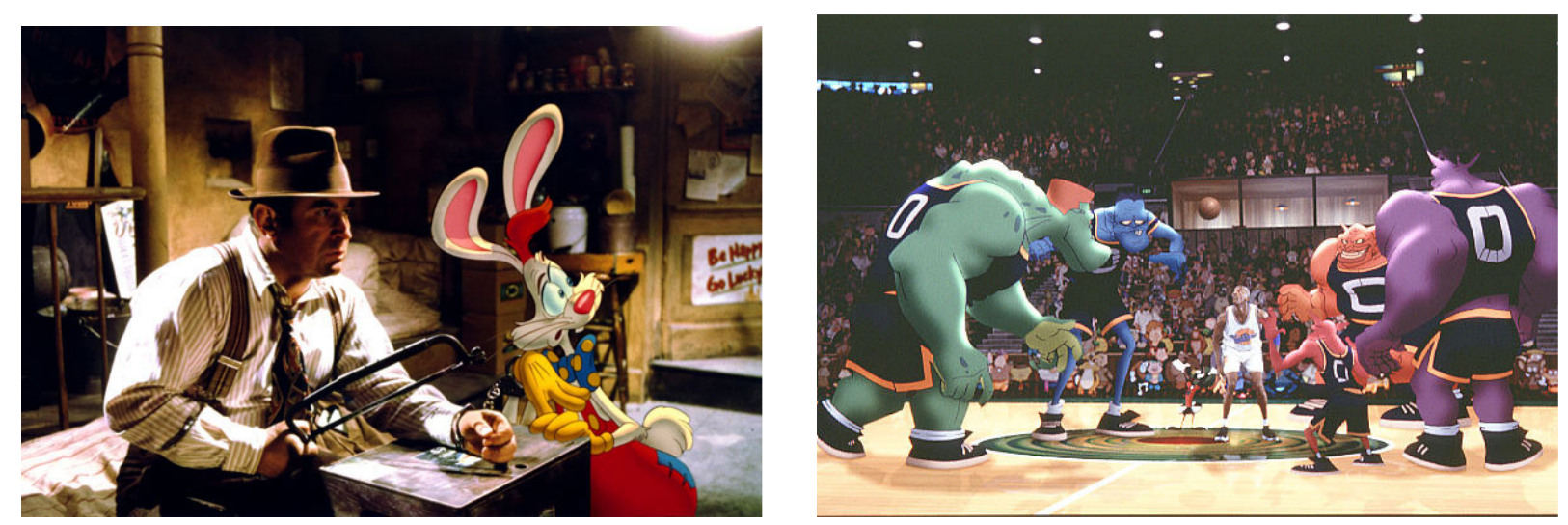

Figura 3 - Cenas dos filmes "Who Framed Roger Rabbit" (esquerda) e "Space Jam" (direita) (AWN SHOWCASE, 2005; ADOROCINEMA.COM, 2007).

Um exemplo de projeto que visa a Realidade Aumentada em sua plenitude é o Vídeo-Avatar do INTERLAB que foi apresentado anteriormente no item 1.1. O objetivo é uma integração homogênea entre a parte virtual e real, seguindo as definições citadas por Azuma. O usuário estará posicionado dentro do ambiente virtual 3D representado por seu vídeo-avatar e poderá interagir com o ambiente através do avatar, se movimentando e interagindo com os objetos.

Devido ao potencial de aplicações e inovação, a Realidade Aumentada é utilizada em diversas áreas do conhecimento, passando pelas áreas da medicina, educação e treinamento militar. 
Um nicho da RA que ganhou seus adeptos é a Realidade Aumentada Espacial. Nesta categoria de RA, são projetadas imagens sobre objetos reais, de forma a proporcionar um ambiente com elementos virtuais para um observador (RASKAR et al., 1998). Uma grande vantagem deste método é a simplicidade de visualização, como os elementos virtuais existem no mundo real como projeções, não é necessário o uso de equipamentos como Head Mounted Displays.

Um projeto desenvolvido no INTERLAB que utiliza o conceito da Realidade Aumentada Espacial é o framework Robot ARena (CALIFE et al., 2007). Este projeto consiste em um robô real construído com peças do Lego Mindstorms que é posicionado sobre uma mesa, onde é realizada a projeção de elementos virtuais, como barreiras e objetos coletáveis. A posição e a orientação do robô são capturadas através de uma câmera posicionada alguns metros acima da mesa

Uma das aplicações criadas sobre este framework é o Footbot $A R$, um jogo de futebol entre robôs, no qual um dos robôs é real e o outro virtual, gerado em RA Espacial. Outro jogo criado em cima desta plataforma é o TanSpace, que utiliza o conceito de Interface Tangível. Para interagir com os elementos virtuais projetados, o jogador manipula um marcador com as mãos que deve ser alinhado com uma mira virtual para destruir as naves inimigas.
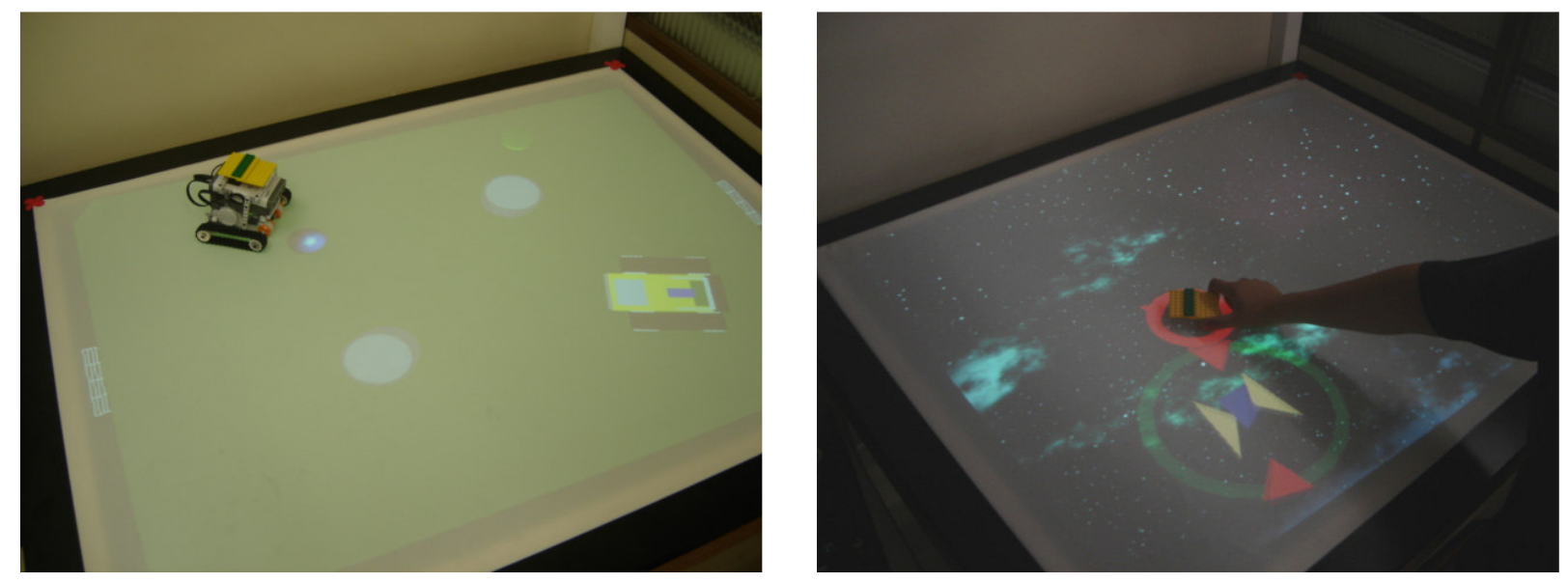

Figura 4 - Imagens do FootBot AR (esquerda) e TanSpace(direita) por Daniel Calife. 


\subsection{Estrutura do Trabalho}

Este trabalho se apresenta em oito tópicos, que podem ser divididos em dois grupos de quatro, sendo o primeiro composto pela a presente Introdução, o item 2 Estereoscopia, que descreve as informações teóricas obtidas na pesquisa literária, o item 3 Metodologia, que relata o procedimento utilizado para seleção das técnicas estereoscópicas e o projeto e execução dos testes, o item 4 Experimentos, que apresenta o processo de criação do sistema de testes e realização da bateria de testes. Estes tópicos representam a parte de conceitualização e execução do trabalho. Os outros tópicos compõem as etapas de análise, discussão e conclusão da pesquisa, sendo o item 5 Análise, o que relata a análise teórica e experimental das soluções estereoscópicas, o item 6 Aplicação em RA, o que apresenta discussões com relação a estereoscopia e a RA, o item 7 Aplicação em Jogos, o que contém a discussão sobre a relação entre a estereoscopia e os jogos, e 0 item 8 Conclusões, o responsável por descrever o fechamento do texto, com as conclusões da pesquisa e propostas de trabalhos futuros. 


\section{ESTEREOSCOPIA}

O termo estereoscopia tem origem em dois termos gregos que representam: "visão" e "sólido" e a origem desta área do conhecimento pode ser resgatada a no mínimo o ano de 1838. Esta é a data na qual o pesquisador inglês Charles Wheatstone desenvolveu um equipamento que possibilitava a um observador visualizar uma cena tridimensional a partir de imagens com perspectivas diferentes (FEHN, 2005). Esta versão inicial do estereoscópio foi aprimorada por David Brewster em 1844 e no final do século 19 estava presente em muitas casas da Europa e Estados Unidos.

Desde então muitos pesquisadores se empenharam para descobrir como o cérebro identifica a profundidade dos elementos da cena. Bela Julesz deu um importante passo nessa direção na década de 1960, quando demonstrou através dos estereogramas de pontos aleatórios (detalhados no item 2.2.4) que o cérebro não precisa de dicas da visão monoocular para realizar este cálculo (BELTRÃO, 2007). Estas informações monooculares, como perspectiva e sombra, são apresentadas no item 2.1 a seguir.

\subsection{A "Visão Sólida"}

A principal característica que permite aos seres humanos a visão sólida, ou seja, a capacidade de identificar a profundidade dos elementos de uma cena é a visão biocular. Através da disparidade na imagem vista por cada olho devido a diferença de perspectiva, o cérebro é capaz de determinar a profundidade do que está sendo visto (HOLLIMAN, 2002).

Do ponto de vista evolutivo, a estereoscopia foi um recurso que surgiu paralelamente em pelo menos dois grupos: mamíferos e aves. Embora apenas uma parcela das aves possua sinais de visão estereoscópica, praticamente todos os 
mamíferos possuem este recurso, mesmo que de forma rudimentar. Esse fato leva a conclusão de que a visão estereoscópica era uma característica presente nos primeiros mamíferos e teve grande valor para o crescimento e sucesso deste grupo (PETTIGREW, 1986).

A Figura 5 ilustra as diversas partes do olho humano. A pupila está localizada entre a córnea e o cristalino e é o ponto de entrada de luz. A retina se encontra na parte interna do olho, revestindo a maior parte da superfície interna.

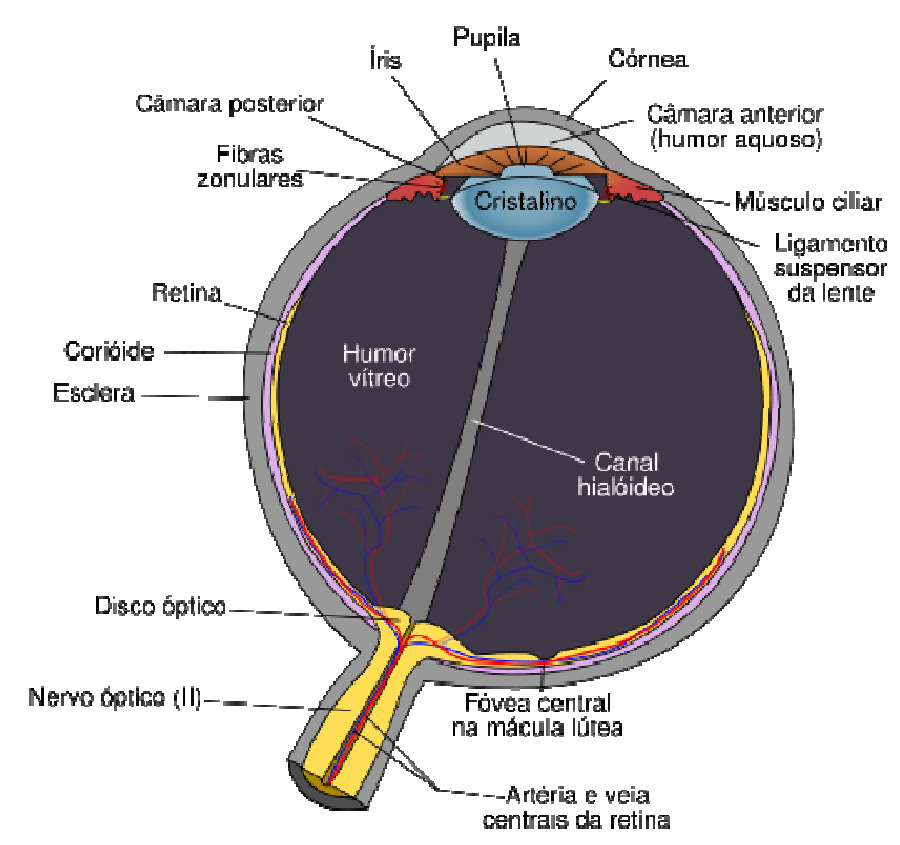

Figura 5 - Anatomia do olho humano (WIKIPEDIA, 2008).

A visão estereoscópica apresenta grande vantagem em relação à visão monoocular, pois permite que o indivíduo obtenha uma série de informações adicionais do ambiente:

- Reconhecimento de profundidade relativa - Identificação da relação espacial entre os objetos pelo observador pode ser realizada instantaneamente; 
- Localização espacial - Permite que o cérebro se concentre nos objetos posicionados a uma certa distância, ignorando as outras profundidades;

- Identificação de camuflagem - Possibilidade de reconhecer objetos camuflados em uma cena sem a necessidade de se mover. Provavelmente esta seja uma das características mais importantes que favoreceram a visão estereoscópica no decorrer do processo evolutivo;

- Percepção da superfície dos materiais - A diferença na imagem vista por cada olho é uma das características responsáveis pela identificação do brilho em metais e pedras preciosas;

- Reconhecimento de superfície curva - A visão biocular facilita o reconhecimento de superfícies curvas.

Algumas dessas informações, em especial a identificação de camuflagem, só podem ser reconhecidas através da visão monoocular caso o observador se mova, gerando a chamada paralaxe de movimento. Em animais que não possuem visão estereoscópica, ou estão impossibilitados de usá-la, a paralaxe de movimento é uma informação importante para descobrir a posição dos objetos. Collett (2004) apresenta o exemplo de um inseto utilizando a paralaxe de movimento para determinar a distância de uma presa. 
(a)

Stationary target
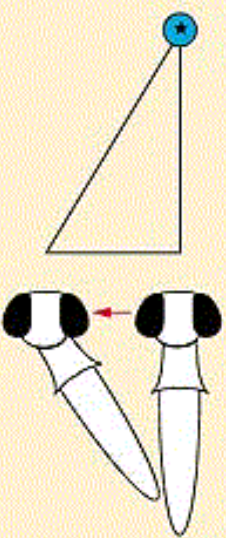

(b)
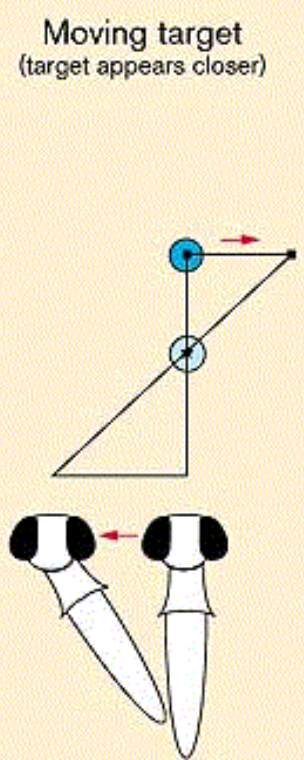

(c)

Moving target

(target appears more distant)
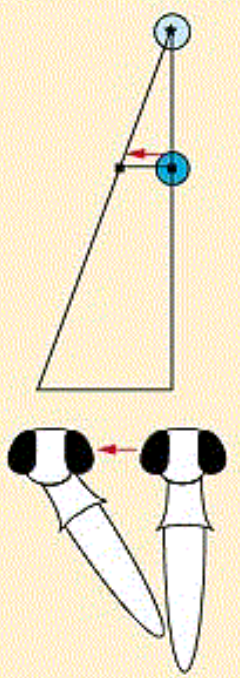

Q 1996 Current Biology

Figura 6 - Da esquerda para a direita: (a) o inseto move a cabeça para determinar a distância do objeto; (b) o objeto é movido simultaneamente no sentido oposto, parecendo estar mais próximo; (c) o objeto é movido no mesmo sentido, parecendo estar mais longe (COLLETT, 2004).

Holliman (2002) demonstra matematicamente que a visão biocular possui restrições de distância. No caso dos seres humanos, a visão estereoscópica é eficiente a partir de alguns centímetros dos olhos, até algumas dezenas de metros de distância. A partir de algumas centenas de metros ela se torna muito ineficiente, possibilitando apenas uma estimativa grosseira de distância.

Embora a estereoscopia forneça a informação primária de profundidade ao cérebro humano, outras características da cena também ajudam a visualizar o correto posicionamento dos elementos no espaço Siscoutto et al. (2006) e Holliman (2002) apresentam os seguintes efeitos:

\subsubsection{Perspectiva}


Por causa da anatomia do olho humano e a forma que a luz entra através do orifício da pupila para ser detectada pela retina, objetos do mundo real que estão mais próximos do observador parecem maiores do que objetos mais distantes, mesmo que ambos tenham o mesmo tamanho físico.

Uma conseqüência do efeito da perspectiva pode ser visto na Figura 7. Ambos os paralelepípedos possuem o mesmo tamanho se comparados com uma régua. No entanto, nosso cérebro interpretando que esta é a imagem de um longo corredor, leva a ilusão de concluir que o paralelepípedo mais a direita é menor do que o central.

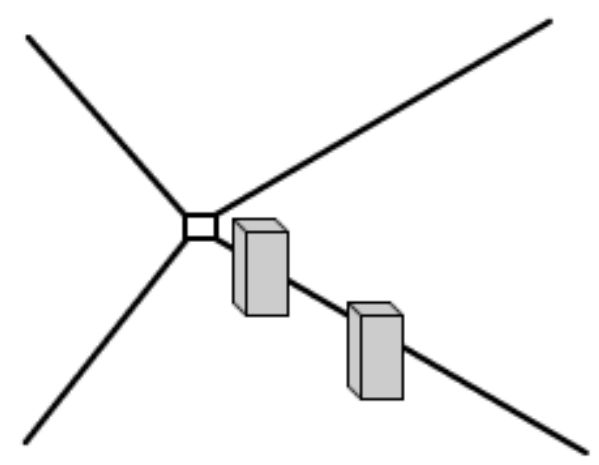

Figura 7 - Exemplo de efeito da perspectiva (baseado em SISCOUTTO et al., 2006)

\subsubsection{Iluminação e Sombra}

A presença de iluminação adiciona informações a cena que permite ao cérebro maior precisão para reconhecer tanto a superfície dos objetos como sua localização. As diferenças de cor na superfície dos objetos causadas pela iluminação criam dicas importantes com relação a sua forma real e a existência de sombra de algum objeto sobre outras superfícies age como referência de sua posição espacial.

A Figura 8 a seguir tem três situações distintas para ilustrar o efeito da iluminação. Na primeira, sem iluminação, os objetos parecem apenas um círculo e um hexágono monocromáticos. Na segunda, a sombra devido à iluminação gera diferenças de cor na superfície dos objetos, o que torna possível a identificação deles como uma 
esfera e um cubo. Por fim, a sombra numa superfície plana de referência indica que o cubo está encostado sobre ela e a esfera está flutuando sobre a superfície.

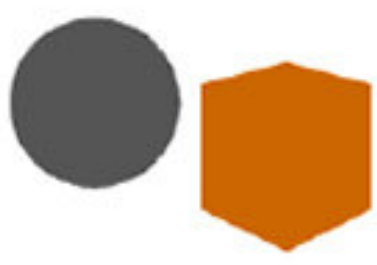

(a)

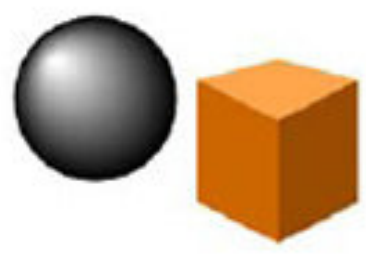

(b)

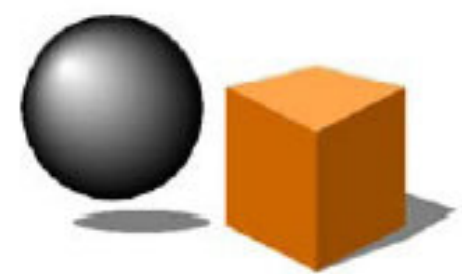

(c)

Figura 8 - Exemplo de efeito da iluminação. (a) Sem iluminação. (b) lluminação com sombra na superfície do próprio objeto. (c) Idem a (b) adicionando as sombras sobre outras superfícies. (SISCOUTTO et al., 2006)

\subsubsection{Oclusão}

O efeito da oclusão ocorre conforme a posição dos objetos no espaço. Como a luz se propaga em linha reta, objetos que estão mais próximos do observador ocultam objetos mais distantes que estão na mesma linha de visão. A oclusão total de um objeto impede que ele seja visto, mas a oclusão parcial fornece informações importantes ao cérebro para reconhecer a posição relativa ente os objetos.

A Figura 9 apresenta uma esfera e um cubo em duas situações distintas, nas quais o efeito da oclusão que define como interpretamos a posição relativa entre eles. $\mathrm{Na}$ imagem da esquerda, o cubo encobre parcialmente a esfera, levando o cérebro a interpretar que o cubo está na frente da esfera. Na imagem da direita ocorre o oposto, a esfera que parece a frente do cubo. 

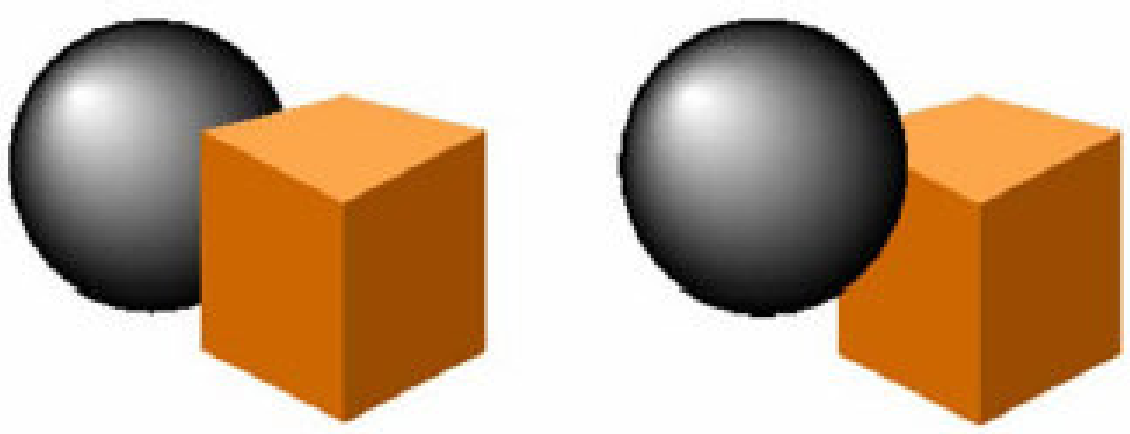

Figura 9 - Exemplo de oclusão parcial (SISCOUTTO et al., 2006).

\subsubsection{Gradiente da Textura}

Este efeito ocorre em superfícies extensas com textura semelhante por toda sua extensão, por exemplo, um gramado. Conforme a distância do observador os detalhes se tornam muito pequenos e não são identificáveis. Na Figura 10 temos a imagem de um gramado, na qual a distinção de que a parte inferior está mais próxima do observador do que a superior é reconhecida devido ao gradiente da textura.

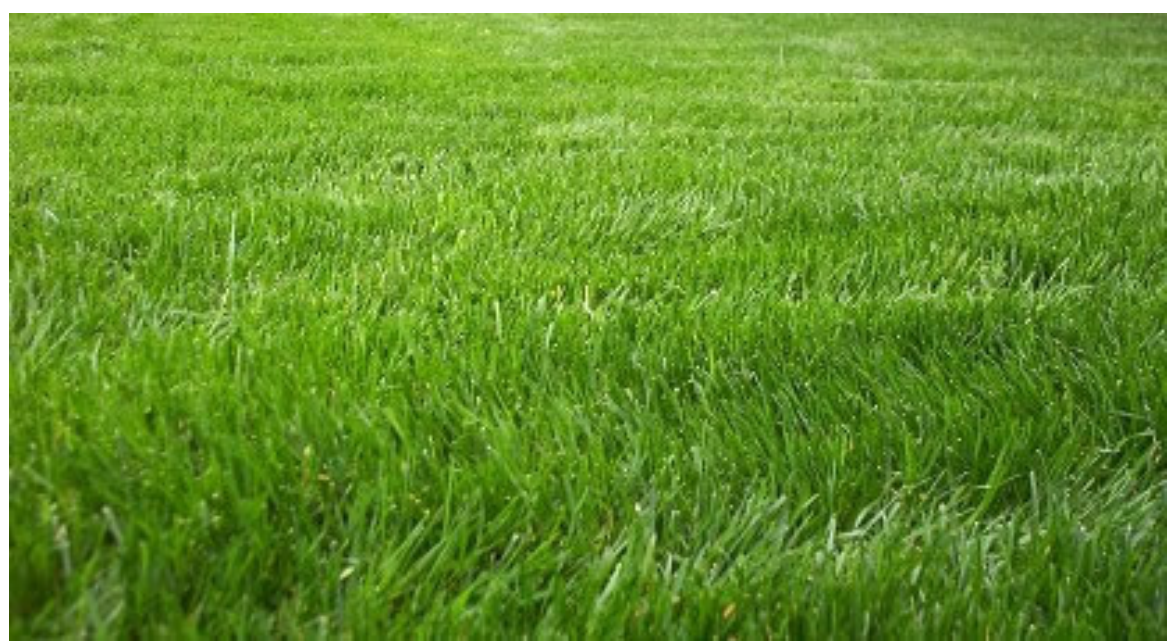

Figura 10 - Imagem de gramado ilustrando o efeito do gradiente da textura (PHOENIX TROPICALS, 2008). 


\subsubsection{Distorção do Meio}

Holliman (2002) utiliza o termo distorção do ar para descrever este efeito. No entanto utilizo o termo mais abrangente distorção do meio, por ser um efeito que não se restringe as situações na qual o observador vê luz que se propagou através do ar. Os raios de luz são susceptíveis a distorções no percurso entre os objetos e os olhos do observador, causadas por diversas razões, como névoa, pó ou chuva. Quanto maior a distância que a luz tem de percorrer, menor o detalhe dos contornos e as cores perdem saturação. Nas figuras a seguir, mesmo sem considerar outros efeitos visuais, é possível reconhecer as árvores que estão atrás pela cor esbranquiçada e identificar a parte do navio naufragado que está mais distante pela cor azulada.

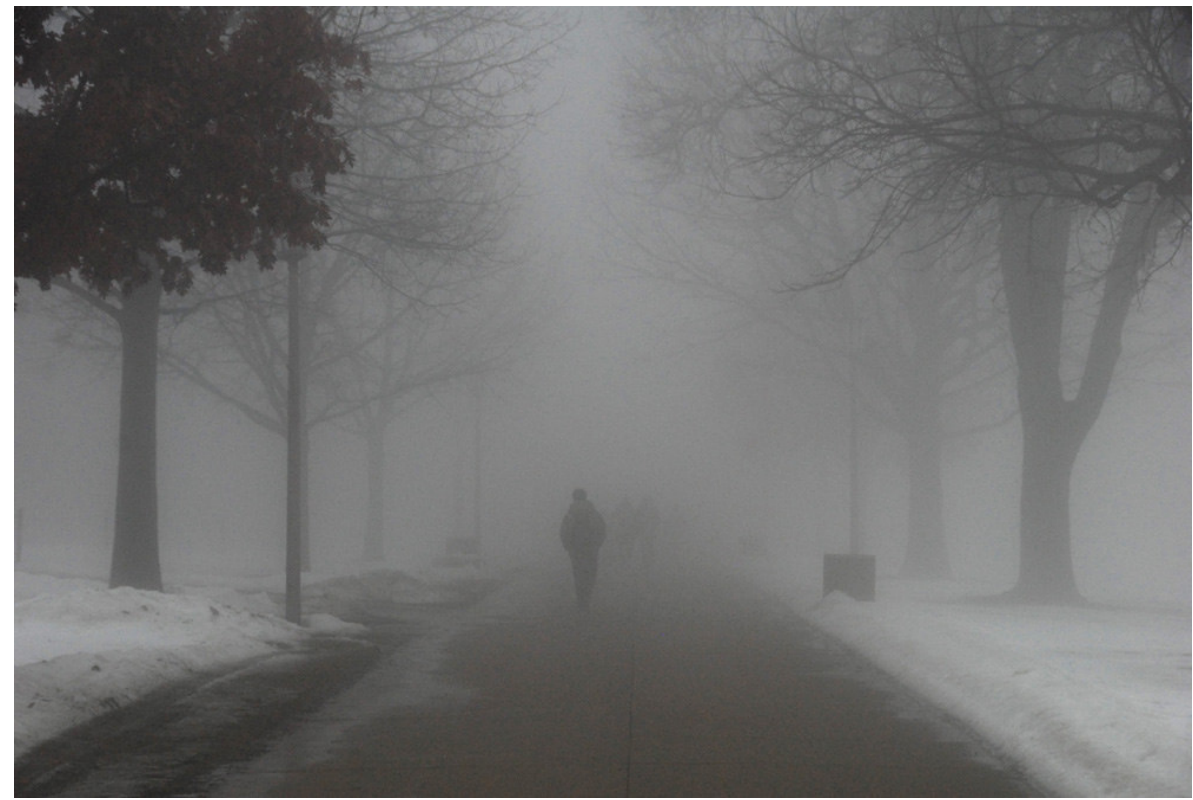

Figura 11 - Exemplo de distorção do meio, causado pela névoa suspensa no ar (O’BRIEN, 2008). 


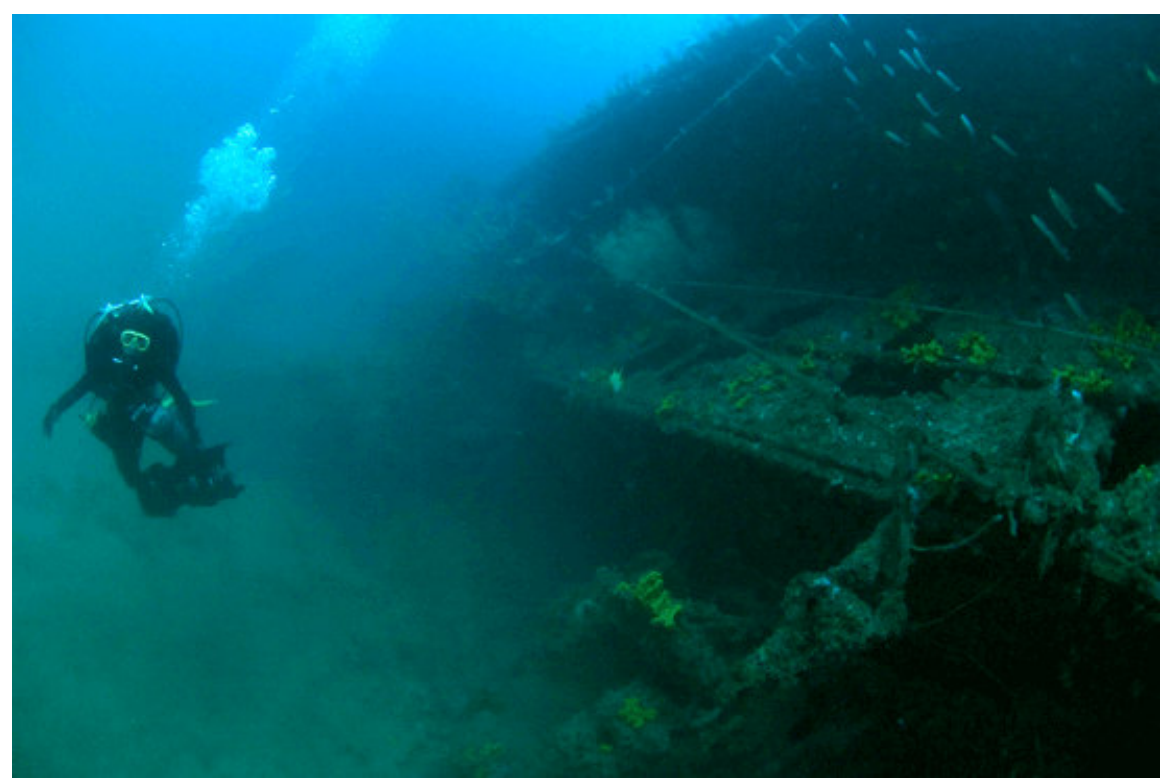

Figura 12 - Exemplo de distorção quando o meio é a água em imagem obtida por mergulhador (DAVY JONES LOCKER, 2007).

\subsection{Soluções de estereoscopia}

\subsubsection{Estereoscópio}

Este foi o equipamento criado por Wheatstone para possibilitar que um observador vislumbrasse uma cena em três dimensões. O estereoscópio se baseia em um esquema de lentes e espelhos que direcionam as imagens corretas para o olho esquerdo e direito seguindo princípios da óptica. $\mathrm{O}$ equipamento também possibilita que a configuração física entre os olhos e entre o observador e as imagens seja ajustada conforme a necessidade (SISCOUTTO et al., 2006). 


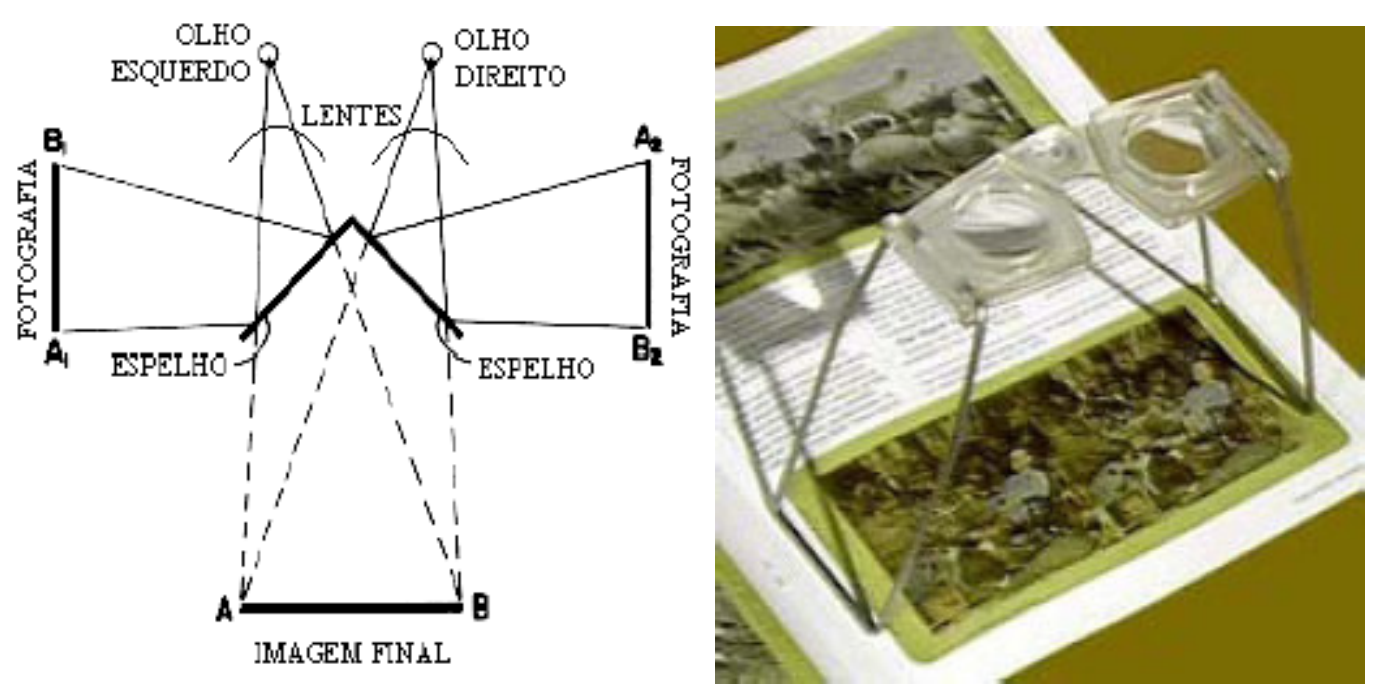

Figura 13 - Diagrama básico de um estereoscópio e um exemplo deste equipamento (SISCOUTTO et al., 2006).

\subsubsection{Slides Estéreo}

Um outro equipamento utilizado para obter efeito estereoscópico são os visualizadores de slides estéreo. Este equipamento consiste de uma pequena caixa que lembra um binóculos, na qual um par de slides estéreo é colocado em um dos lados e o lado oposto possui dois orifícios para que o observador possa posicionar os olhos.

O website da Rocky Mountain Memories (2001) ensina como criar seus próprios slides estéreo para diversos padrões de visualizador. Um ponto que é ressaltado no website é o efeito da Stereo Window, que ocorre devido ao limitado campo de visão que um slide contém. Para a montagem ficar coerente é necessário que nenhum elemento da imagem que esteja na borda do slide fique posicionado para fora do plano do slide quando visualizado em 3D. 

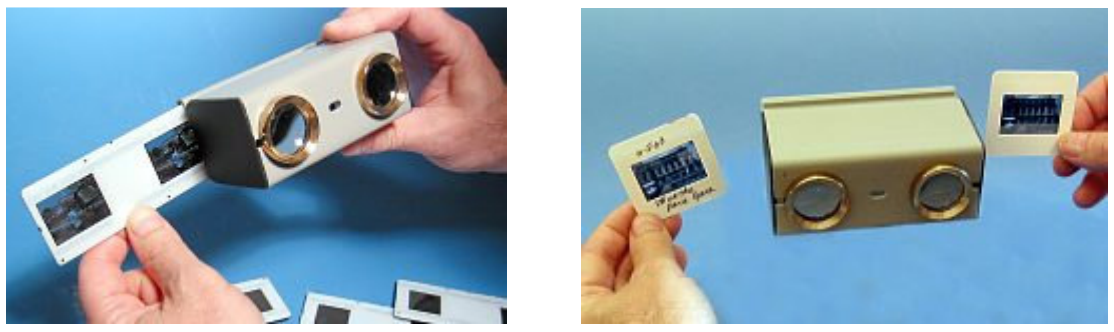

Figura 14 - Exemplos de visualizadores de slides estéreo (REEL 3D, 2008).

\subsubsection{Par Estéreo}

Um par estéreo é simplesmente a apresentação de duas imagens que formam um par estereoscópico lado a lado, que pode ser observado sem o auxílio de nenhum equipamento. Para que o observador possa vislumbrar o efeito estereoscópico a olho nú é necessário ainda utilizar uma das técnicas de visualização apresentadas a seguir. A Figura 15 contém dois exemplos de par estéreo, um em visão paralela e outro em visão cruzada.

Um efeito interessante que pode ser notado ao visualizar as imagens é que ao posicionar os olhos para visualização de um dos pares é possível também enxergar o outro par em estéreo, no entanto sem a mesma nitidez de profundidade. A conclusão é que mesmo invertendo a informação dos olhos o cérebro consegue interpretar as imagens como um par coerente e formar a cena tridimensional.

\section{Visão Paralela}

Para utilizar a técnica da visão paralela (tradução livre do nome inglês: walleye/wide-eye) as imagens precisam estar posicionadas lado a lado, com a imagem esquerda do lado esquerdo e a direita do lado direito. O efeito estereoscópico é obtido se o observador olhar para as imagens divergindo os olhos, no entanto dominar a técnica pode ser difícil para um iniciante (COLLIER, 1993). Quando bem sucedido são visualizadas três imagens, sendo que a imagem central é uma versão 
estereoscópica da cena contida nas outras duas imagens. Esta técnica possui um limite humano no tamanho das imagens, pois os olhos não conseguem divergir muitos graus.

Uma dica para dominar esta técnica de visualização é olhar através das imagens como se estivesse observando um ponto distante, relaxando os olhos até que a terceira imagem central entre em foco.

\section{Visão Cruzada}

$\mathrm{Na}$ técnica da visão cruzada (tradução livre do nome inglês cross-eye) as imagens devem estar posicionadas de forma invertida, ou seja, a imagem esquerda do lado direito e a imagem direita do lado esquerdo. Ao contrário da visão paralela, para obter o efeito estereoscópico na visão cruzada os olhos do observador devem convergir. Como os olhos conseguem convergir um ângulo maior, esta técnica possibilita a visualização de imagens com tamanho bem superior (COLLIER, 1993). Neste caso também, quando a técnica é realizada com sucesso o observador visualiza três imagens sendo a central estereoscópica.

Para aprender esta técnica a dica é posicionar um dedo entre os olhos e focar a visão no dedo com as imagens ao fundo, movendo o dedo em direção as imagens existe um momento no qual serão visualizadas as três imagens, esse é o ângulo que os olhos devem estar para enxergar a imagem central em 3D. 

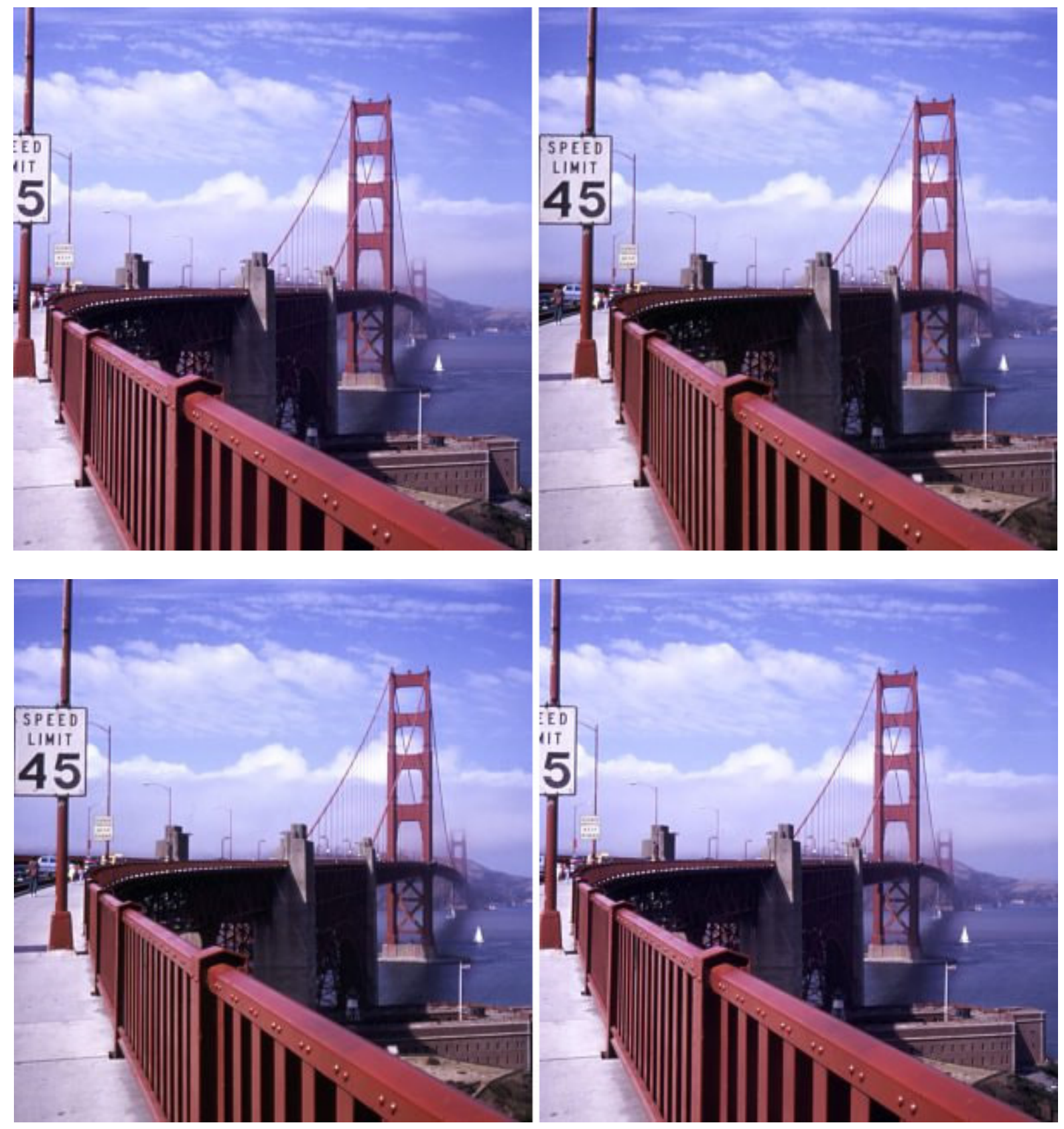

Figura 15 - 0 par estéreo superior está preparado para visão paralela e o inferior para visão cruzada (KLEIN, 2008)

\subsubsection{Estereograma}

Os estereogramas são simples imagens 2D que contêm a informação estereoscópica oculta nelas. Duas formas clássicas de estereogramas são de 
pontos aleatórios e de textura, ambas podem ser visualizadas utilizando-se a mesma técnica aplicada para visão de um par estéreo.

O princípio do estereograma está em juntar a visão do olho esquerdo e direito em uma única imagem. No entanto para juntar ambas as imagens é necessário reajustar as cores dos pixels de modo a manter a coerência entre um pixel de um ponto visto na imagem esquerda com o pixel do mesmo ponto visto na imagem direita (MINH et al., 2002). Devido a esta restrição, o resultado final do estereograma acaba sendo uma imagem com pontos aleatórios ou alguma espécie de textura.
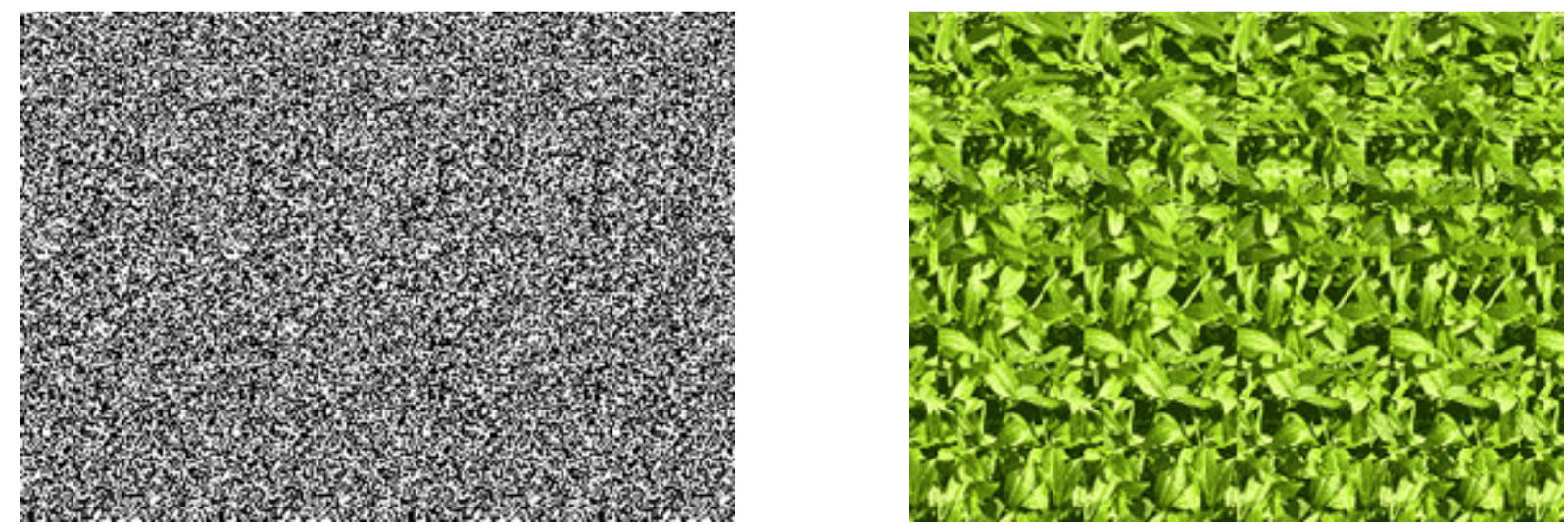

Figura 16 - A esquerda um estereograma de pontos aleatórios com o texto "3D" e a direita um estereograma de textura com um ponto de interrogação (BEENE, 2008; BWH VENTURES, 2008).

Uma vertente da técnica do estereograma são os estereogramas animados, que contém uma sequência de imagens ao invés de uma única imagem estéreo da cena. Alguns exemplos de estereogramas animados podem ser encontrados na internet, no website de Beene (2008) estão disponíveis as animações de um ventilador e um pêndulo.

Existem também esforços para utilizar estereogramas em jogos de computador. Um jogo pioneiro na abordagem da visão estéreo é Magic Carpet (Bullfrog - Eletronic arts, 1994) que implementa renderização estereoscópica na forma de estereogramas e também anaglifos. 


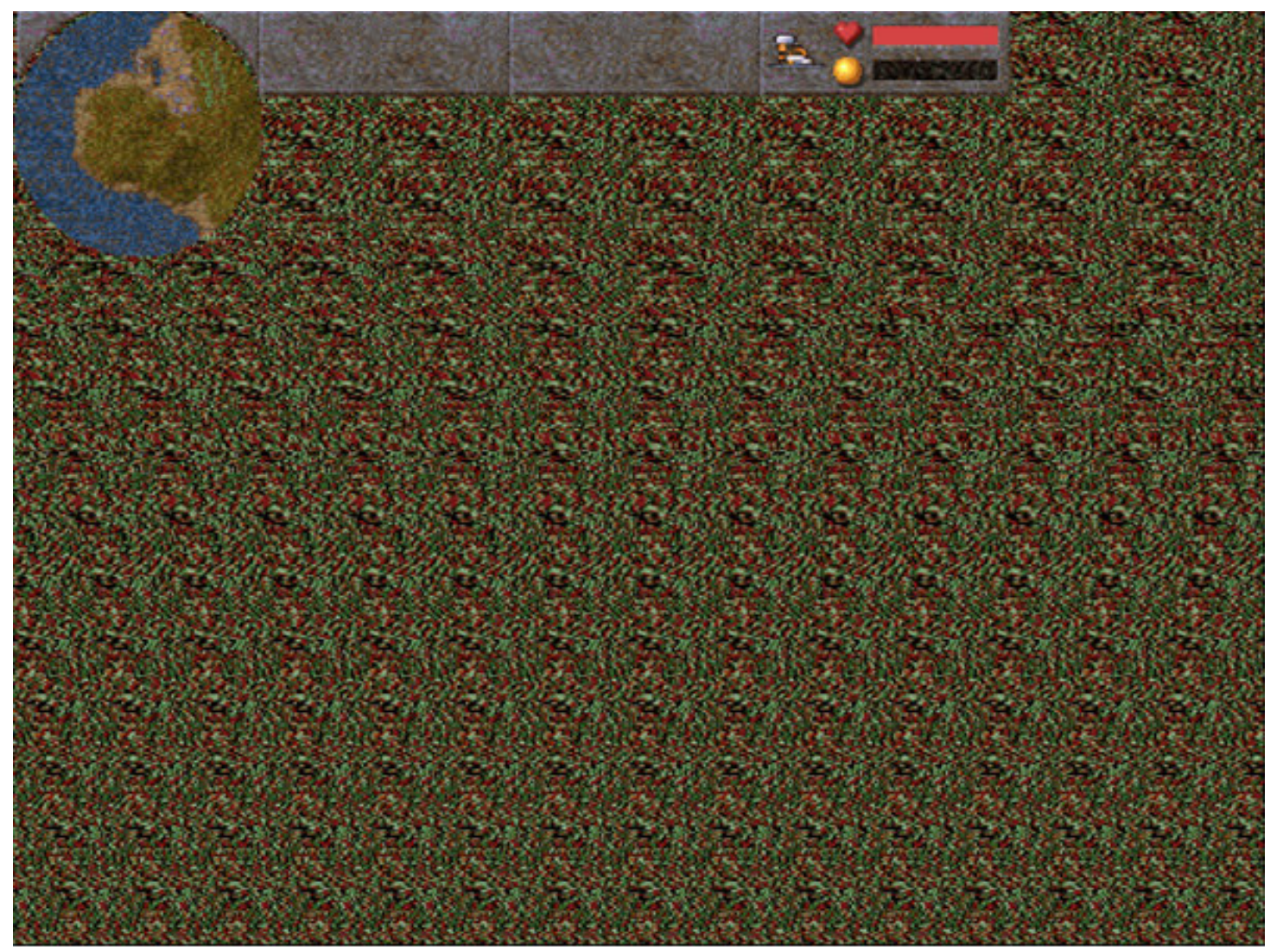

Figura 17 - Imagem do jogo Magic Carpet em estereograma. A cena é uma visão área de um morro com vegetação esparsa e uma estrutura na forma de " $\pi$ " ao centro.

\subsubsection{Efeito Pulfrich}

A estereoscopia por efeito Pulfrich se baseia na característica da visão humana de perceber luz menos intensa de forma mais lenta. Para criar o efeito tridimensional o observador deve usar um filtro que torna a visão mais escura para um dos olhos, assim ao observar uma animação os olhos têm uma velocidade diferente de percepção, levando a um pequeno deslocamento entre as imagens vistas por cada olho, o que gera a sensação de profundidade. Os problemas deste método são a falta de um controle maior da profundidade e a limitação de só funcionar com cenas em movimento (SISCOUTTO et al., 2006). 

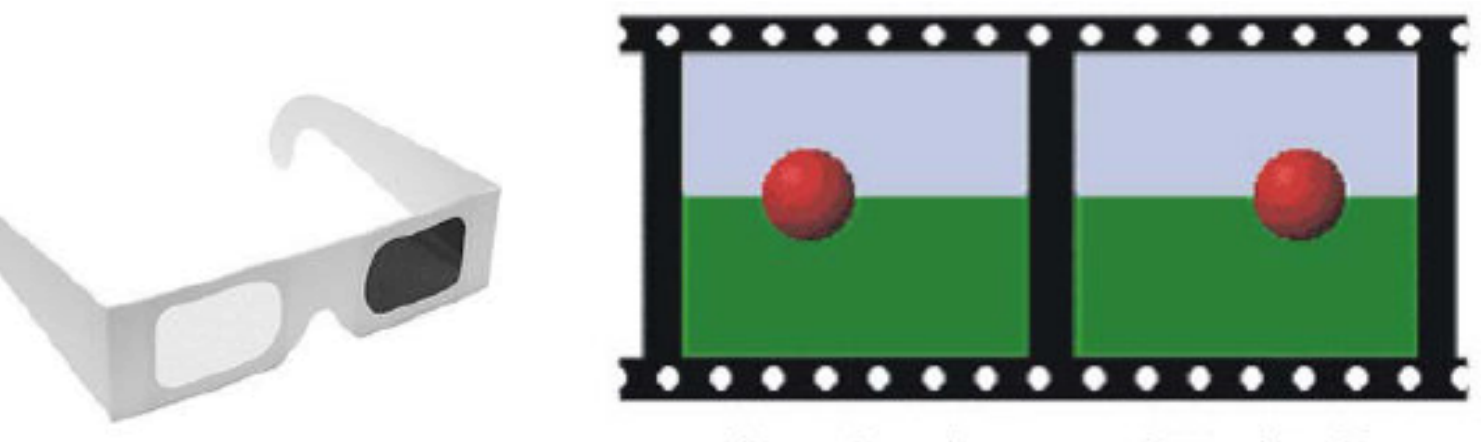

Quadro 1

Quadro 2

Figura 18 - A esquerda óculos com filtro para criar efeito Pulfrich e a direita quadros de uma animação, enquanto $o$ olho sem filtro percebe o quadro atual 20 olho com filtro ainda visualiza o quadro 1 (SISCOUTTO et al., 2006).

Uma aplicação comercial desta técnica foi a criação de vídeos em VHS que vinham com óculos baseados no efeito Pulfrich. Um exemplo é o vídeo "A Walk Through the Roses of Reynolda Gardens" de 1998 produzido por Dave Combs (2008).

\subsubsection{ChromaDepth}

Esta forma de estereoscopia se baseia no uso das cores para definir a profundidade dos elementos. As lentes dos óculos com tecnologia ChromaDepth tem a propriedade de desviar a luz de acordo com a sua cor, proporcionando a disparidade entre a visão do olho esquerdo e direito necessária para o efeito tridimensional. Nessa técnica os elementos de cor vermelha são vistos mais próximos do observador e quanto mais a cor do objeto caminha no espectro visual em direção a cor azul, ele parece estar mais distantes (SISCOUTTO et al., 2006). Este efeito é ilustrado na Figura 19. 


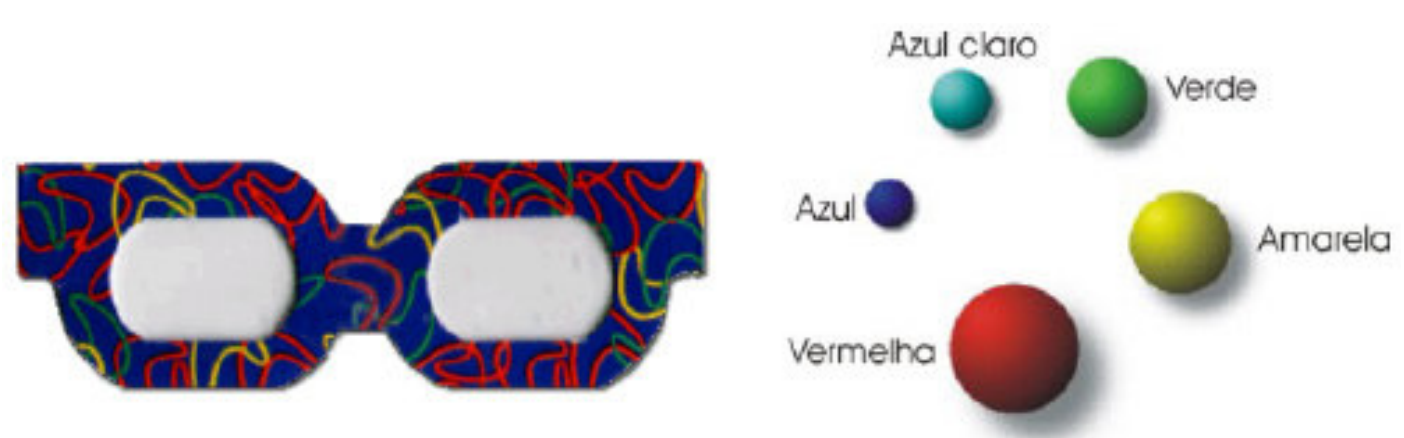

Figura 19 - Óculos com filtro ChromaDepth e diferença na distância percebida para diferentes cores (SISCOUTTO et al., 2006).

Esta solução apresenta o problema direto de impossibilitar o uso natural da cor, pois as cores dos diferentes pontos da cena contêm a informação adicional da sua profundidade. Os óculos são vendidos em duas versões: a Standard (STD) para mídia impressa e a High Definition (HD) para mídia eletrônica (APO, 2008).

\subsubsection{Anaglifo}

A técnica do anaglifo explora a divisão da imagem em seu espectro de cor, alocando uma gama de cores para o olho esquerdo e outra gama complementar para o olho direito. Para visualizar uma imagem em anaglifo o observador deve usar um óculos especial com filtros que permitem somente a passagem das cores alocadas para cada olho. O filtro mais comum nos anaglifos é utilizar o vermelho em uma das lentes e o azul ou ciano na outra lente. Assim, o olho que vê através da lente vermelha percebe apenas luz na faixa vermelha e o olho com o filtro azul/ciano percebe apenas a luz na respectiva faixa (SISCOUTTO et al., 2006). 

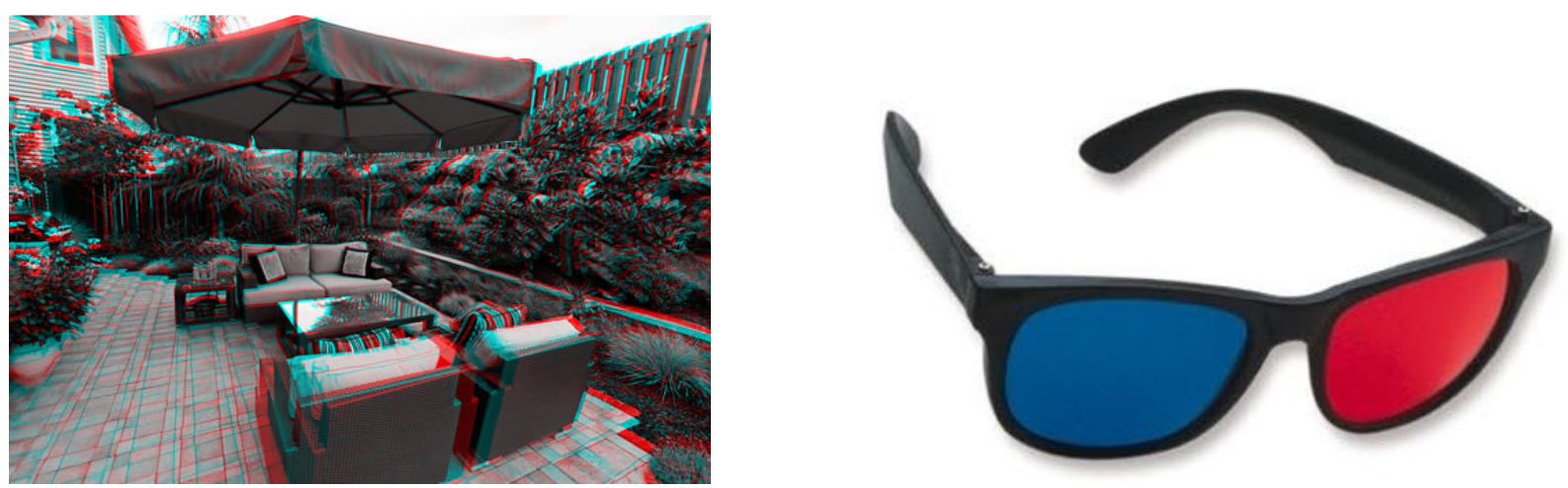

Figura 20 - Anaglifo clássico com imagem em escala de cinza quando visto a olho nú e óculos para visualização de anaglifos, com filtros vermelho e azul (3D EXPERIENCE, 2006; RAINBOW SYMPHONY, 2000).

Uma variante da técnica clássica para geração dos anaglifos são os chamados anaglifos coloridos ou colorglyphs. A principal diferença dos anaglifos coloridos é exibir boa parte das cores reais da imagem quando vistos a olho nú, no entanto quando visualizados em 3D através dos filtros boa parte da informação de cor se perde.

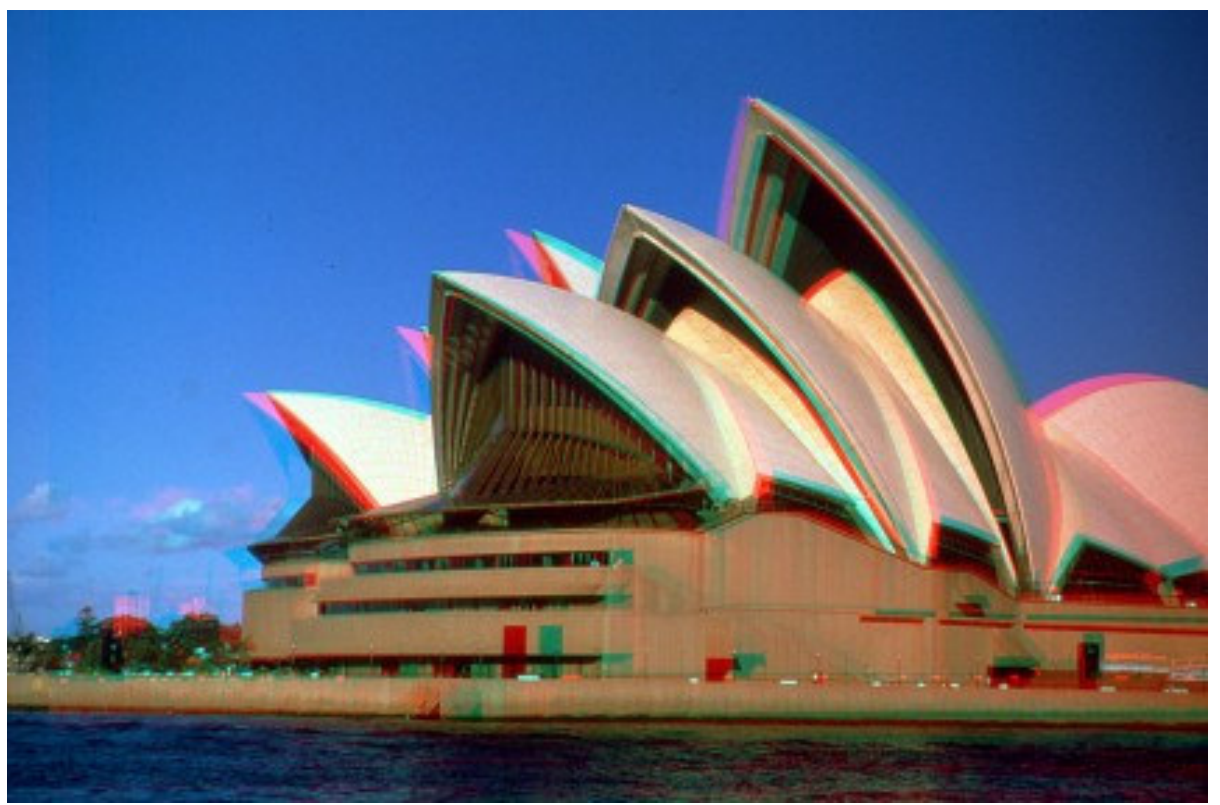

Figura 21 - Anaglifo colorido, também chamado de colorglyph (BURDER, 2005).

A solução dos anaglifos foi concebida no meio fotográfico, a sua invenção é atribuída aos inventores Joseph D'Almeida e Louis Ducos du Hauron na década de 1850 (LPI, 1999). No ano de 1858 D'Almeida promoveu uma apresentação de slides 
em 3D para uma platéia que usava óculos com filtros vermelho e azul. Além dos anaglifos, Hauron também desenvolveu o método trichrome em 1869, utilizado em fotografia colorida e criou os anaglifos impressos (BRITANNICA, 2008). O primeiro filme em anaglifos foi exibido em 1893, criado por William Friese-Green.

\subsubsection{ColorCode 3-D}

Esta solução, na sua essência, usa a mesma idéia da técnica dos anaglifos: separar a imagem que cada olho recebe isolando uma faixa do espectro para o olho esquerdo e outra para o olho direito. A diferença entre as duas técnicas esta justamente na faixa do espectro determinada para cada olho, ao invés de tentar dividir de forma equilibrada a amplitude de cores que cada olho recebe, os filtros ColorCode separam de forma desbalanceada, deixando uma pequena parcela de freqüências para um dos olhos e todas as freqüências restantes para o outro. É como se um dos olhos recebesse toda a informação de cores da imagem, com um deslocamento na palheta de cores observadas, e o outro olho complementa com a informação de profundidade, como se estivesse vendo em escala de cinza (COLORCODE, 2008).

A Figura 22 mostra um exemplo de imagem em ColorCode. Visto a olho nu é possível notar que a imagem pode ser dividida em uma parte colorida principal, em tons amarelados e uma sombra azul, que é a parte com a informação de profundidade. A mesma figura também apresenta um óculos com filtros ColorCode que possuem as cores âmbar e azul. 

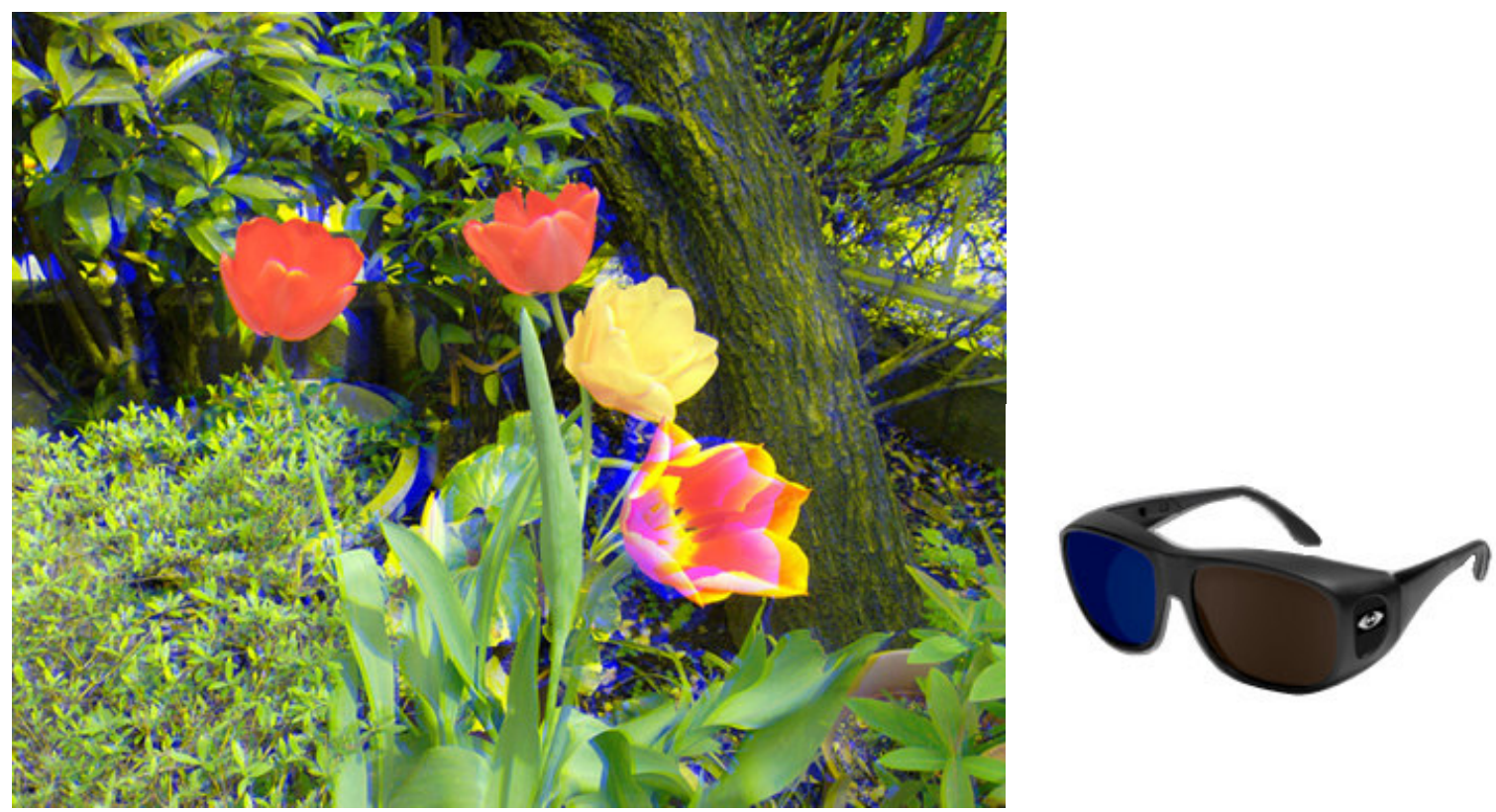

Figura 22 - Imagem em ColorCode 3-D e óculos com filtros ColorCode (COLORCODE, 2008).

A patente do ColorCode 3-D foi publicada em 2004 e foi assinada por três pesquisadores dinarmaqueses (US PATENT 6687003). A patente apresenta uma imagem com a resposta dos filtros ColorCode em nível de transparência para um certo comprimento de onda do espectro eletromagnético. A Figura 23 apresenta dois gráficos cobrindo a faixa de comprimento de onda das cores visíveis. No primeiro gráfico as curvas representam a sensibilidade dos olhos humanos a um dado comprimento de onda, considerando que o sistema visual humano é tricromático e possui três categorias de cones sensíveis a luz, com distintos pontos de sensibilidade máxima (DEEB; MOTULSKY 2005):

- Cones Azuis 420nm (short wavelength);

- Cones Verdes 530nm (middle wavelength);

- Cones Vermelhos $~ 560 n m$ (long wavelength).

O segundo gráfico mostra a resposta dos filtros ColorCode. Baseado no gráfico pode-se concluir que um dos filtros permite a passagem dos comprimentos de onda que sensibilizam os cones azuis e o outro filtro é complementar, permitindo a luz que sensibiliza os cones verdes e vermelhos. 

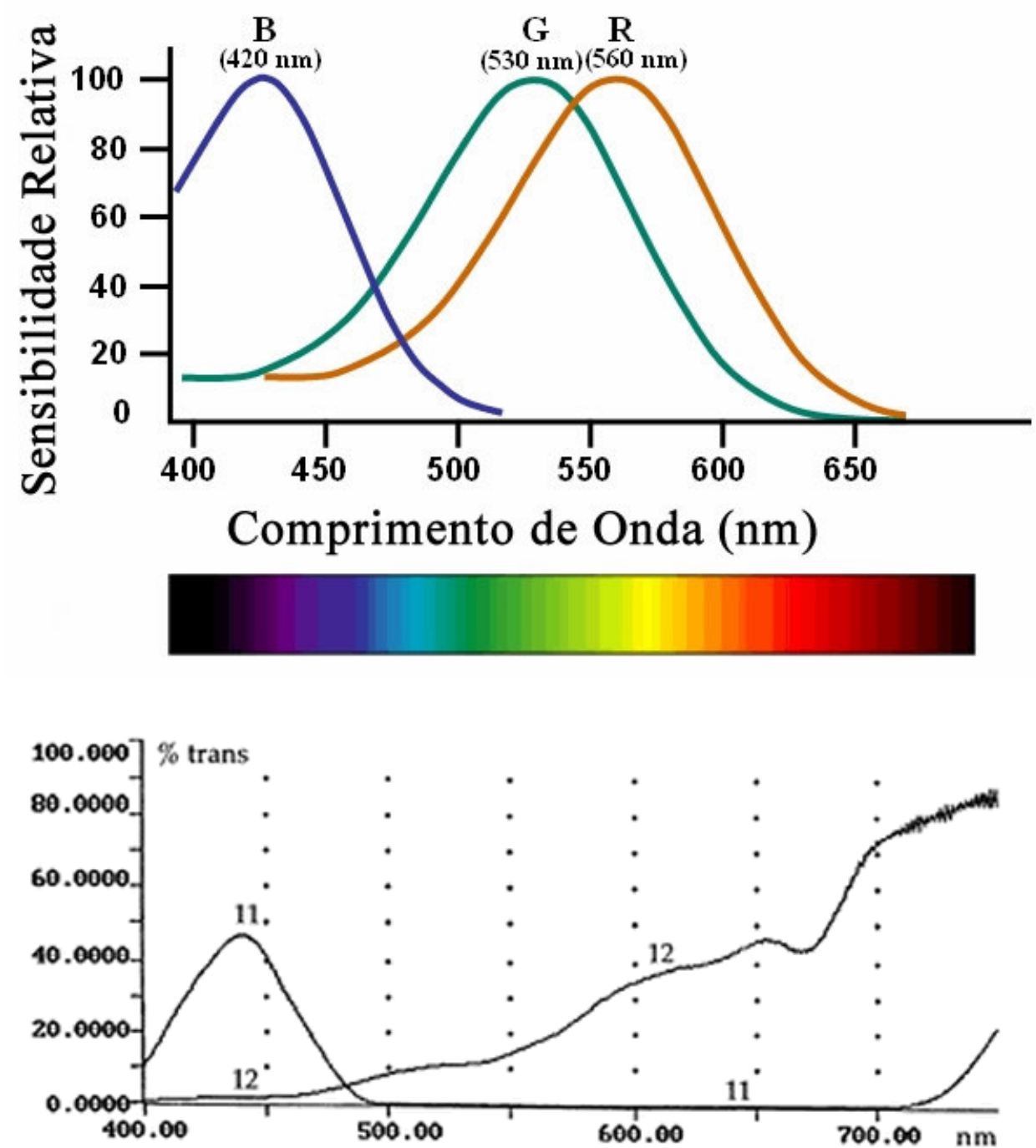

Figura 23 - Gráficos com a sensibilidade do olho humano (cima) e a resposta dos filtros ColorCode (baixo) a diferentes comprimentos de onda da luz visível (baseado em DEEB; MOTULSKY 2005; US PATENT 6687003).

\subsubsection{Polarização da Luz}

A luz visível constitui uma faixa do espectro eletromagnético e se propaga através de ondas eletromagnéticas que vibram de forma arbitrária para todas as direções perpendiculares a direção de deslocamento. O processo de polarizar a luz faz com que essas direções de vibração não sejam mais arbitrárias, fazendo a luz vibrar de 
forma organizada. A luz normalmente é polarizada em três padrões: linear, elíptica e circular, sendo a polarização circular um caso especial de polarização elíptica (NAVE, 2006). A Figura 24 apresenta estes três formatos de polarização que podem ser visualizados graficamente no website WebPhysics (WOLFGANG; DANCY 2008).

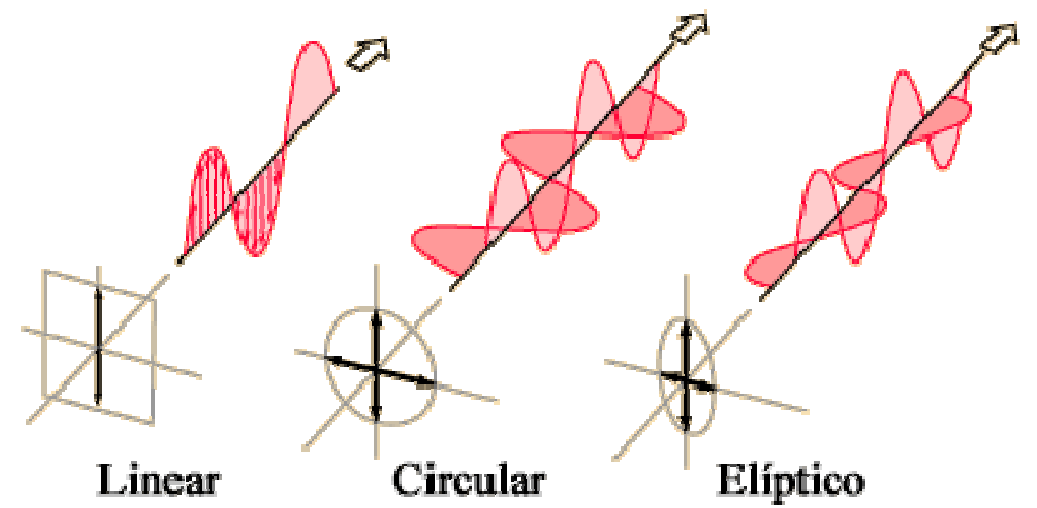

Figura 24 - Padrões de polarização da luz (baseado em NAVE, 2006)

Este conceito de polarização pode ser aproveitado no campo da estereoscopia como uma técnica para separar a informação recebida por cada olho e assim possibilitar a visualização estereoscópica. Para isso é necessário que as imagens esquerda e direita estejam sobrepostas, mas com polarizações diferentes, de forma que um observador utilizando um óculos com os filtros polarizadores apropriados receba a imagem correta para cada olho. Além disso, para obter o resultado esperado é importante que os filtros utilizados para cada olho produzam ondas ortogonais entre si. No caso da polarização linear isso é obtido utilizando-se um filtro horizontal e o outro vertical, já na polarização circular e elíptica é preciso que um filtro seja antihorário (chamado também de esquerdo) e o outro horário (chamado também de direito). Um filtro é classificado como horário ou anti-horário de acordo com a diferença de fase nas componentes vertical e horizontal, se a vertical está atrasada em relação a horizontal (como ocorre na Figura 24) o filtro é horário e no caso contrário é anti-horário.

Uma prática comum para aplicar polarização em estereoscopia é utilizar dois projetores alinhados com filtros ortogonais e projetar o par estereoscópico em uma tela que mantenha a polarização da luz. Os observadores então utilizam óculos com filtros compatíveis com aqueles colocados nos projetores, o que permite que cada 
olho receba apenas a imagem produzida por um dos projetores, possibilitando a visualização estereoscópica (SISCOUTTO et al., 2006).

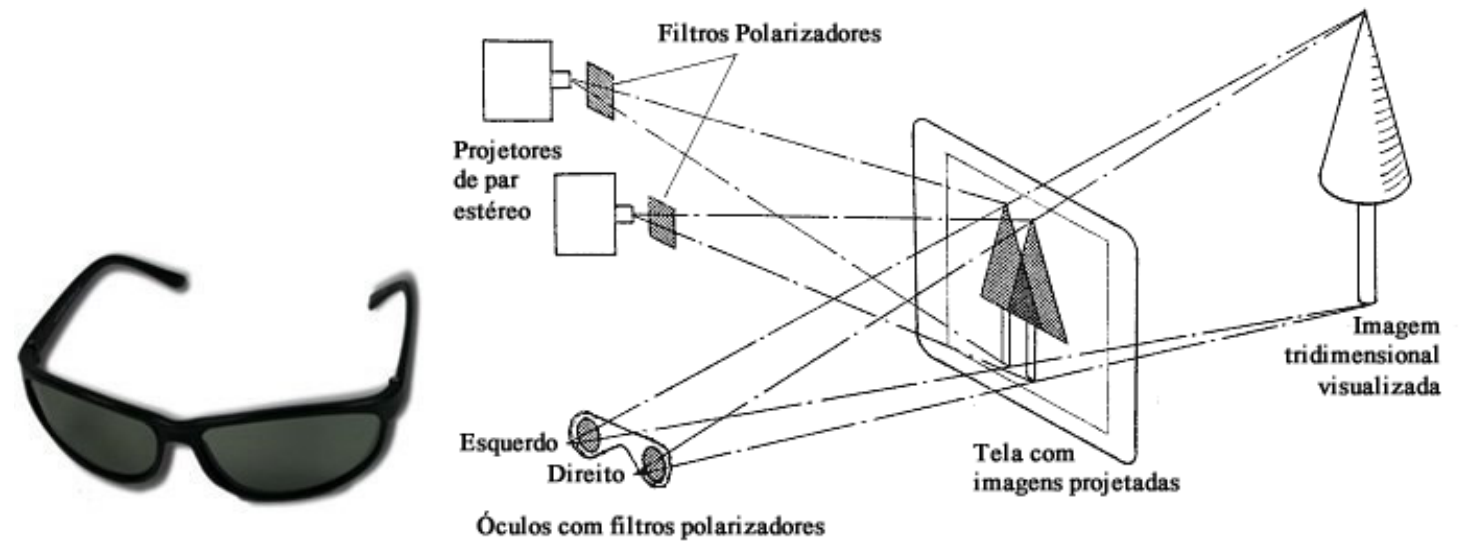

Figura 25 - Óculos com filtros polarizados e esquema de visualização estereoscópica por polarização da luz (AMAZON, 2008; baseado em WAACK, 2004).

Uma nota final é a restrição de movimento do observador quando utilizada a polarização linear. Como um filtro é horizontal e o outro vertical, caso o observador não esteja alinhado em relação à tela, não será observado o efeito estereoscópico. No caso da polarização circular este problema é eliminado, tornando esse tipo de polarização mais flexível e robusto em ambientes não muito controlados.

\subsubsection{0 Óculos Obturadores (LCS/Shutter Glasses)}

Nesta solução estereoscópica, as imagens esquerda e direita aparecem de forma alternada para o observador e é necessário um equipamento que bloqueie a visão do mesmo para que veja as imagens através do olho correto. Este equipamento é normalmente um óculos obturador que utiliza lentes de cristal líquido e bloqueia a visão do observador em sincronia com as imagens que são exibidas (ENGDAHL, 1999). Esta tecnologia foi muito desenvolvida comercialmente e existem diversas patentes registradas nessa área (STARKS, 2008). 
Esta tecnologia foi explorada tanto para visualização 3D em computadores como também em televisores. Engdahl (1999) lista vários dos diferentes padrões que foram criados para obter a percepção estereoscópica através de óculos obturadores. Mesmo considerando apenas as soluções para computadores, muitos formatos diferentes foram concebidos (WOODS, 2005), sendo os principais:

- Page Flipping - Produz os melhores resultados dentre os formatos, consiste em mudar diretamente de uma imagem para a próxima diretamente na memória de vídeo;

- Interlaced - Provavelmente o método mais simples que utiliza o mesmo esquema dos padrões PAL e NTSC de atualizar linhas pares e ímpares alternadamente. As imagens de um olho são exibidas nas linhas pares e do outro nas ímpares;

- Sync Doubling - Funciona dividindo a imagem em duas metades e associando um olho para a metade superior e o outro para a inferior. Um sinal externo de sincronismo vertical é gerado sempre no ponto vertical médio, para que cada metade seja exibida como uma imagem completa do monitor;

- Line Blanking - Usado quando imagens entrelaçadas são mostradas em um monitor não-entrelaçado. Um equipamento externo limpa a informação das linhas não atualizadas naquele quadro para não misturar as imagens dos dois olhos.

Além dos diversos formatos para gerar as imagens, existem diferentes padrões para conectar os óculos no computador e possibilitar a sincronização entre a geração das imagens e o bloqueio dos olhos do observador. Alguns modelos são conectados a uma saída especial da placa de vídeo, que sinaliza os pulsos de sincronia vertical para os óculos. Outros modelos são conectados diretamente a saída VGA, encaminhando o sinal de vídeo para o monitor e a sincronia vertical para os óculos. Existem soluções que oferecem também óculos obturadores sem fio, nos quais a sincronia é feita por transmissão de infravermelho. 

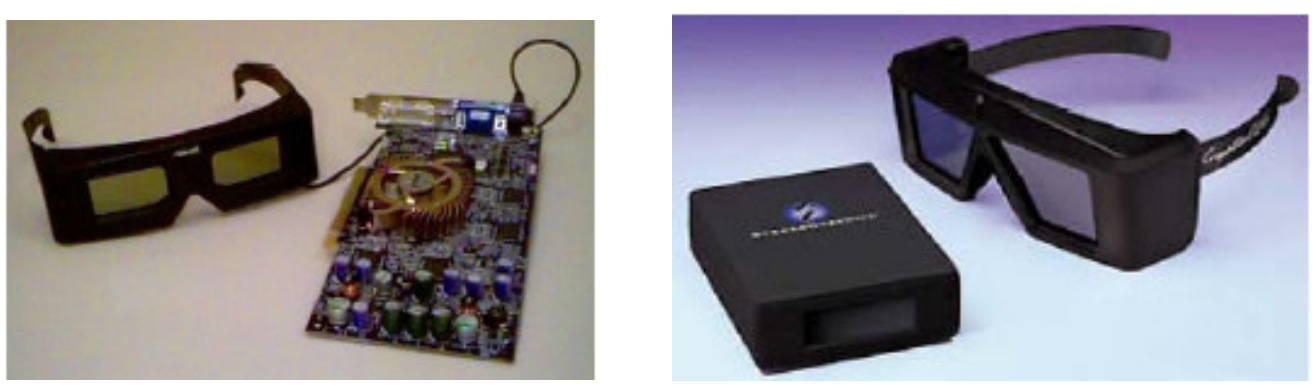

Figura 26 - Óculos obturador em versão com fio e sem fio (SISCOUTTO et al., 2006).

Esta tecnologia apresenta dois problemas principais: o crosstalk e o flicker (ENGDAHL, 1999). O problema do crosstalk consiste na incapacidade do sistema de isolar completamente as imagens que devem ser exibidas ao olho esquerdo das imagens destinadas ao olho direito. Por isso os olhos acabam vendo "fantasmas" das imagens destinadas ao outro olho. No caso do flicker o problema é causado pela falta de velocidade do sistema de alternar entre as imagens, o que torna o resultado estereoscópico inconsistente para o observador. Como a freqüência de atualização para cada olho é dividida por dois, a freqüência do sistema deve ser de pelo menos $100 \mathrm{~Hz}$ a $120 \mathrm{~Hz}$, para atingir uma atualização de $50 \mathrm{~Hz}$ a $60 \mathrm{~Hz}$, que é o padrão utilizado em televisão.

\subsubsection{Head Mounted Display}

Os equipamentos conhecidos como Head Mounted Displays (HMDs) estão de tal forma ligados ao desenvolvimento da realidade virtual e aumentada que existem autores que associam o seu uso como um requisito para criar tais ambientes. A grande vantagem dos HMDs quanto ao aspecto da estereoscopia é o completo isolamento entre a imagem gerada para o olho esquerdo e a gerada para o olho direito, permitindo uma visualização completamente livre de crosstalk (AZUMA, 1997). Os HMDs são classificados em duas categorias básicas: óptico e vídeo. 


\section{HMDs de Vídeo}

Nesse tipo de HMD o observador enxerga apenas o conteúdo que é exibido por vídeo nos displays do equipamento. O vídeo pode conter cenas do mundo real, no entanto estas cenas são primeiro capturadas através de uma câmera e depois repassadas para o observador. Em um sistema de realidade aumentada, esse vídeo do mundo real é incrementado de elementos virtuais, que precisam ter sua posição corretamente registrada com relação aos objetos reais.

Um HMD deste tipo pode ser visto na Figura 27, juntamente com uma imagem de um sistema de realidade aumentada. As grandes vantagens desta tecnologia são:

- Flexibilidade para compor as imagens de conteúdo real e virtual;

- Amplo campo de visão por ser possível corrigir as distorções ópticas digitalmente;

- Sincronia na atualização do conteúdo real e virtual;

- A cena capturada digitalmente pode ser usada para auxiliar no registro dos elementos virtuais.
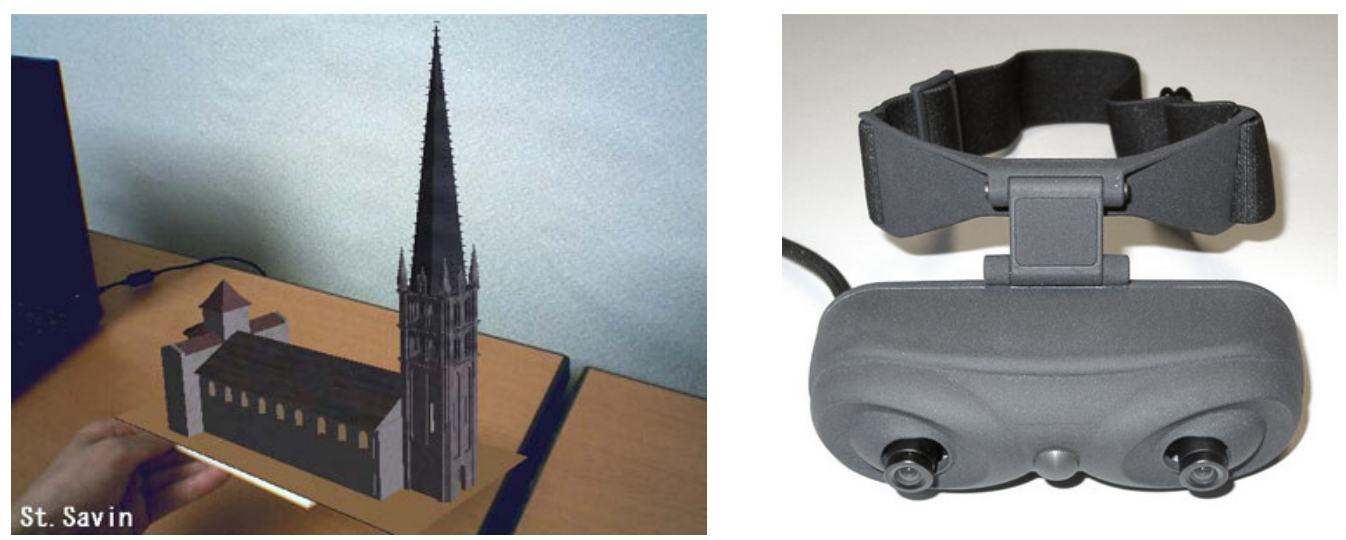

Figura 27 - Imagem resultante de sistema usando HMD de vídeo e o HMD AR-Vision-3D com tecnologia video see-through e duas câmeras acopladas (KONDO et al., 2007; INITION, 2008).

Um problema importante de segurança para o observador que utiliza um equipamento destes é a dependência do aparelho para visualizar o mundo real ao 
seu redor. Caso ocorra alguma falha e o vídeo do mundo real deixe de ser exibido, o observador estará "cego" até retirar o equipamento.

\section{HMDs Ópticos}

A peça chave deste equipamento são as lentes semi-transparentes nas quais ocorre a combinação entre a visão natural do mundo real e o conteúdo virtual gerado pelo sistema. Ao contrário dos HMDs de vídeo, qualquer manipulação de imagens do mundo real que o observador recebe só podem ser manipuladas através de esquemas ópticos. Caso ocorra alguma falha do sistema o usuário continuará enxergando o mundo real, no entanto a intensidade da luz recebida é menor, devido à característica semitransparente das lentes.

$\mathrm{Na}$ Figura 28 tem uma imagem resultante de um sistema destes e um exemplo de HMD óptico. A seguir são apresentadas as principais vantagens deste tipo de HMD:

- Simplicidade e menor custo;

- Resolução das imagens reais limitada apenas pelo sistema óptico humano;

- Mais seguro do que HMDs de vídeo. No caso de falha o observador continua vendo o mundo real, apenas como se estivesse com um óculos de sol;

- O ponto de vista das imagens observadas é exatamente a posição dos olhos. No caso de HMDs de vídeo as imagens são relativas a posição das câmeras.
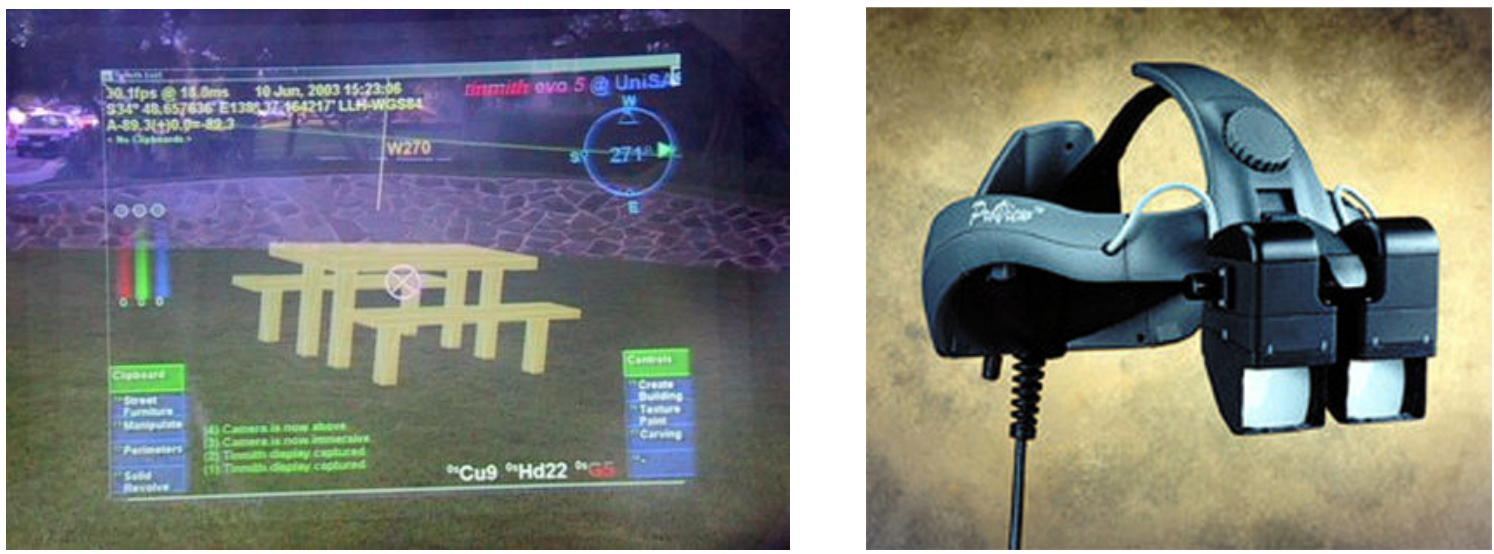

Figura 28 - Imagem resultante de sistema usando HMD óptico e o HMD ProView XL40/50 com tecnologia optical see-through (PIEKARSKI, 2004; SILVA, 2003). 


\subsubsection{Autoestereoscopia}

Esta categoria de solouções estereoscópicas engloba diversos produtos e tecnologias diferentes. Dependendo da definição de autoestereoscopia utilizada, este grupo pode abordar qualquer tipo de solução que permita observar com sensação de profundidade a olho nú. Entretanto, no escopo deste trabalho será considerada uma solução autoestereoscópica aquelas que atendem aos seguintes requisitos:

1) Permite a visualização estereoscópica sem que o observador utilize nenhum equipamento óptico para separar o canal esquerdo do direito;

2) Não exige nenhuma técnica de visualização por parte do observador;

A primeira restrição vem da própria natureza do termo autoestereoscopia que reflete a visualização estereoscópica sem a necessidade de equipamentos ópticos. O segundo requisito visa restringir um pouco mais o conceito de autoestereoscopia, de forma que qualquer observador com visão normal e nenhum conhecimento prévio da solução possa visualizar a cena com sensação de profundidade, assim ficam excluídas, por exemplo, soluções por estereograma e par estéreo.

Considerando estes requisitos são apresentadas algumas das soluções nessa área que vem sendo alvo intenso de pesquisa, sendo muito citada na conferência "Stereoscopic Displays and Applications" e por empresas que fabricam este tipo de produto.

\section{Barreiras de Paralaxe}

O primeiro tipo de solução autoestereoscópica foram as barreiras de paralaxe que consistiam em dividir duas ou mais imagens em tiras verticais e posicioná-las atrás de barreiras verticais opacas de mesma freqüência, de forma que um observador 
visualiza imagens diferentes dependendo do ponto de vista (ROBERTS, 2003). O primeiro a demonstrar que era possível visualizar imagens diferentes por esse método foi o pintor francês G. A. Bois-Clair em 1692, no entanto o uso desta técnica para a estereoscopia foi aplicado apenas em 1903 por Frederick E. Ives e posteriormente desenvolvida por seu filho Herbert E. Ives.

Uma aplicação comum desta técnica são os cartões holográficos conhecidos também por colorgrams. Estes cartões apresentam diversas imagens diferentes impressas sob uma barreira de paralaxe, de forma que um observador consegue visualizar imagens diferentes inclinando levemente o cartão. Schreck (2008) explica em seu website como criar esse tipo de cartão utilizando programas de processamento de imagens e impressora jado de tinta.
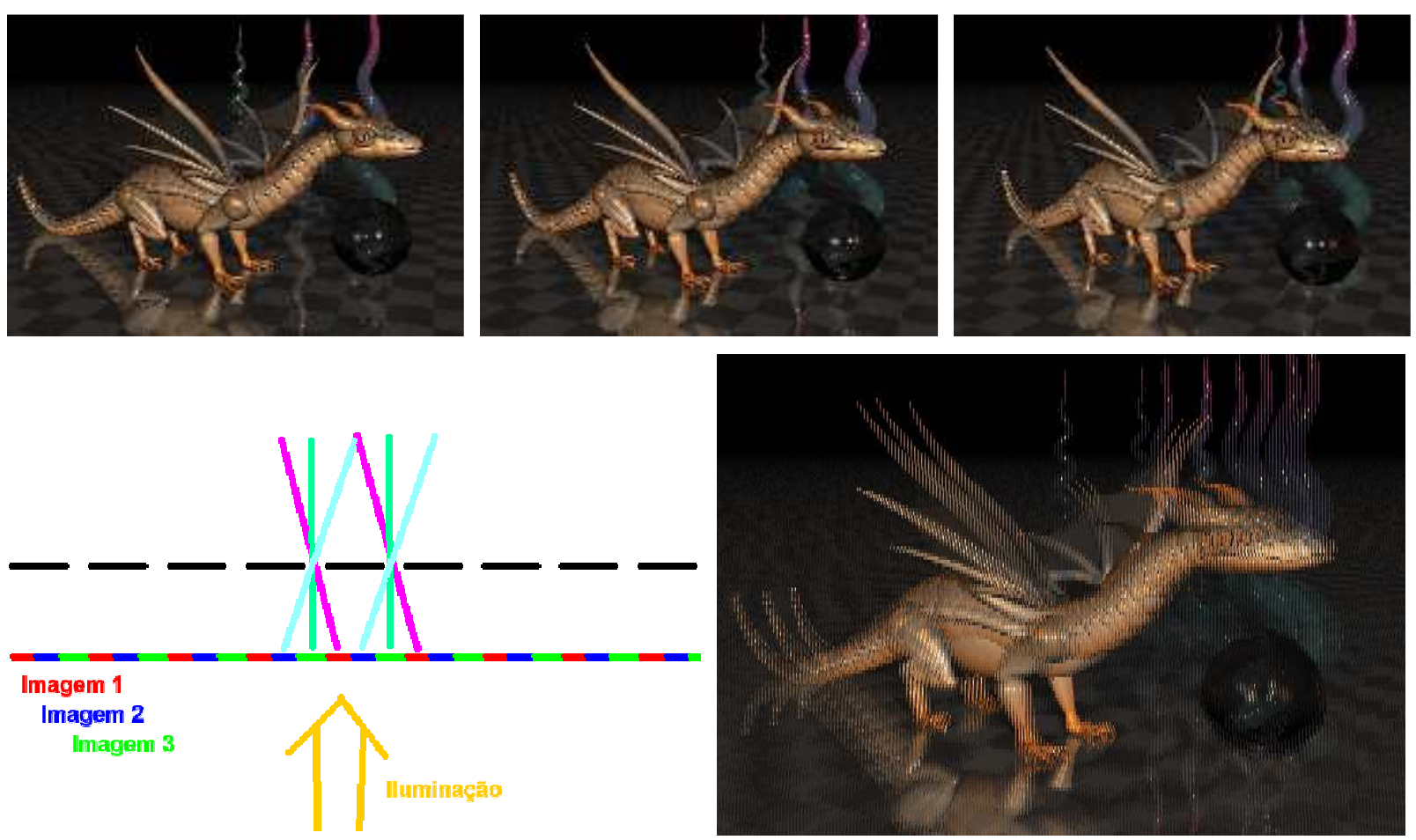

Figura 29 - Cartão holográfico criado por Schreck (2008). Na parte superior estão as imagens iniciais, a esquerda o esquema de funcionamento desta técnica e na direita o resultado final.

\section{Lentes Lenticulares}

Esta técnica utiliza o mesmo princípio das barreiras de paralaxe, direcionar os raios de luz de forma que cada olho receba a respectiva imagem esquerda e direita, mas 
para isso são utilizadas lentes ao invés de simples barreiras (ROBERTS, 2003). passo inicial nesta linha foi dado por Gabriel M. Lippmann em 1908, com a fotografia integral, na qual uma série de lentes do tipo "olho de mosca" são colocadas sobre uma fotografia especial, permitindo que fosse visualizada sob diversos pontos de vista. Alguns anos depois, já na década de 1920, diversos pesquisadores incluindo Herbert E. Ives continuaram trabalhando em uma simplificação do método de Lippmann e foi proposta a utilização de uma série de lentes concatenadas, chamada de folha de lentes lenticulares (lenticular lens sheet). A grande vantagem desta forma de agrupar as lentes é que opticamente ela se torna muito similar às barreiras de paralaxe e, portanto, permite aproveitar grande parte da pesquisa utilizada para as barreiras.

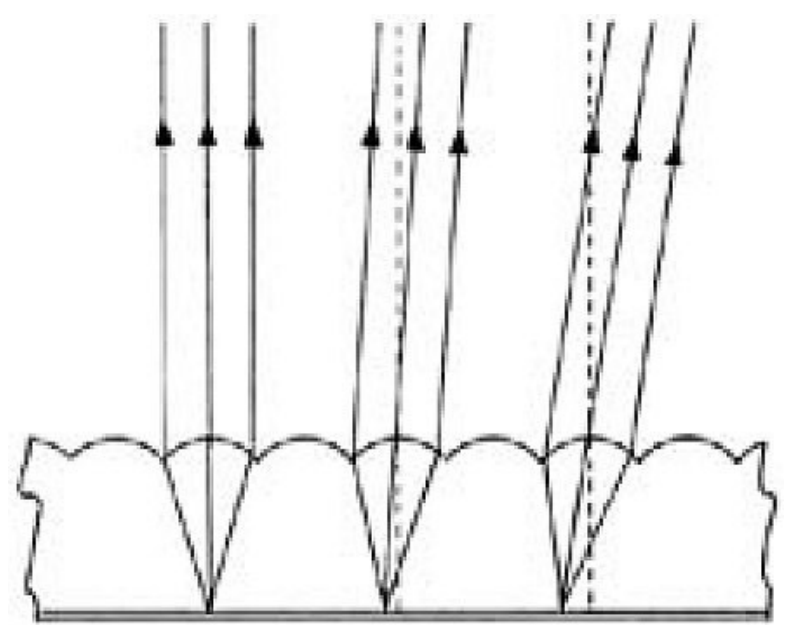

Figura 30 - Esquema do comportamento óptico das lentes lenticulares (ROBERTS, 2003).

\section{Displays Volumétricos (Volumetric Displays)}

Uma abordagem diferente para o problema da autoestereoscopia é a categoria dos displays volumétricos. Neste tipo de solução, ao invés de tentar que um par de imagens planares seja visualizado com profundidade, a idéia é reconstruir uma cópia dos objetos no espaço, assim um observador pode visualizar o objeto com profundidade, pois esta informação estará presente de forma natural. Conforme Halle (1997) para realizar esta tarefa, as soluções deste tipo precisam de alguma forma preencher ou varrer um volume no espaço. Diversas tecnologias diferentes 
surgiram para essa finalidade, no entanto todas apresentam grandes limitações e esta ainda é uma área de intensa pesquisa (WIKIPEDIA, 2008).

Um dos representantes mais recentes desta tecnologia é um projeto desenvolvido pelo Institute for Creative Technologies (ICT) da University of Southern California. Neste projeto entitulado "Rendering for an Interactive 360 Light Field Display" os pesquisadores conseguiram criar um display volumétrico, no qual diversos observadores simultâneos podem visualizar o objeto reconstruído. Mas um dos grandes diferenciais desta tecnologia em relação a outras soluções de displays volumétricos é a possibilidade de oclusão da parte oposta do objeto, a que estaria oculta caso fosse um objeto real (JONES et al., 2007). A solução consiste em utilizar um projetor superior direcionado para um espelho inclinado à $45^{\circ}$ que reflete a projeção em direção aos observadores. O espelho gira com uma freqüência de aproximadamente $20 \mathrm{~Hz}$ e o projetor é especialmente modificado para ser capaz de exibir cerca de 4800 quadros monocromáticos por segundo.

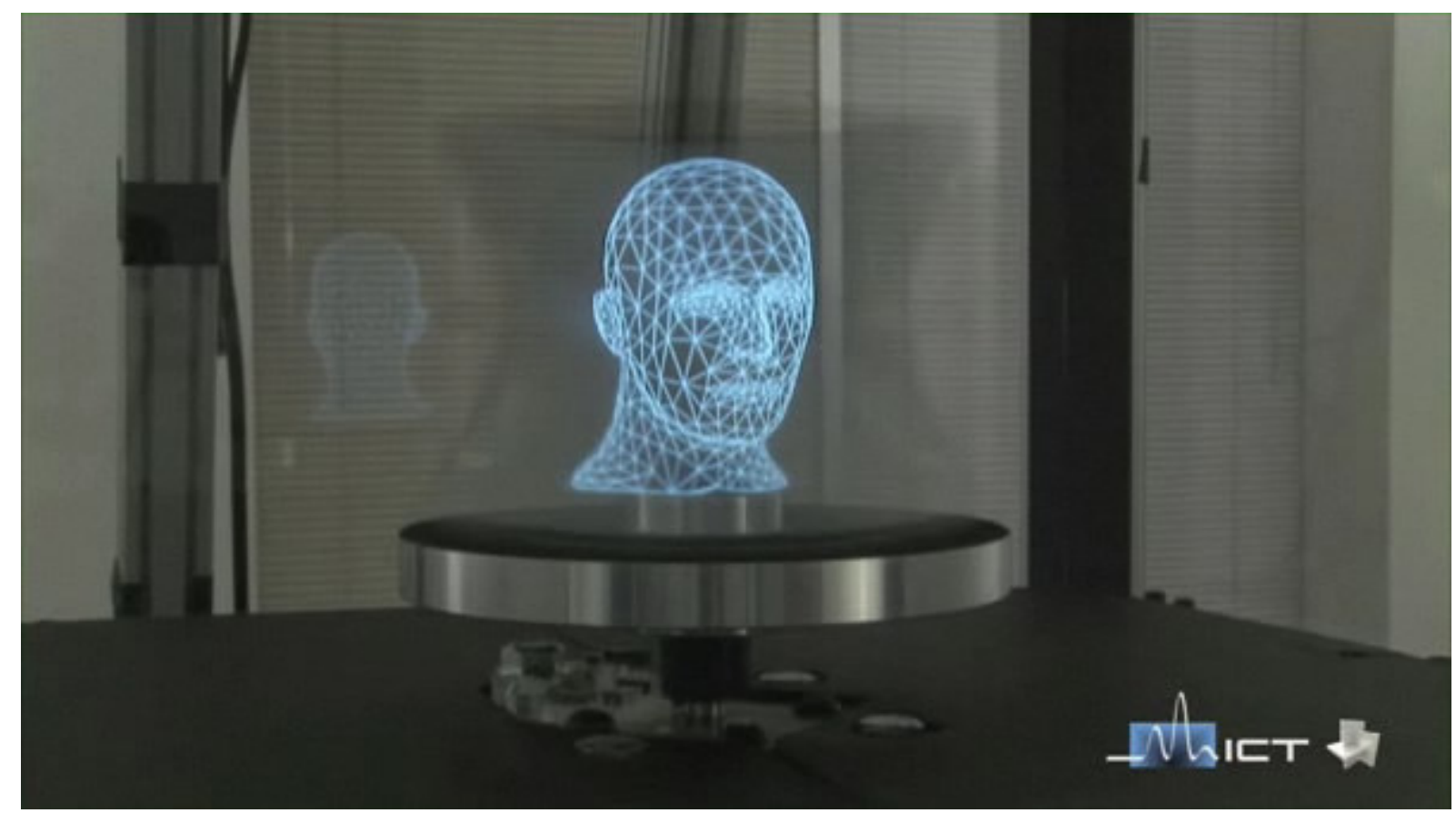

Figura 31 - Fotografia da solução desenvolvida pelo ICT. Notar o detalhe da parte oclusa de trás da cabeça reconstruída refletida no vidro (JONES et al., 2007).

\subsubsection{Par Estéreo Alternado (Wobble/Wiggle Stereo)}


Esta técnica permite a visualização de cenas com noção de profundidade, no entanto ela não pode ser considerada como uma solução estereoscópica, pois seu funcionamento não está baseado na disparidade das imagens obtidas por cada olho, mas sim no princípio da paralaxe de movimento.

Uma imagem neste formato é na realidade uma animação, a qual é constituída de pelo menos duas imagens que retratam uma mesma cena de dois pontos de vista levemente diferentes. Exibindo estas imagens de forma cíclica e alternada um observador tem a mesma sensação de paralaxe obtida ao olhar o mundo real deslocando levemente a cabeça.

Esta técnica já é descrita de forma aproximada em uma patente de 1996, enviada por Benjamin R. Halpern (US PATENT 5524188). A patente aborda a técnica de forma mais abrangente, descrevendo diversas formas de se explorar a paralaxe com uma forma de possibilitar a sensação de profundidade. O responsável pela produção das primeiras versões digitais na internet e posterior popularização desta técnica foi Jim Gasperini (2002) que inclusive disponibiliza em seu website algumas dicas para quem deseja criar este tipo de imagens animadas.
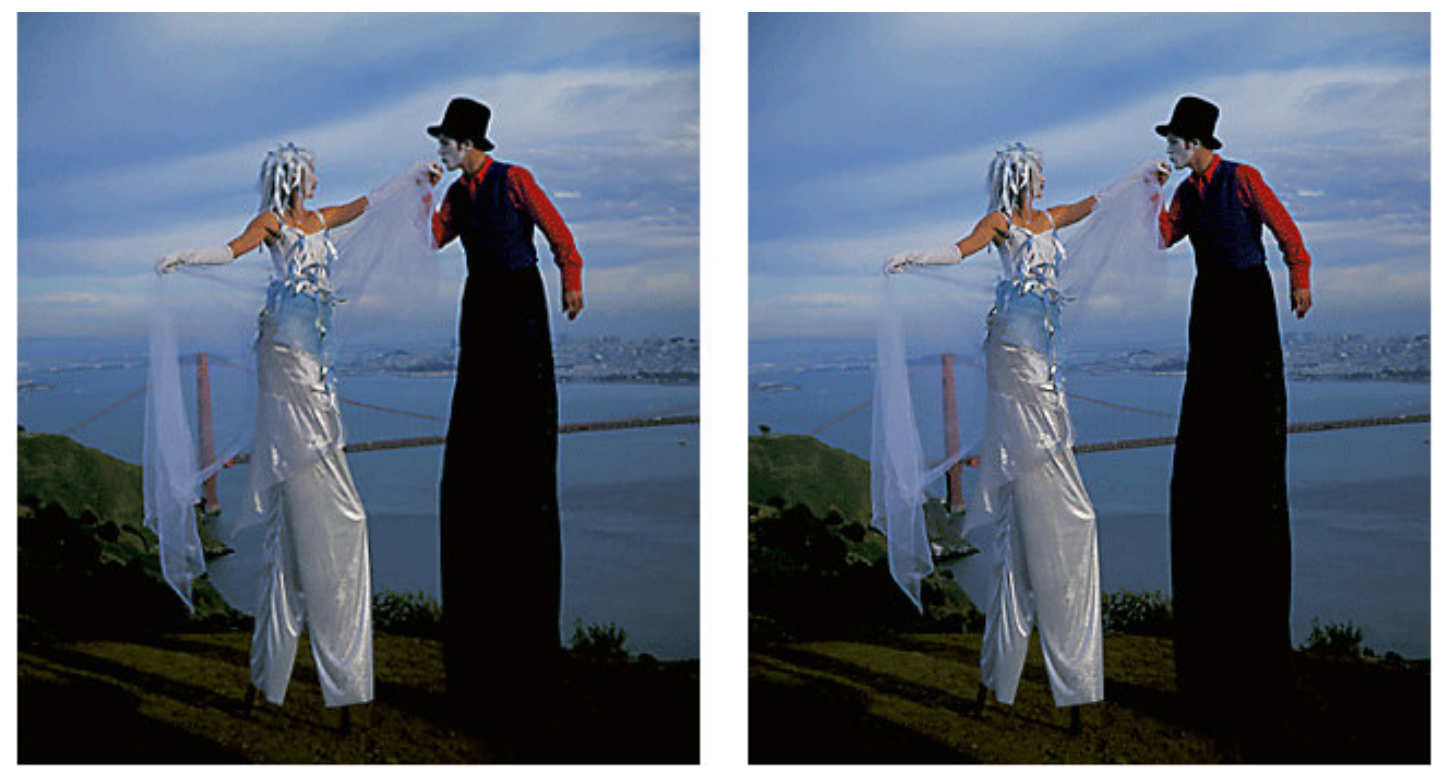

Figura 32 - Imagens usadas por Gasperini (2002) em uma animação de par estéreo alternado. 


\subsection{Mercado de Estereoscopia}

Especialmente para aplicações que não utilizam os HMDs, a estereoscopia ainda é um tema que busca uma consolidação maior no mercado. Sazonalmente, uma solução estereoscópica que possibilita o uso popular ganha fama e diversas empresas começam a fabricar o equipamento, no entanto depois de alguns anos de empolgação a tecnologia volta para o segundo plano e fica esperando a próxima grande explosão do mercado estereoscópico. Consequências desse comportamento do mercado são os diversos produtos criados em diferentes épocas, listas com diversos desses produtos podem ser encontradas online em sites especializados como Stereo3D.com e Stereoscopy.com.

No final da década de 1990 e início da década de 2000, os produtos da vez eram os óculos obturadores que frequentemente vinham juntamente com placas gráficas $3 D$ e prometiam que qualquer jogo com renderização tridimensional fosse visto com sensação de profundidade. Embora na época grandes produtoras de hardware tenham também participado da empolgação, o que acabou acontecendo é que os óculos nunca passaram de um produto de nicho e com o tempo apenas alguns poucos fabricantes restaram. Um dos possíveis responsáveis para o recuo dos óculos obturadores foi a popularização dos monitores LCD (Liquid Crystal Display), que devido ao modo como atualizam a tela, não são compatíveis com esse tipo de solução estereoscópica (WEINAND, 2005a), ou pelo menos não eram compatíveis na época.

Depois desta queda do mercado de óculos obturadores, uma das empresas responsáveis por manter este mercado vivo é a NVidia (2008), que mantém ativo um projeto de drivers voltados a visualização estereoscópica. Com estes drivers instalados em computador com sistema operacional e placa gráfica compatíveis, o usuário pode selecionar uma entre diferentes formas de soluções estereoscópicas que define a forma que a placa gráfica renderiza qualquer aplicação com ambientes virtuais, independente se o aplicativo foi criado já com o suporte a estereoscopia em mente. 
Uma linha de equipamentos que tentam atingir o grande público são as linhas dos monitores autoestereoscópicos e monitores polarizados. O primeiro tipo utiliza a mesma técnica das lentes lenticulares, dividindo o monitor em faixas verticais, onde metade das faixas exibem a imagem esquerda e a outra metade a imagem direita (WEINAND, 2005b). Entretanto estes monitores apresentam alguns problemas:

- Não é possível exibir imagens 2D comuns por causa das lentes lenticulares;

- As imagens têm metade da resolução horizontal de um monitor comum;

- O observador tem que estar posicionado numa estreita faixa em frente ao monitor, caso contrário a imagem não é vista corretamente.
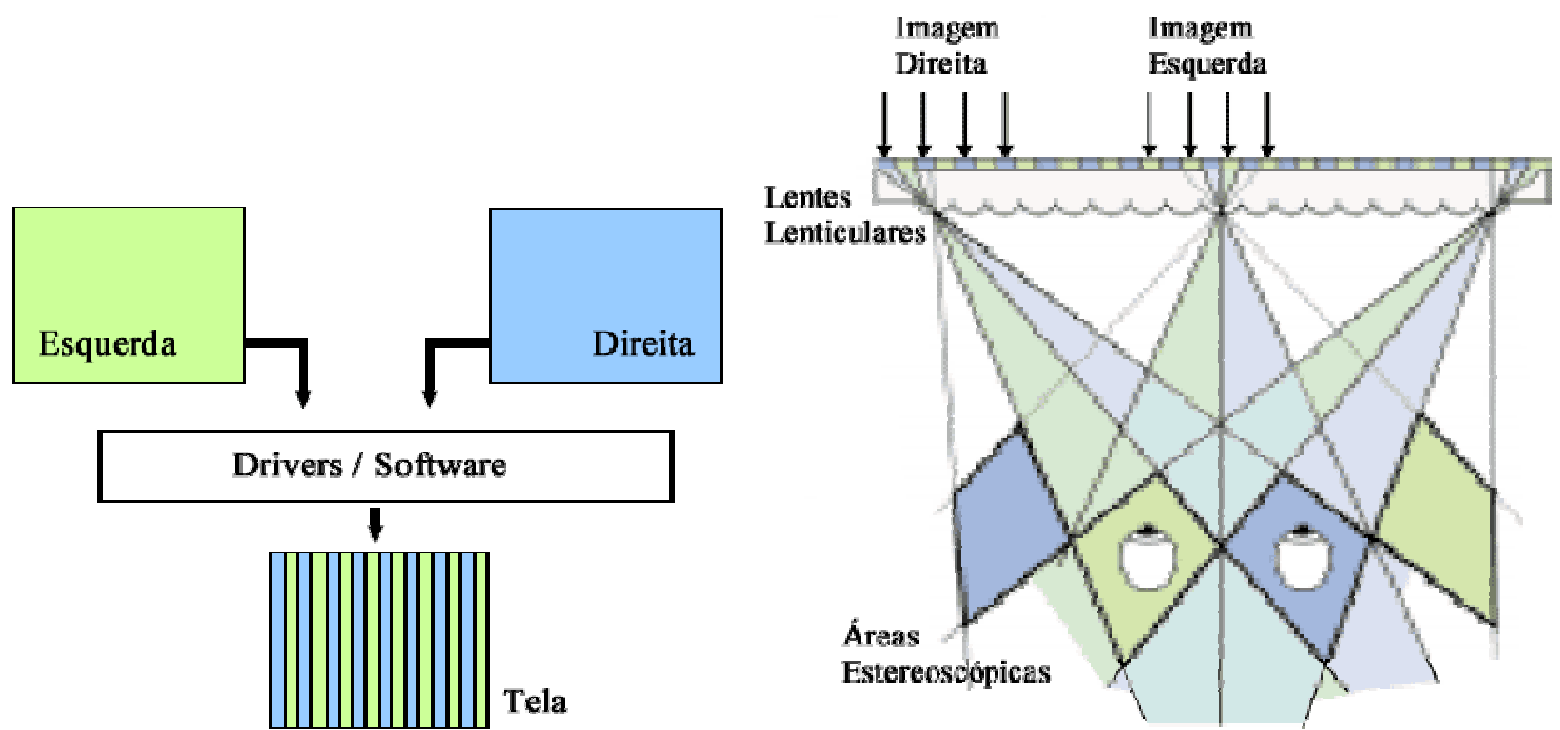

Figura 33 - Esquemas de funcionamento dos monitores autoestereoscópicos. Junção das imagens esquerda e direita (esquerda) e o que ocorre na observação do monitor (baseado em WEINAND 2005b).

Os monitores polarizados utilizam a tecnologia de polarização da luz, permitindo que um observador com óculos equipados com filtros apropriados visualize a imagem produzida na tela de forma estereoscópica. Um modelo desse tipo é o Trimon produzido pela Zalman (2008), este modelo permite a visualização de imagens 2D e $3 \mathrm{D}$ em um largo campo visual horizontal, mas está limitado a aproximadamente $10^{\circ}$ de movimento do observador na vertical. A principal limitação deste tipo de solução é a necessidade do observador utilizar óculos especiais. 

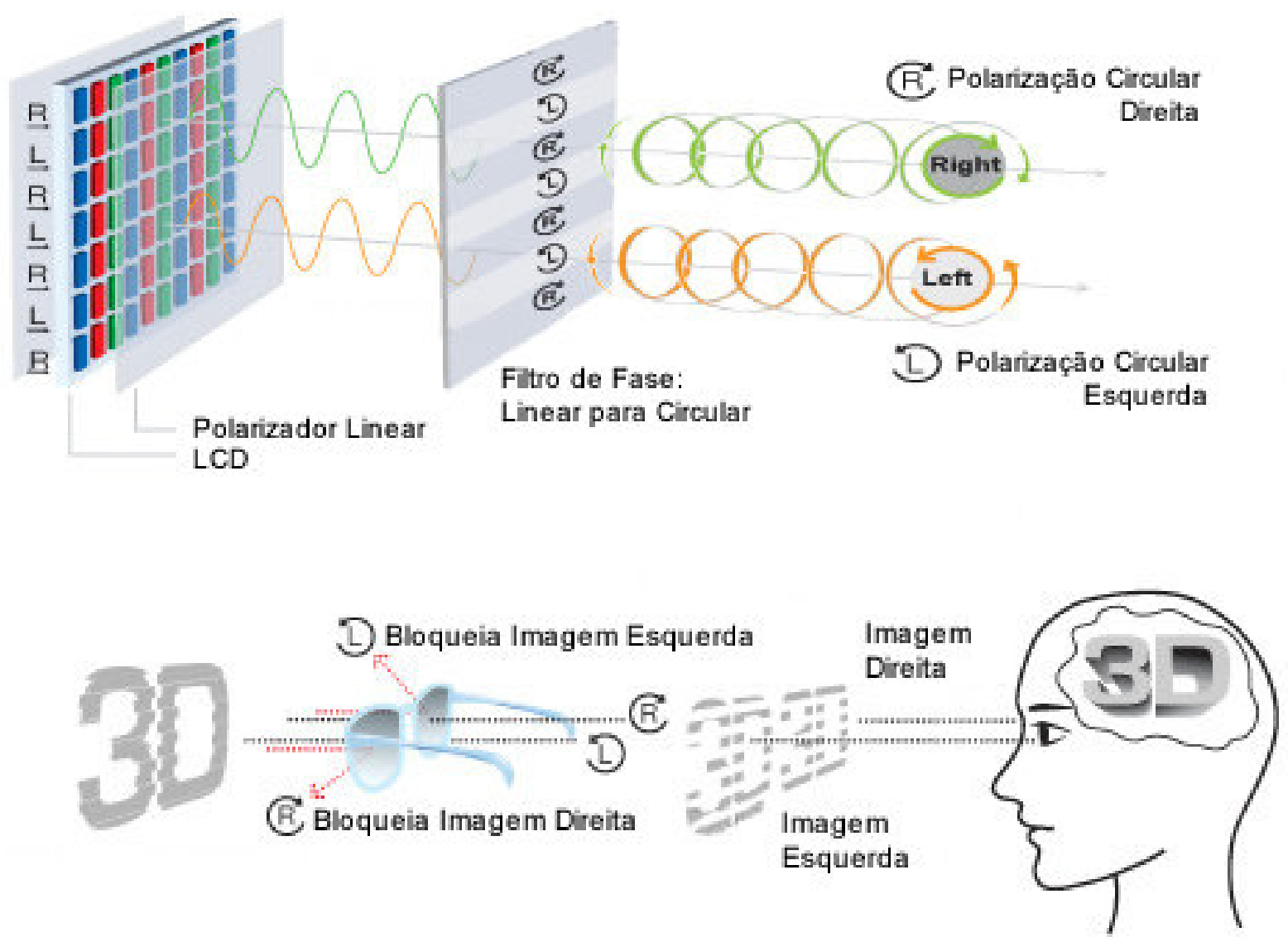

Figura 34 - Esquemas do funcionamento dos monitores polarizados. Geração das imagens polarizadas (cima) e como o observador visualiza as imagens de forma estereoscópica (baseado em ZALMAN, 2008).

Além do uso doméstico, cada vez mais a indústria do cinema passa a explorar a estereoscopia, com mais filmes e cinemas equipados com salas 3D. A conferência anual "Stereoscopic Displays and Applications" que faz sessões de filmes 3D, vem apresentando listas cada vez maiores de filmes (WOODS, 2008a). Woods (2008b) mostra que grandes produtoras como "20th Century Fox" e "Warner Brothers" estão se arriscando nesse nicho, graças também ao processo desenvolvido por David Geshwind (2006) que possibilita a conversão de um filme 2D para ser exibido em 3D, no entanto o processo ainda é muito lento para que os filmes sejam lançados simultaneamente em 2D e 3D.

Outra produção de Hollywood que impulsiona esta fase de crescimento da estereoscopia é o Avatar (2009). Escrito e dirigido por James Cameron, Avatar é o primeiro blockbuster que explora a estereoscopia desde a sua concepção. Além de ter sido produzido com o suporte a cinemas $3 \mathrm{D}$ em mente, a publicidade do filme 
também foi direcionada de modo a estimular os espectadores a assistirem o filme em 3D. O filme é o maior sucesso de bilheteria de todos os tempos, com um faturamento mundial bruto acima de US $\$ 2,6$ bilhões, três meses após a data de seu lançamento (IMDB, 2010). Embora seja complicado estimar qual a contribuição da estereoscopia ao sucesso de Avatar, uma contribuição irrefutável é o preço do bilhete. A diferença entre o preço do bilhete para uma sala comum e uma sala 3D inflacionou a receita bruta do filme, pois o público esta disposto a pagar mais por uma sala 3D. De qualquer forma, este sucesso comercial evidencia ainda mais a estereoscopia, promovendo para um público de diversificada faixa etária os efeitos visuais desta tecnologia.

\subsection{Trabalhos em Realidade Virtual e Aumentada}

A estereoscopia está presente na área da realidade virtual e aumentada a partir do momento em que os HMDs passaram a suportar a exibição de imagens diferentes para cada olho, pois a exibição de um par estéreo é um requisito básico da estereoscopia. Apesar disso, muitos dos projetos envolvendo estereoscopia tem caráter experimental. A seguir são apresentados alguns projetos que envolvem os dois conceitos de alguma forma, começando pelo AVTC do INTERLAB.

\subsubsection{Augmented Virtuality Tele-Conferencing (AVTC)}

Como descrito em outros capítulos deste trabalho, o AVTC é na verdade uma proposta de arquitetura para teleconferência usando o conceito de virtualidade aumentada. A estereoscopia é aplicada como mais um elemento que aumenta a sensação de tele-presença dos usuários deste tipo de sistema. A Figura 35 
apresenta a arquitetura do AVTC e em seguida cada módulo é detalhado em poucas palavras.

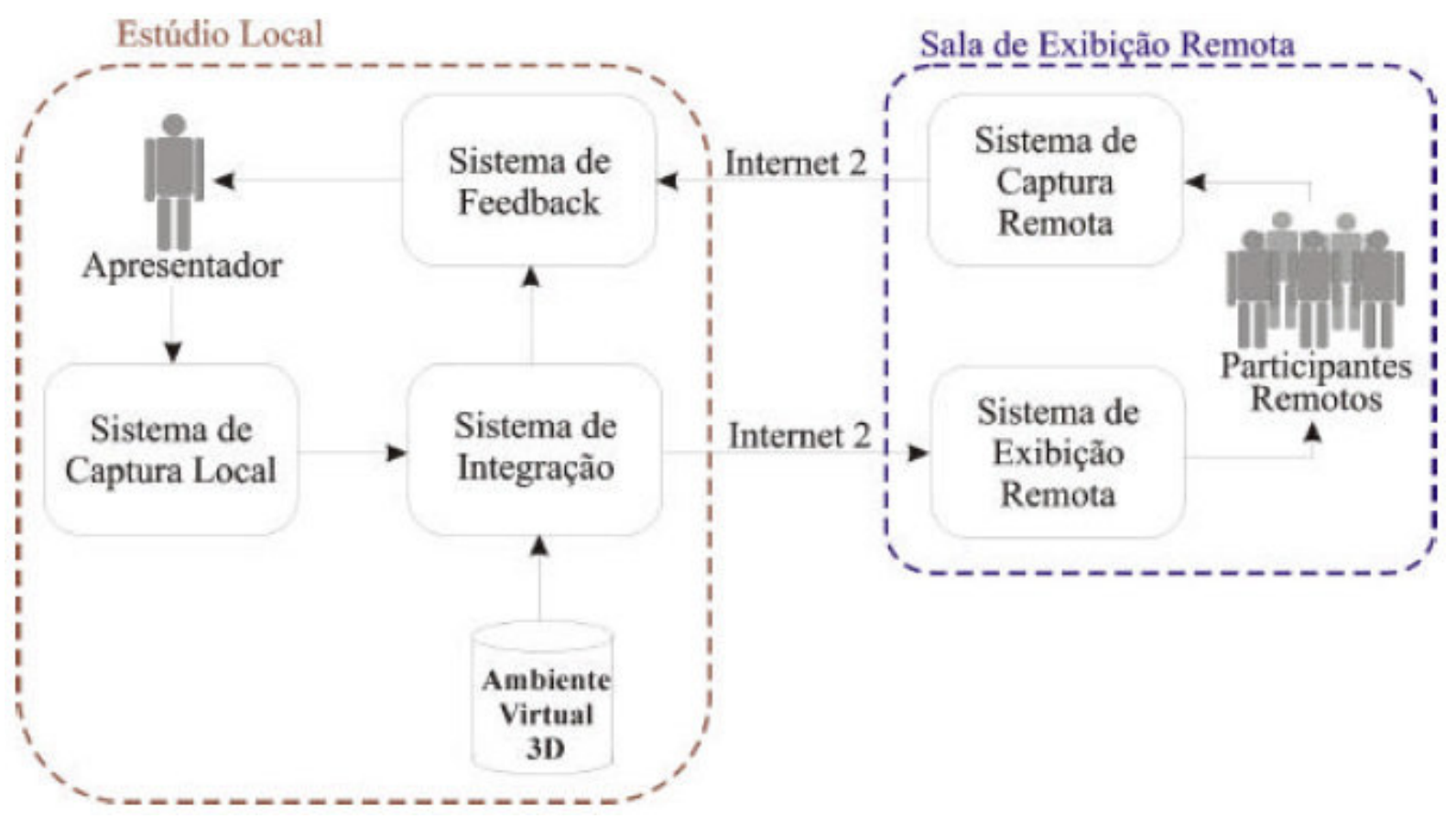

Figura 35 - Arquitetura conceitual do AVTC (SISCOUTTO, 2003).

No AVTC os usuários são divididos em apresentador e participantes remotos, que tem responsabilidades distintas dentro do sistema (SISCOUTTO, 2003). O apresentador é a pessoa que tem sua imagem capturada por vídeo e inserida na forma de um vídeo-avatar dentro do ambiente virtual. Os participantes visualizam o apresentador dentro do ambiente virtual, com ou sem estereoscopia, e podem interagir através da voz. No estúdio onde o apresentador estará localizado, estão presentes os seguintes módulos:

- Sistema de Captura Local - Responsável pela captura das ações do apresentador, por vídeo, som e comandos de movimento;

- Sistema de Integração - Unifica os dados capturados do apresentador, incluindo o vídeo-avatar, com o ambiente virtual formando a cena que os participantes visualizam; 
- Sistema de Feedback - Recebe os dados da integração entre apresentador e ambiente virtual, juntando estas informações a voz e vídeo capturadas dos participantes. Esta informação é repassada para o apresentador.

O outro ponto do sistema é a sala de exibição, na qual estão presentes os participantes e contém os seguintes módulos:

- Sistema de Captura Remota - Obtém os dados de som e vídeo dos participantes para serem enviados ao apresentador;

- Sistema de Exibição Remota - Parte responsável por exibir para os participantes o resultado da integração entre o ambiente virtual e o vídeoavatar do apresentador.

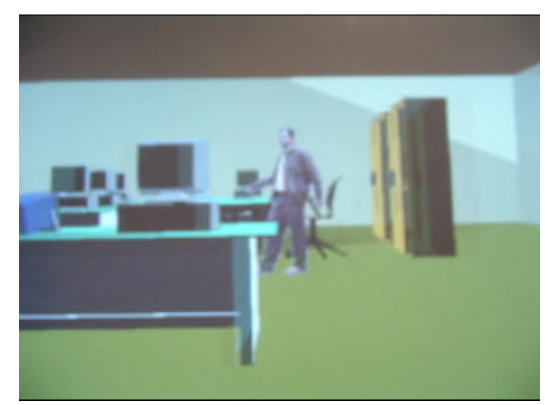

(a)

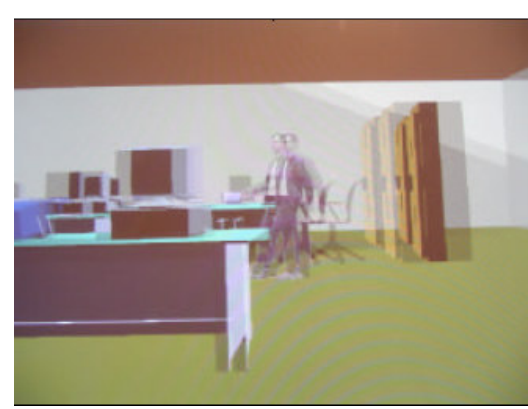

(b)

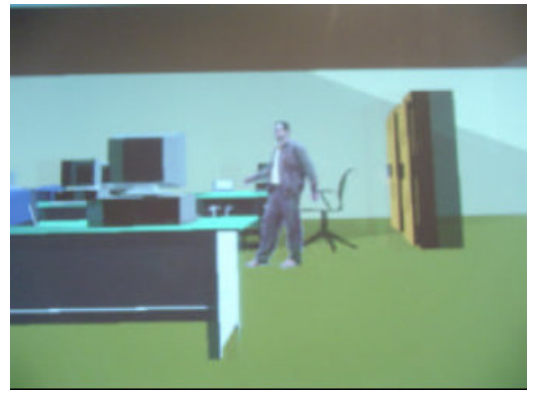

(c)

Figura 36 - Imagens do protótipo da arquitetura AVTC. Visão esquerda (a), Visão direita (c) e o resultado estéreo para óculos obturadores (b) (SISCOUTTO 2003).

Com base no conhecimento adquirido com este protótipo do AVTC, o INTERLAB segue na linha de avatares estereoscópicos gerados por vídeo com o projeto VideoAvatar que participa do projeto de ensino a distância TIDIA-AE, com recursos da FAPESP.

\subsubsection{CyberMED}


O projeto CyberMED é composto por um conjunto de bibliotecas que visam simplificar o desenvolvimento de aplicações em realidade virtual para a área médica. O CyberMED apresenta funcionalidades como: criação e manipulação de ambiente virtual, detecção de colisão, deformação dos modelos tridimensionais, interação háptica, avaliação do treinamento do usuário e visualização estereoscópica (SANTOS; MACHADO, 2008).

As bibliotecas do CyberMED utilizam como base o OpenGL, um padrão aberto de bibliotecas que facilitam a manipulação das placas gráficas, agilizando 0 desenvolvimento de aplicações em 3D. Considerando a parte de visualização, o CyberMED possui a saída planar comum e mais três tipos de saídas estereoscópicas: anaglifo, anaglifo colorido e óculos obturadores.
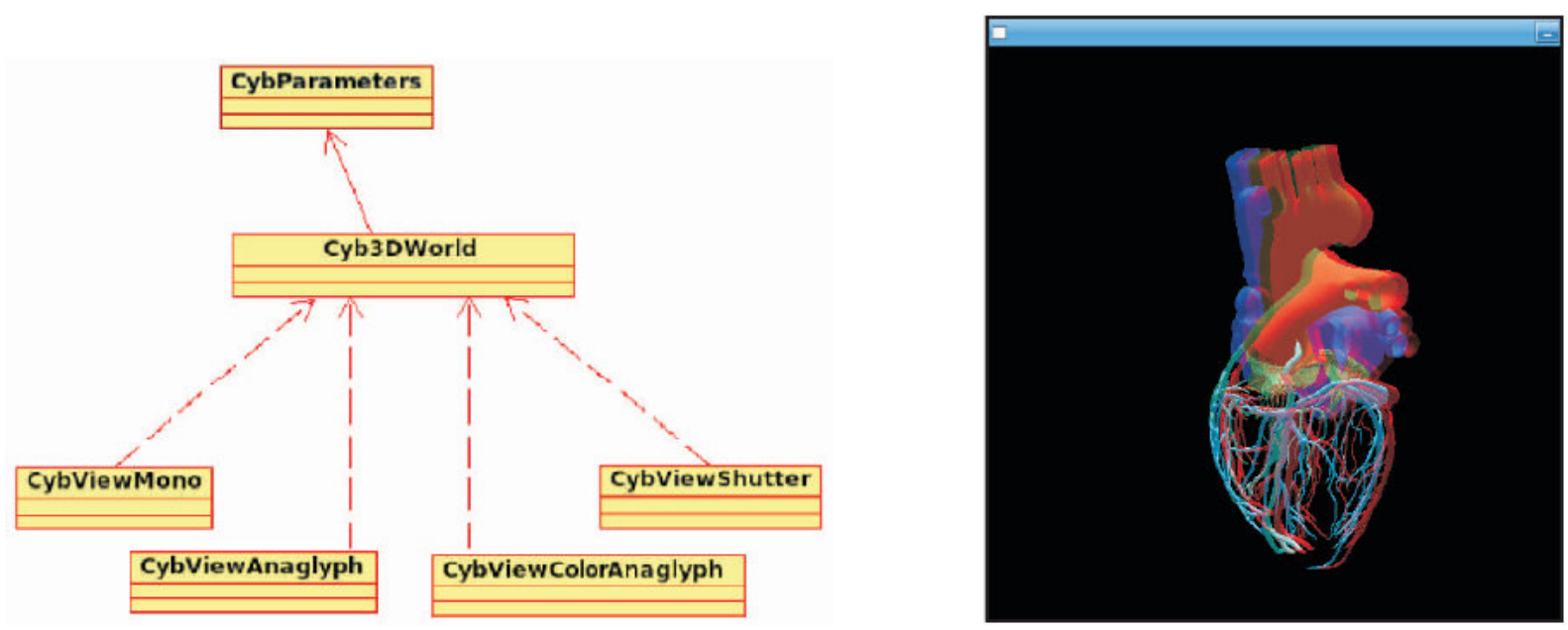

Figura 37 - Arquitetura das classes de visualização do CyberMED e o resultado em anaglifo colorido de uma imagem de um coração (SANTOS; MACHADO, 2008).

\subsubsection{IllusionHole}

O IllusionHole é uma aplicação da estereoscopia por óculos obturadores, no entanto esta solução tem uma característica especial: permite que múltiplos usuários visualizem um mesmo objeto em 3D de diferentes pontos de vista (KITAMURA et al., 2001). Para alcançar este efeito o IllusionHole é composto por uma superfície lisa 
plana como uma mesa na qual é feito um buraco circular. Alguns centímetros abaixo deste primeiro plano tem outra superfície, na qual são projetadas as imagens que cada um dos usuários enxerga, conforme esquematizado na Figura 38.

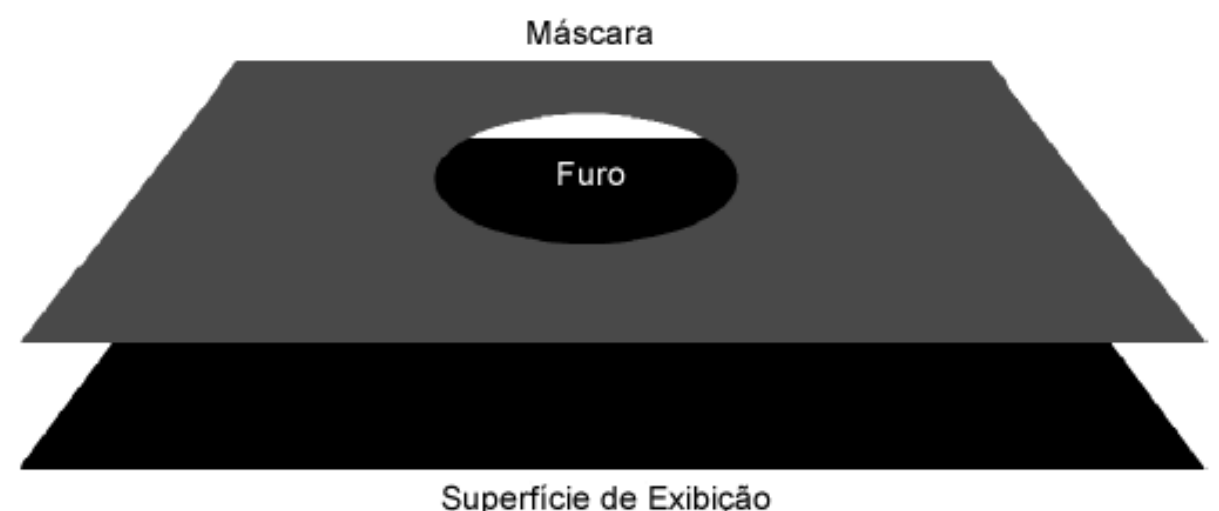

Figura 38 - Esquema de montagem do IllusionHole (baseado em KITAMURA et al., 2001).

Outro equipamento adicional desta solução são rastreadores acoplados aos óculos obturadores, utilizados para identificar qual a posição de cada observador em relação à superfície de projeção. Com essa informação é possível gerar imagens específicas para a posição atual do usuário, de forma que os usuários têm a sensação de estar olhando para um mesmo objeto. 


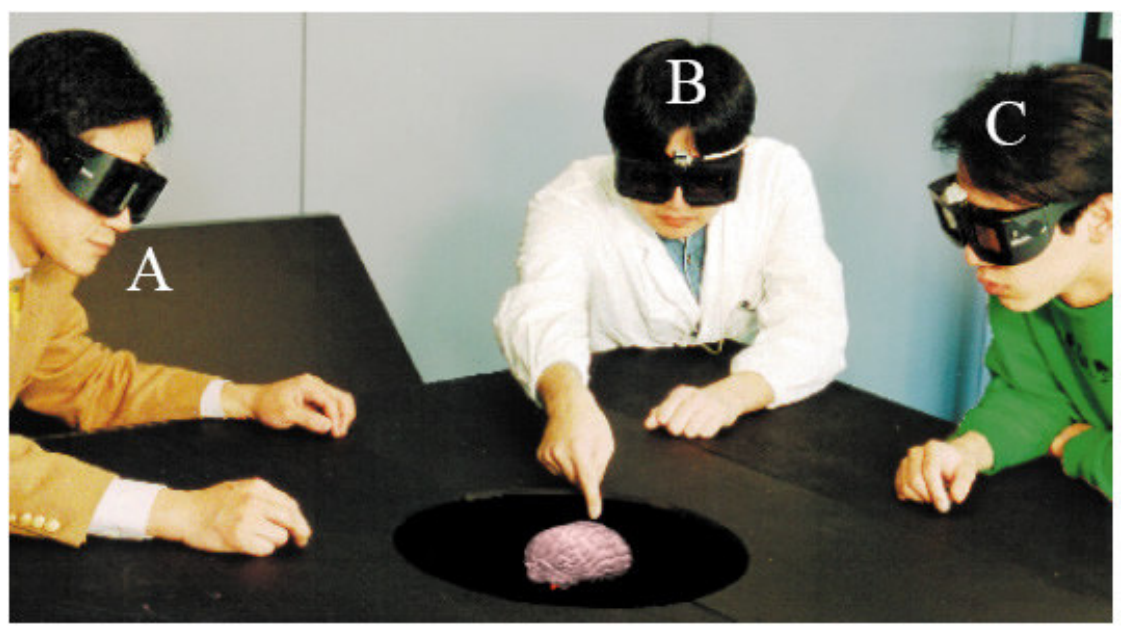

(a) Visão do ponto de vista de um quarto observador

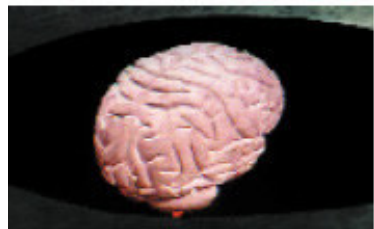

(b) Observador $\mathrm{A}$

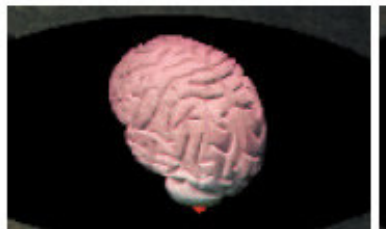

(c) Observador B

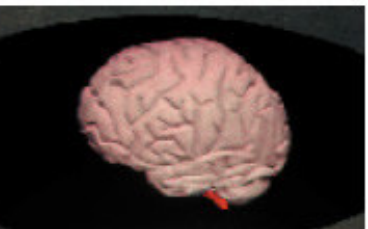

(d) Observador C

Figura 39 - IllusionHole em ação e os pontos de vista dos observadores (baseado em KITAMURA et al., 2001). 


\section{METODOLOGIA}

O passo inicial e fundamentação da pesquisa é a revisão literária com respeito ao estado da arte da estereoscopia. Devido a amplitude abrangida por esta área do conhecimento, conforme descrito no item 2, este trabalho engloba um recorte em especial deste tópico, envolvendo tecnologia e equipamentos que possibilitam a aplicação da estereoscopia em computação gráfica.

Esta pesquisa literária fornece o arcabouço teórico para as duas etapas seguintes realizadas em paralelo: a seleção das técnicas a serem avaliadas e a definição dos testes que serão aplicados.

Em seguida, através de protótipos baseados inicialmente no projeto AVTC (descrito no item 2.4.1), o sistema de testes é desenvolvido. A cada nova versão do protótipo são avaliadas características, como performance e flexibilidade para incorporação das técnicas estereoscópicas. A versão final do sistema não pode restringir soluções e testes futuros, seja por causa de restrições da plataforma ou limitações da linguagem utilizada para o desenvolvimento.

Com o sistema de testes implementado e funcional, a etapa seguinte é o refinamento dos testes, partindo de uma versão inicial desenvolvida a partir da conceitualização teórica e evoluindo gradativamente. Os testes são considerados maduros quando a solução estereoscópica utilizada e a decorrente percepção de profundidade são os principais fatores que influenciam os resultados do observador.

\subsection{Seleção das Técnicas}

Primeira etapa baseada na pesquisa teórica sobre estereoscopia - a seleção de quais soluções de estereoscopia apresentam potencial para a área da realidade virtual e aumentada. A importância desta etapa é destacada devido a história da 
estereoscopia, nascida como um recurso para incrementar os resultados obtidos em fotografia e cinema. Por causa desse fator histórico, diversas das soluções não são adequadas para aplicações com as características exigidas por sistemas de RV e RA, como por exemplo renderização em tempo real e controle do ponto de vista da cena pelo observador.

Outro fator considerado para seleção das soluções é a disponibilidade, pois devido a constante pesquisa e investimentos nessa área, algumas ainda são protótipos ou só podem ser obtidas desembolsando um elevado valor monetário. Embora este fator adicional restrinja a abrangência desta pesquisa, não afeta significativamente o seu valor, pois a grande contribuição experimental deste trabalho é a proposta, implementação e validação do sistema utilizado para avaliar o desempenho de observadores com diferentes soluções estereoscópicas. A realização de testes com outras técnicas e equipamentos podem ser feitos posteriormente, sem comprometer os resultados obtidos nesta pesquisa.

Os resultados deste processo de seleção podem ser vistos no item 4, que descreve o desenvolvimento experimental.

\subsection{Definição dos Testes}

Segunda frente de ação a partir da pesquisa teórica - a definição dos testes a serem realizados pelos observadores através do sistema. Os testes devem possibilitar a avaliação das soluções estereoscópicas, sem que outros elementos da cena influenciem na sensação de profundidade visualizada pelo observador. $O$ item 2.1 detalha estes outros elementos que incluenciam a percepção de profundidade.

O processo para projeto e desenvolvimento de cada teste foi o mesmo. Inicialmente foram determinadas qualidades de uma cena em RV ou RA, vista estereoscopicamente, que podem ser mensuradas, sejam resultados quantitativos ou qualitativos. Esta etapa resultou na seguinte lista de características: 
- Registro - coêrencia entre a posição dos elementos no ambiente virtual e a profundidade visualizada estereoscopicamente;

- Estabilidade - precisão no posicionamento dos elementos ao longo do tempo;

- Campo de Visão - liberdade de ângulo de visão que o observador tem em relação a fonte de pares estereoscópicos, ainda obtendo plena percepção estereoscópica;

- Sensação Visual - qualidade da percepção de profundidade obtida pelo observador;

- Fidelidade Visual - correspondência na imagem observada estereoscopicamente em relaçao a observada sem estereoscopia;

- Conforto e Ergonomia - dificuldade de adaptação e incômodo sentido pelo observador ao usar os equipamentos exigidos pela solução estereoscópica;

- Tempo de Resposta - tempo necessário para o sistema responder visualmente a um comando do observador;

- Processamento - custo, em termos do processamento, para executar uma cena de forma estereoscópica.

Com o intuito de facilitar a visão geral das características levantadas, a Tabela 1 seguinte foi criada. Nela, as características estão classificadas em dois eixos: a objetividade métrica dos resultados e a especifidade para área de estereoscopia.

Tabela 1 - Classificação das características levantadas para os testes

\begin{tabular}{|c|c|c|}
\hline & Específico & Geral \\
\hline Quantitativo & $\begin{array}{c}\text { Registro } \\
\text { Estabilidade } \\
\text { Campo de Visão }\end{array}$ & $\begin{array}{c}\text { Tempo de Resposta } \\
\text { Processamento }\end{array}$ \\
\hline Qualitativo & $\begin{array}{l}\text { Sensação Visual } \\
\text { Fidelidade Visual }\end{array}$ & Conforto e Ergonomia \\
\hline
\end{tabular}




\subsection{Descrição dos Testes}

Os testes foram projetados com foco especial na característica de Registro, que explora a relação entre a posição no ambiente virtual e a percepção de profundidade do observador. Os testes foram agrupados conforme a Tabela 1 para facilitar a identificação da característica avaliada por cada teste.

\section{Específico - Quantitativo}

Esta categoria engloba os testes que buscam mensurar de forma objetiva a sensação de profundidade que o usuário observa ao visualizar um ambiente gerado por computador de forma estereoscópica. O objetivo destes testes é identificar a consistência tridimensional que o observador tem da cena.

- Profundidade (Registro) - O observador deve indicar qual a ordem dos elementos presentes na cena, com relação a profundidade. Métrica: Erro de ordem das esferas;

- Proporção (Registro) - O observador deve ajustar a escala e a profundidade de uma peça virtual de forma que encaixe em outra. Métrica: Erro de escala e profundidade;

- Interação (Registro) - O observador deve tocar elementos virtuais distribuidos em diferentes profundidades através de um outro objeto virtual controlado por ele. Métrica: Consistência do tempo necessário para realizar o teste;

- Posição relativa (Registro) - O observador estima qual a posição de um elemento virtual em relação a métrica proposta por uma "régua" virtual. Métrica: Erro de posição;

- Posição no espaço (Registro) - O observador indica a posição no espaço físico de pontos virtuais que ele visualiza para "fora" da tela, devido ao posicionamento estereoscópico. Esta posição é capturada por câmeras 
posicionadas perpendicularmente ao lado e acima do observador. Métrica: Erro entre as posições relativas indicadas para os pontos.

\section{Específico - Qualitativo}

Esta categoria engloba os testes que buscam mensurar de forma subjetiva a sensação de profundidade que o usuário observa ao visualizar um ambiente gerado por computador de forma estereoscópica. O objetivo destes testes é identificar a consistência visual que o observador tem da cena.

- Consistência (Sensação Visual) - Um ambiente virtual aumentado com um avatar em vídeo é gerado e o observador deve julgar qual o grau de integração entre o ambiente e o avatar. Métrica: Nota de 1 a 5;

- Coerência (Sensação Visual) - Um ambiente virtual aumentado com um avatar em vídeo é gerado e o observador deve julgar a estabilidade na posição relativa entre os elementos virtuais e reais da cena. Métrica: Nota de 1 a 5 ;

- Fidelidade das Cores (Fidelidade Visual) - São apresentadas de forma seqüencial objetos virtuais de diferentes cores. O observador deve identificar e relatar qual a cor do objeto que está visualizando. Métrica: Erros de classificação de cor.

\section{Geral - Quantitativo}

Esta categoria engloba os testes que buscam mensurar de forma objetiva o software ou hardware envolvidos, não sendo relacionados diretamente a estereoscopia.

- Overhead (Processamento) - Este teste visa obter de forma objetiva qual o acréscimo de tempo de processamento acrescentado ao sistema devido ao uso da técnica estereoscópica. Métrica: Acréscimo do tempo de processamento em porcentagem; 
- Desempenho (Processamento) - Este teste visa obter de forma objetiva qual a performance das soluções no hardware e software utilizado para os testes. Métrica: Número de quadros por segundo.

\section{Geral - Qualitativo}

Esta categoria engloba os testes que buscam mensurar de forma objetiva o software ou hardware envolvidos, não sendo relacionados diretamente a estereoscopia.

- Conforto e ergonomia - Após realizar todos os outros testes o observador avalia com uma nota o nível de conforto ao utilizar a técnica estereoscópica sendo julgada. Métrica: Nota de 1 a 5.

\subsection{Processo de realização dos testes}

Visando a determinação de um padrão que cada observador participante deve seguir no processo de testes, foi criado um guia para realização dos mesmos. Este guia é apresentado na íntegra no Anexo A. Durante o processo de testes, o pesquisador auxilia na navegação do sistema e no andamento geral dos testes, no entanto não realiza nenhum gesto ou comentário que possa influenciar nas escolhas do observador.

\subsubsection{Preparação}


A seleção da ordem das soluções estereoscópicas e dos testes realizados por cada observador é aleatória, evitando a criação de tendências devido a familiarização com o sistema e com a estereoscopia. O computador e equipamentos são preparados de forma que a troca de uma solução estereoscópia para outra seja o mais simples possível, bastando alterar no sistema de testes e solicitar ao observador para trocar de óculos.

O observador tem um tempo inicial de adaptação a solução estereoscópica e ao sistema de testes antes do início do processo. No momento em que o observador estiver confortável com o equipamento e o sistema a sessão de testes começa.

\subsubsection{Execução}

Os testes são executados seguindo a ordem que foi sorteada inicialmente, com todos os testes sendo realizados para a mesma solução estereoscópica antes de partir para a próxima. A cada novo teste, o observador tem uma tentativa inicial de familiarização que é descartada, apenas os resultados da segunda tentativa em diante são registrados. Após a obtenção de cinco resultados válidos em um teste é carregado o próximo teste a ser realizado pelo observador.

\subsubsection{Resultados}

Os resultados foram anotados em uma folha de respostas (Anexo A) e além dos dados obtidos nos testes, informações sobre o tempo de execução e comentários adicionais dos observadores sobre as soluções foram também incluídos nessa folha de respostas. A apresentação dos dados de forma unificada pode ser vista a seguir no item 5, bem como uma análise dos resultados encontrados. 


\subsection{Análise de Resultados dos Testes}

Testes que dispensam a participação de mais de um observador, como os testes de processamento, devem ser realizados pelo próprio pesquisador, enquanto os outros testes são realizados por diferentes observadores para possibilitar uma maior generalização dos resultados obtidos e também avaliar o desempenho do sistema em um cenário real de uso. O pesquisador deve anotar os dados coletados na folha de respostas, conforme o processo descrito anteriormente no item 3.4.

Nos testes quantitativos, os dados coletados no decorrer dos testes servem de base para calcular a performance de cada observador com as diferentes soluções estereoscópicas. A principal métrica na análise deste tipo de teste é o erro cometido pelo observador, na forma de desvio quadrático. A exceção é o teste de Interação, no qual não existe uma medida de erro. Para esse teste a análise é feita em termos da consistência na performance do observador, ou seja, a semelhança dos resultados obtidos pelo observador ao efetuar repetidas vezes um teste com a mesma solução estereoscópica. A premissa é que a performance do jogador não varia muito nesse teste, desde que esteja visualizando a cena com a percepção correta de profundidade.

As soluções estereoscópicas podem ser comparadas considerando a performance do observador ao utilizar diferentes técnicas estereoscópicas, inclusive sem estereoscopia. A eficiência de uma solução pode ser dada pela comparação com a performance do observador ao fazer o teste sem nenhum equipamento estereoscópico.

Entretanto, em testes qualitativos nos quais os observadores avaliam cada solução com uma nota, a comparação é mais direta, sendo a nota do observador o fator determinante na indicação de qual solução estereoscópica é melhor.

$\mathrm{Na}$ medida do possível, tabelas comparativas das soluções avaliadas que unificam os resultados obtidos são criadas, visando facilitar a análise dos dados. Além da 
análise e comparação dos dados puramente experimentais, as soluções são também avaliadas a nível teórico, unificando e consolidando as conclusões e classificações das técnicas estereoscópicas. 


\section{EXPERIMENTOS COM AS TÉCNICAS DE ESTEREOSCOPIA}

Considerando o foco deste trabalho em sistemas de RV e RA, as soluções de estereoscopia pré-selecionadas a participarem da etapa experimental devem apresentar potencial para este tipo de aplicação. Portanto, as técnicas precisam atender a alguns requisitos básicos destes sistemas:

1) Apresentar imagens sem muitas distorções, que sugestionem ao observador coesão entre o mundo real e o virtual;

2) Ser adequada ao uso em um sistema interativo, no qual o usuário controla o ponto de vista.

Além disso, neste trabalho é feita uma restrição adicional para possibilitar que um observador sem conhecimento prévio da solução possa visualizar a cena em três dimensões:

3) O observador visualiza o efeito estereoscópico de forma natural, sem utilizar técnicas de visão.

A Tabela 2 a seguir resume visualmente quais destas restrições cada uma das soluções estereoscópicas atende. Um quadrado escuro representa uma restrição que a solução atende e um quadrado branco representa uma restrição não atendida, quadrados de cor intermediária significam uma restrição atendida de forma limitada.

Conforme está exposto na tabela, considerando as restrições impostas, as soluções com potencial para a RA são: Anaglifo, ColorCode 3D, Polarização da luz, Óculos obturadores, Head Mounted Displays e Autoestereoscopia.

Para selecionar aquelas técnicas que serão efetivamente analisadas, ainda é necessário avaliar a disponibilidade dos equipamentos e das informações técnicas para implementar as soluções. Com estes pontos em mente, a solução autoestereoscópica ainda representa um custo elevado e o hardware é de difícil acesso quando comparado as outras soluções. Além disso, a ColorCode 3D, devido a restrições de patente e pouca informação disponível, acaba se tornando muito difícil de ser implementada corretamente. 
Tabela 2 - Restrições das soluções estereoscópicas

\begin{tabular}{ll|l|l}
\hline \multicolumn{1}{c}{ Solução } & \multicolumn{3}{c}{ Restrição } \\
\cline { 1 - 2 } & $\mathbf{1}$ & $\mathbf{2}$ & $\mathbf{3}$ \\
\hline Estereoscópio & & & \\
Slides Estéreo & & & \\
Par Estéreo & & & \\
Estereograma & & & \\
Efeito Pulfrich & & & \\
ChromaDepth & & & \\
Anaglifo & & & \\
ColorCode 3D & & & \\
Polarização da Luz & & & \\
Óculos Obturadores & & & \\
Head Mounted Display & & & \\
Autoestereoscopia & & & \\
Par Estéreo Alternado* & & & \\
\hline
\end{tabular}

* Conceitualmente não é uma solução estereoscópica, pois ambos os olhos vêem a mesma imagem.

\subsection{Protótipos}

Definidas as soluções a serem implementadas no sistema de testes, o passo seguinte é o desenvolvimento do software, que além dos módulos com as soluções estereoscópicas, envolve também a implementação de um componente capaz de exibir imagens de ambientes e outros elementos virtuais gerados por computação gráfica.

Algumas versões preliminares foram implementadas antes de alcançar a versão definitiva do sistema que é utilizado para realização dos testes das soluções estereoscópicas. Todos os protótipos seguem a metodologia de alta fidelidade, ou seja, o mais semelhantes possível ao resultado esperado para o sistema final (HOM, 1998). 


\subsubsection{Primeira versão}

A inspiração da primeira versão do protótipo foi o projeto AVTC (descrito no item 2.3.1) que utiliza a tecnologia Java como base para implementação. Com o intuito de agilizar o processo de desenvolvimento do protótipo, foi utilizado como plataforma o EnJine, um engine para jogos baseado em Java (ENJINE, 2007). A vantagem de basear a implementação em um engine é a camada de abstração que ele oferece para tratamento de tarefas comuns como: dispositivos de entrada e saída, definição de comportamento, detecção de colisões, renderização em 3D, entre outras (NAKAMURA et al., 2006).

O EnJine é um projeto desenvolvido pelo INTERLAB que segue a ideologia de software opensource, um ponto positivo adicional em um projeto acadêmico que visa a continuidade por outros pesquisadores. Embora o objetivo principal do EnJine seja atender as necessidades do curso de introdução a computação gráfica, como uma ferramenta didática, uma de suas aplicações é justamente como uma plataforma experimental, graças a sua simplicidade e arquitetura robusta.

Do ponto de vista técnico, o EnJine faz uso somente de biliotecas em Java, em especial o Java 3D que é responsável pela geração gráfica. Devido a esta característica, mantém uma herança da tecnologia Java que é a sua portabilidade, ou seja, possibilidade de execução do sistema em diversas plataformas diferentes sem a necessidade de refazer a codificação. Maiores informações sobre o EnJine, bem como suas distribuições e código fonte, podem ser obtidas na página oficial na internet (ENJINE, 2007). 


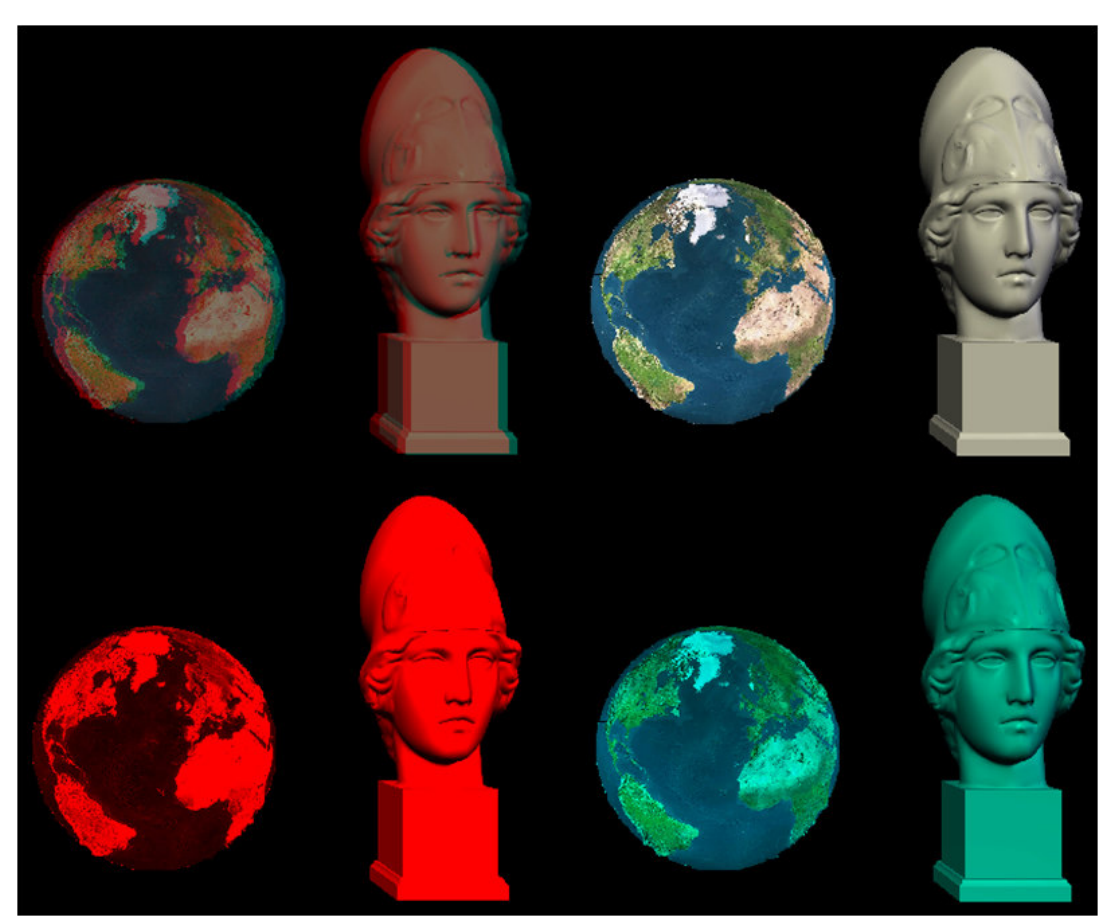

Figura 40 - Imagem gerada pelo protótipo em Java. Superior direito: renderização normal, inferiores: par anaglífico vermelho/ciano, superior esquerdo: anaglifo completo.

Um problema que se mostrou o maior limitante desta versão do sistema foi sua falta de flexibilidade. Devido a restrições do próprio Java e das bibliotecas utilizadas, 0 acesso aos dispositivos de hardware é muito lento ou complexo. Por exemplo, a renderização em anaglifos exigia quatro etapas: renderização da cena em um buffer temporário em vermelho, repetição do processo em ciano, unificação dos dois buffers temporários e finalmente a renderização da imagem unificada na tela. Esta tarefa pode ser realizada de forma mais simples com o uso de outras tecnologias que oferecem um melhor acesso ao hardware, como por exemplo o OpenGL (OPENGL, 2010).

Por causa do interesse em realizar testes que exploram a realidade aumentada, uma das necessidades do sistema é o acesso a câmeras de vídeo conectadas ao computador. A criação de um vídeo-avatar como descrito no projeto AVTC (SISCOUTTO, 2003) exige que duas câmeras de vídeo sejam acessadas simultaneamente, de forma que um par estereoscópico coerente do avatar seja exibido para o observador. Novamente as restrições do Java para acesso ao hardware dificultaram a tarefa. Utilizando bibliotecas do Java como a Java Media Framework (JMF, 2010) apenas uma câmera é acessada por vez, o que é suficiente para aplicações domésticas como tele-conferência, mas impossibilita a criação de 
um vídeo-avatar estereoscópico. A alternativa utilizada para contornar este problema foi o uso do recurso Java Native Interface (JNI, 2004) que permite ao Java acessar bibliotecas em linguagem nativa da máquina. Neste caso, a biblioteca nativa foi 0 OpenCV (OPENCV, 2010) que é uma biblioteca escrita em C++ voltada a visão computacional. Embora este método alternativo tenha permitido o acesso simultâneo a duas câmeras, o custo em termos de processamento para realizar esta tarefa se mostrou muito elevado e a causa para este custo adicional foi justamente o uso da JNI.

Uma última limitação que foi detectada durante o desenvolvimento deste protótipo ocorria devido a própria arquitetura do Java 3D. Para aplicações que usam renderização tridimensional comum, sem estereoscopia, o Java 3D oferece um recurso que facilita muito a construção do ambiente virtual, o grafo de cena (FOSTER, 2010). No entanto, neste método de criação do mundo virtual o controle que o desenvolvedor tem do processo de renderização é limitado e, durante o processamento das técnicas de estereoscopia, muitas vezes é necessário um controle fino, com comandos de baixo nível, para que a cena seja renderizada corretamente.

\subsubsection{Segunda versão}

Após o reconhecimento das limitações citadas no item anterior, sobre a primeira versão do protótipo, o passo seguinte foi estabelecer uma plataforma que pudesse atender a flexibilidade e controle exigidos para implementação das técnicas estereoscópicas. A solução encontrada foi migrar da tecnologia Java para a $\mathrm{C}++$ que possui as bibliotecas OpenGL e o OpenCV, apresentadas na primeira versão. Com esta decisão, a portabilidade do Java e as facilidades oferecidas pelo EnJine foram trocadas pelo controle de baixo nível e alta performance oferecidas pelo OpenGL e C++. 
A codificação do sistema seguiu o paradigma de Orientação a Objetos, assim foram definidos alguns componentes para compor o sistema como um todo. Um diagrama de classes no padrão UML (Unified Modeling Language) que representa o sistema como um todo é apresentado a seguir:

Para simplificar a complexidade da programação baseada em OpenGL, foi utilizada uma biblioteca adicional chamada GLUT (GLUT, 2010). Esta biblioteca facilita a codificação de tarefas como a criação de janelas, o laço de renderização e a utilização de mouse e teclado. Uma limitação que não era esperada mas se tornou aparente durante o desenvolvimento em OpenGL foi a falta de bibliotecas para carregar modelos 3D. Mesmo pesquisando extensivamente na internet por bibliotecas deste tipo, comumente chamadas de loaders, não foi encontrada nenhuma que atendece plenamente as necessidades do sistema. A solução foi a criação de um loader próprio que foi baseado no GLM (GLM, 2010). Este loader é o resultado do esforço de diversos pesquisadores do INTERLAB.

O maior controle do processo de renderização oferecido pelo OpenGL permitiu a implementação das técnicas de estereoscopia sem maiores dificuldades ou limitações. Esta versão suporta a renderização do ambiente virtual para as seguintes soluções estereoscópicas: anaglifos, óculos obturadores, óculos polarizados e HMD. A título de curiosidade foi implementado também o par estéreo alternado (wobble stereo).

A Figura 41 a seguir apresenta uma imagem do teste de profundidade renderizada em anaglifos, para ilustrar os resultados obtidos nesta versão. 


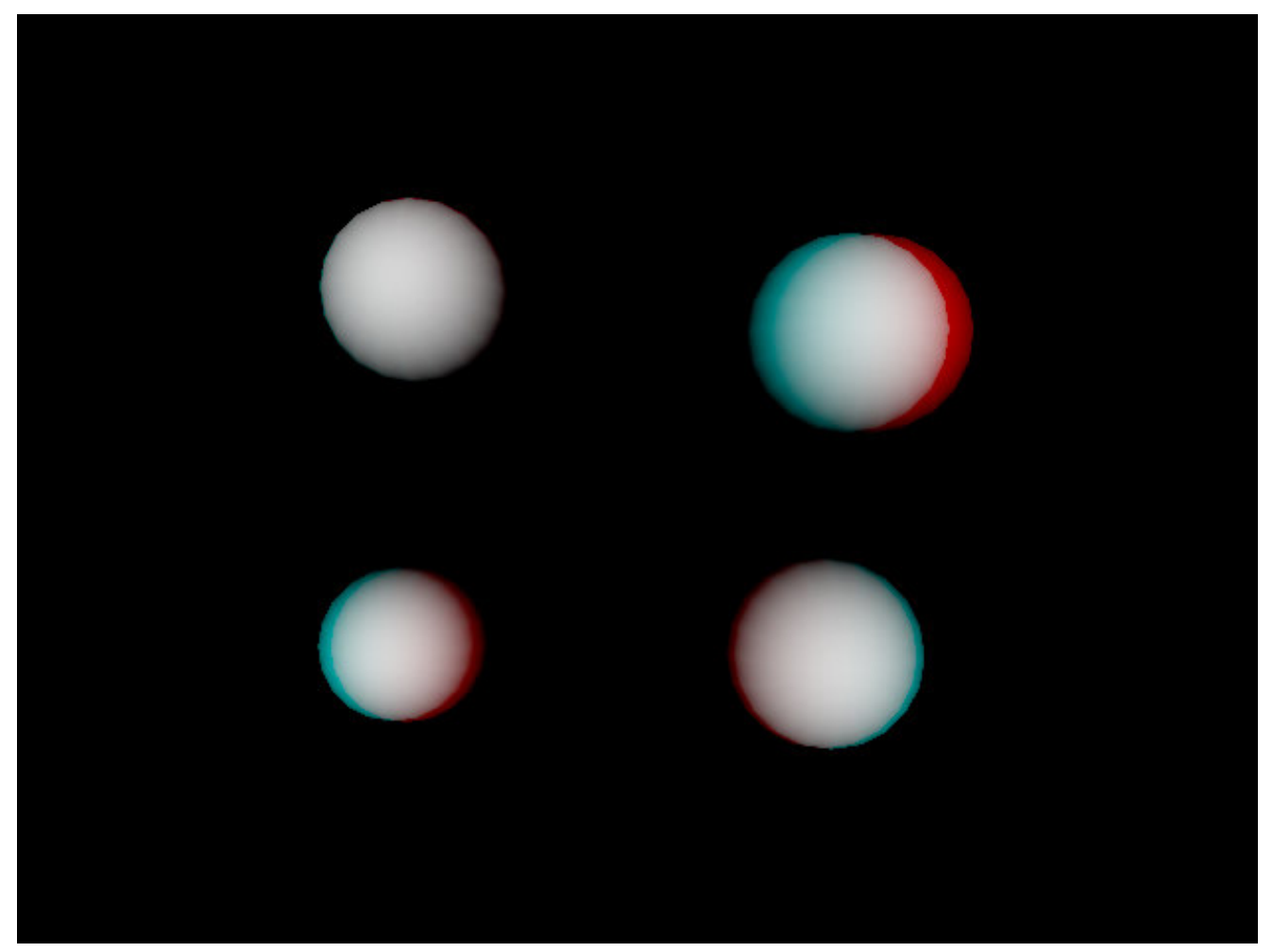

Figura 41 - Imagem renderizada em anaglifos do teste de profundidade gerada pelo protótipo em OpenGL.

\subsection{Versão final do sistema}

A versão final se baseia no segundo protótipo e foi desenvolvida utilizando a mesma tecnologia, linguagem de programação $\mathrm{C}_{++}$com Orientação a Objetos e a biblioteca OpenGL para renderização 3D. A principal mudança do protótipo para versão final é sua arquitetura, a organização dos componentes que formam o sistema foi redefinida para facilitar a expansão dos módulos existentes e criação de novos módulos. Desta forma simplificando o trabalho exigido para incorporar novas soluções estereoscópicas ao sistema, com diferentes modos de renderização, e também testes adicionais. Uma visão geral da arquitetura pode ser vista na Figura 42. 


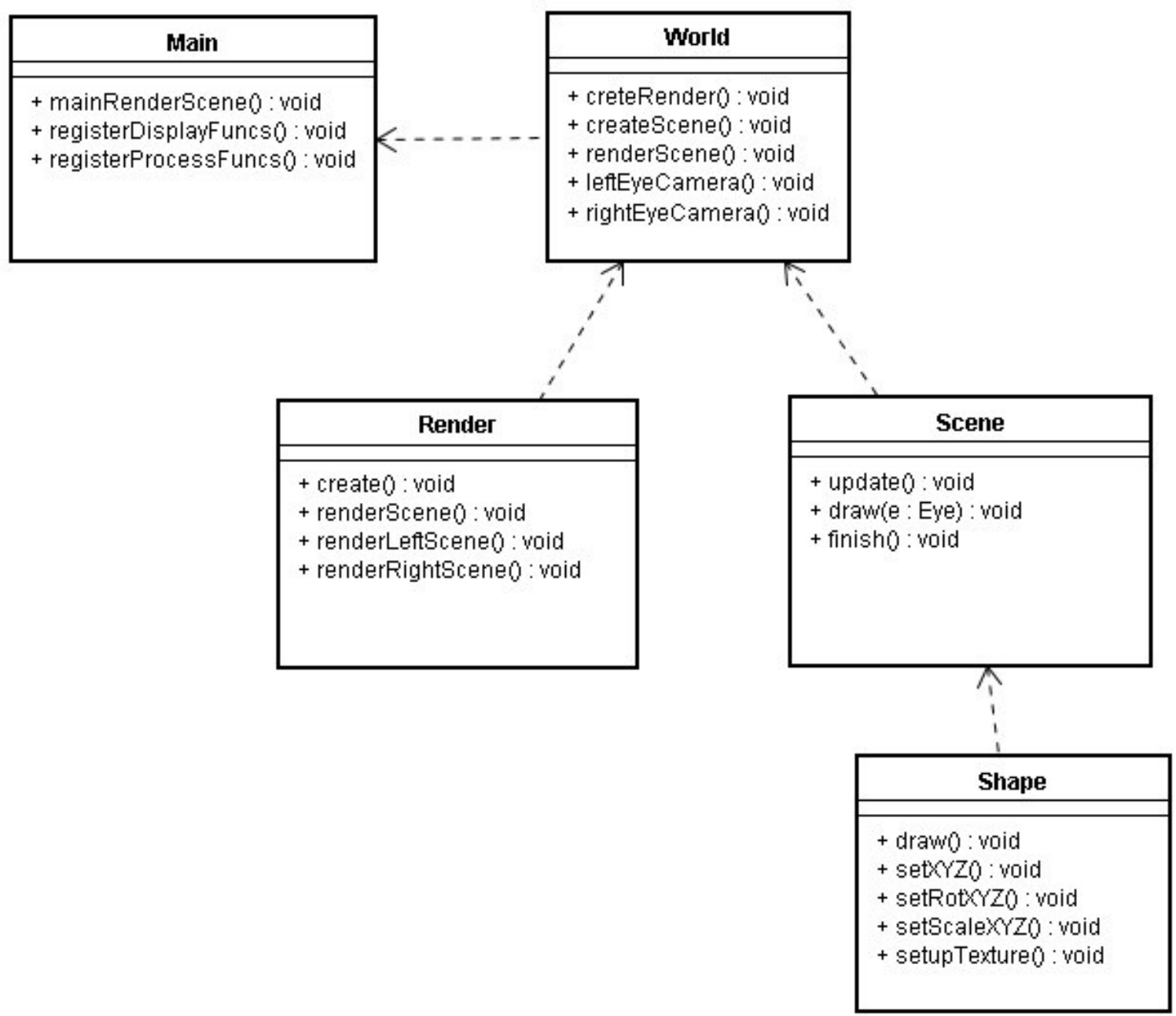

Figura 42 - Diagrama UML com principais componentes do sistema

Detalhando cada um dos componentes:

\section{Main}

Raiz do sistema, define as funções de inicialização do software. Por causa de limitações do componente GLUT diversas funções deste módulo são implementadas fora do padrão orientado a objetos, em especial as que registram as chamadas de atualização de imagem e captura de entradas do teclado.

\section{World}


Principal módulo, responsável por gerenciar os modos de renderização e as cenas de cada um dos testes. As entradas de teclado capturadas pelo Main são redirecionadas para este componente para que o usuário possa selecionar os tipos de Render e Scene.

\section{Render}

Este é um componente abstrato que deve ser implementado para criar um novo modo de renderização. Até o momento foram implementados cinco tipos de renderização:

- Normal - sem estereoscopia;

- Anaglifos - renderização para óculos vermelho/ciano;

- HMD / Óculos Obturadores - implementação da técnica conhecida por page-flip utilizando o recurso quad-buffer disponível em OpenGL;

- Óculos Polarizados - criação de duas janelas que compõe um par estéreo, para ser utilizado em placas de vídeo com saída dupla e projetores;

- Par Estéreo Alternado - implementação da técnica wobble stereo para dar sensação de profundidade.

\section{Scene}

Representa uma cena 3D. Cada um dos testes do sistema é uma implementação deste componente abstrato. A tela com o menu principal do sistema é a Cena 1 e os outros testes são numerados sequencialmente, esta situação é ilustrada na . 0 usuário do sistema consegue selecionar as cenas na ordem que desejar bastando utilizar teclas de atalho.

\section{Shape}


Este componente genérico representa um objeto no mundo virtual. Todos os objetos criados nas cenas são especializações deste componente. Como no OpenGL não existe o conceito de grafo de cena, os objetos virtuais precisam ser recriados em cada um dos quadros renderizados e este módulo simplifica a tarefa de persistência dos objetos de um quadro para o outro.

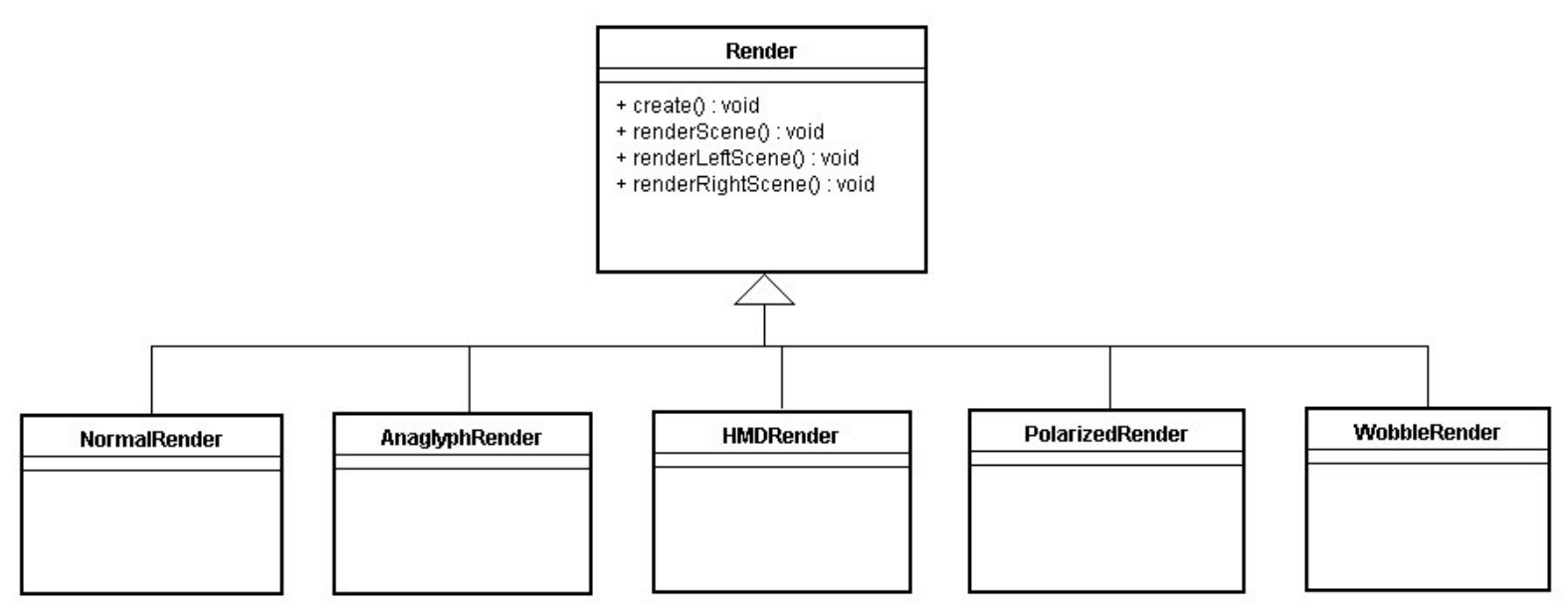

Figura 43 - Diagrama com as implementaçoes do módulo Render

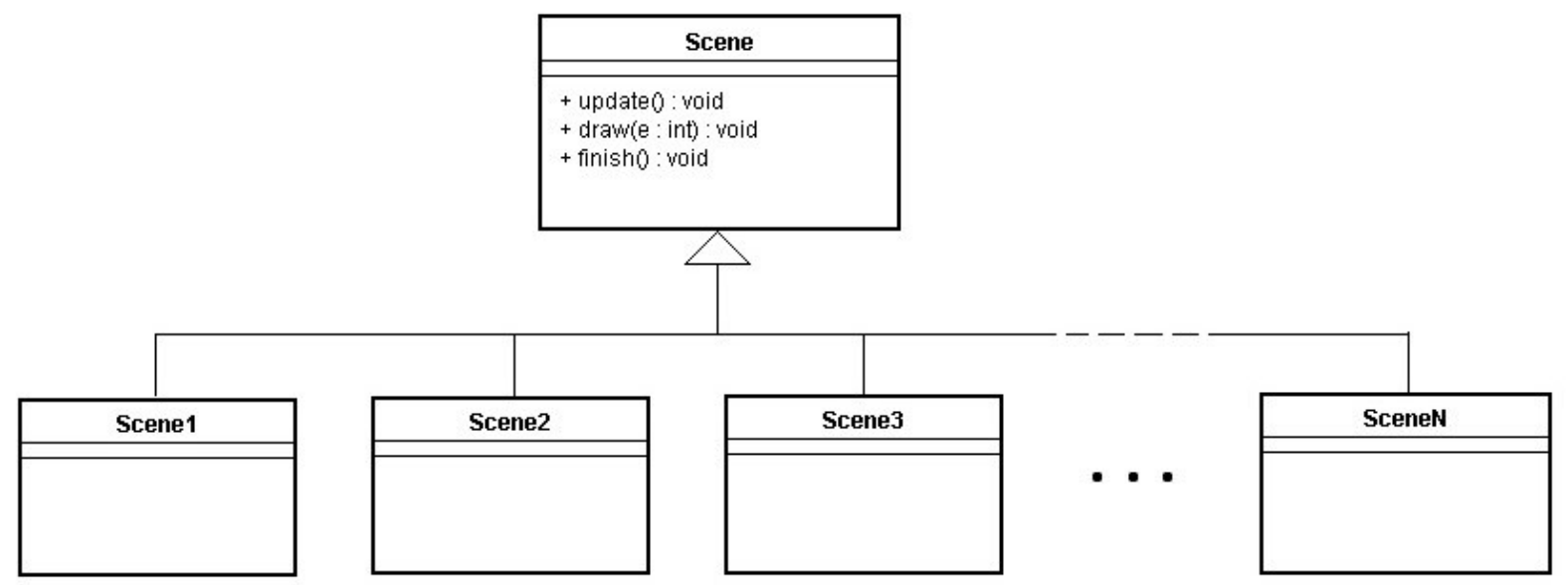

Figura 44 - Diagrama ilustrando a organização das cenas

\subsection{Equipamentos}


Os equipamentos utilizados para a realização dos testes seguem padrões de mercado e de fácil acesso ao público em geral. Inclusive as soluções estreoscópicas avaliadas são encontradas sem grandes dificuldades em lojas especializadas.

\section{Hardware}

O computador que executa o sistema é uma máquina comum da linha PC, nos parágrafos que se seguem é apresentada a sua configuração com mais detalhes.

A placa de vídeo é uma Quadro FX1700, que oferece o importante recurso de quadbuffer, além da performance necessária. Este recurso é interessante pois permite a implementação de estereoscopia com grande controle por parte do desenvolvedor ao utilizar o OpenGL.

O monitor é um samsung 2233RZ, o modelo é importante pois a solução por óculos obturadores exige o suporte de frequências de atualização vertical acima de $100 \mathrm{~Hz}$. Este monitor foi obtido juntamente com os óculos obturadores, modelo Nvision3D, ambos são vendidos como um pacote denominado "3D Vision Bundle" comercializado pela empresa Nvidia.

Os óculos anaglifícos foram comprados através da internet e não possuem nenhum recurso especial, seguem o padrão vermelho/ciano.

Outros componentes menos relevantes para a experiência são a CPU, que conta com um processador quad-core da Intel, 4gb de memória RAM e um disco rígido padrão SATA com algumas centenas de gigabytes.

\section{Software}

O sistema operacional do computador de testes é o Windows XP 32bit e a única instalação adicional para execução do sistema de testes são drivers de vídeo com suporte a estereoscopia por quad-buffer em OpenGL. Para a execução dos testes foi 
utilizado o driver Forceware versão 192.0 e o suporte ao Nvision3D (óculos obturadores) para Windows XP, disponíveis no website da Nvidia.

\subsection{Condições do ambiente}

Os testes foram realizados dentro do laboratório, com o monitor posicionado em uma baia comum. O ambiente do laboratório no qual os testes foram realizados é estruturalmente isolado de luz natural, mas nenhum procedimento adicional foi adotado visando um controle maior das condições do ambiente.

\subsection{Implementação dos Testes}

Os testes implementados para a execução dos experimentos foram baseados nas descrições do item 3.3, no entanto nem todos os testes foram selecionados para a bateria de testes experimental por diferentes fatores, mais detalhes podem ser encontrados no item 4.6.

Caso o leitor deseje avaliar a sensação estereoscópica experimentada pelos observadores, basta obter um óculos anaglífico padrão vermelho/ciano e comparar as imagens dos testes sem renderização estereoscópica e com renderização estereoscópica exibidas a seguir.

\subsubsection{Específico - Quantitativo}


Esta categoria engloba os testes que buscam mensurar de forma objetiva a sensação de profundidade que o usuário observa ao visualizar um ambiente gerado por computador de forma estereoscópica. O objetivo destes testes é identificar a consistência tridimensional que o observador tem da cena.

\section{Profundidade (Registro)}

O sistema gera quatro esferas e posiciona cada esfera em um quadrante da tela, considerando que existe um eixo vertical e um horizontal que se cruzam no centro da tela. As esferas são posicionadas em profundidades diferentes e possuem o mesmo diâmetro. Para que o observador não consiga deduzir qual a esfera mais próxima devido ao efeito de perspectiva, o mesmo foi desabilitado durante a realização deste teste.

Realização: O observador deve indicar qual a ordem de profundidade das esferas, da mais próxima a mais distante.

Métrica: Erro de ordem das esferas.
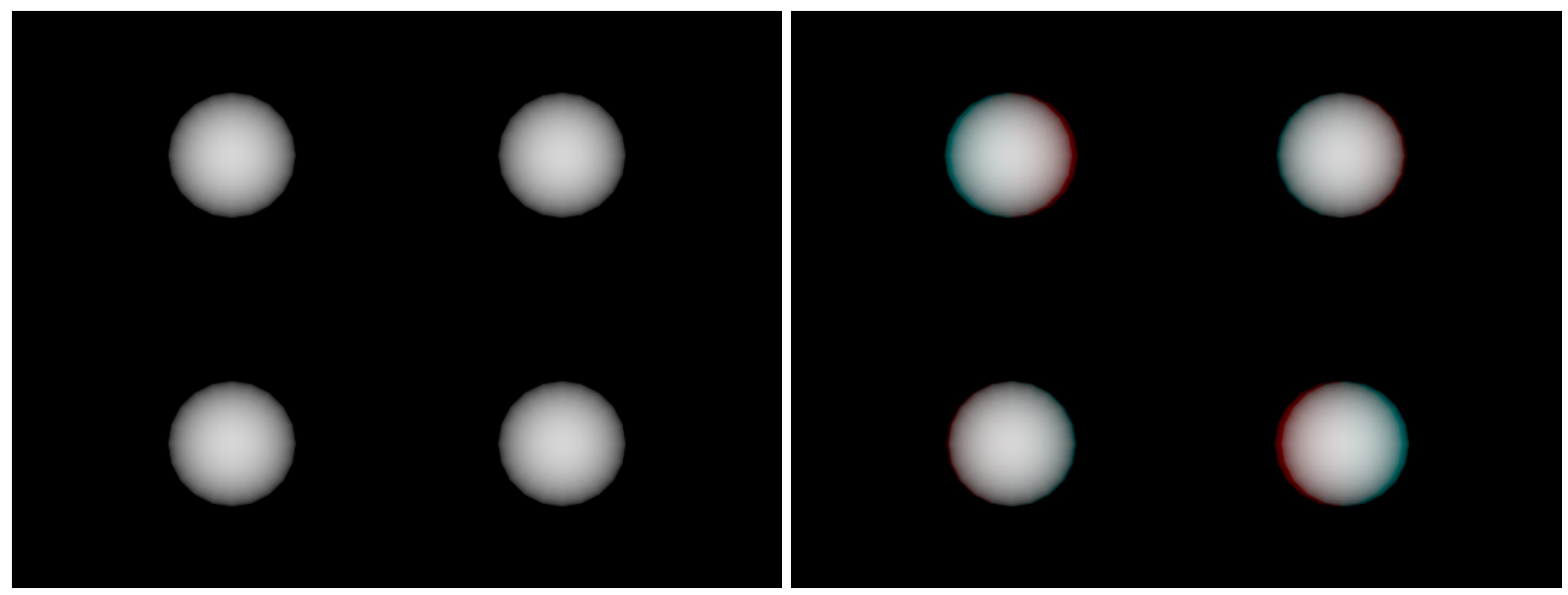

Figura 45 - Teste de Profundidade. Imagem sem estereoscopia (esquerda) e em anaglifos (direita)

\section{Proporção (Registro)}


São carregados os modelos de duas peças que se encaixam perfeitamente, cada uma em uma metade da tela, mas para cada peça é atribuído um valor diferente de escala. Como as peças também são posicionadas em profundidades diferentes, o desafio para o observador é ajustar a profundidade e a escala da peça do lado direito de forma que as peças se encaixem perfeitamente quando posicionadas na mesma profundidade.

Realização: $O$ observador pode aumentar ou diminuir a escala da peça direita e também ajustar sua profundidade. Ao finalizar, o sistema indica qual foi o erro de escala quando posicionada na mesma profundidade que a peça da esquerda.

Métrica: Erro de escala e profundidade
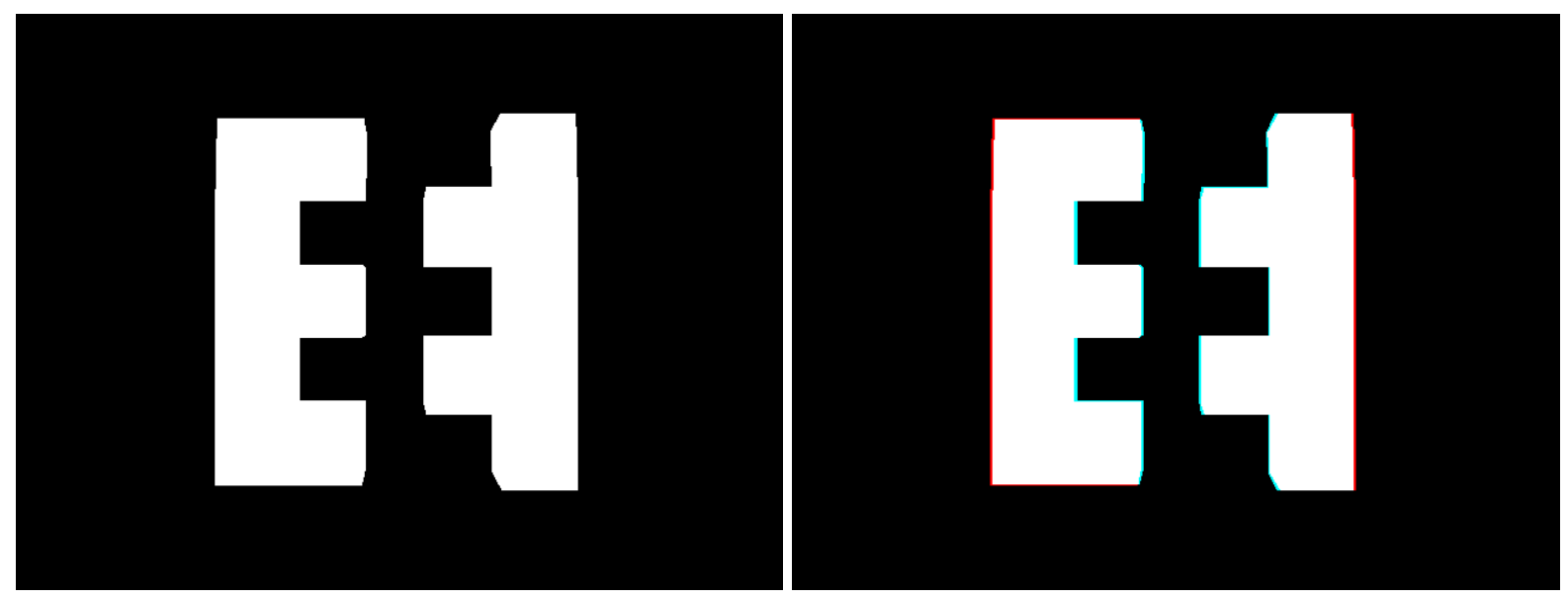

Figura 46 - Teste de Proporção. Imagem sem estereoscopia (esquerda) e em anaglifos (direita)

\section{Interação (Registro)}

É criada uma nave que o observador pode movimentar nos diferentes eixos e argolas que são posicionadas no espaço virtual com tamanhos iguais mas diferentes profundidades. A meta é mover a nave pelo espaço visando atravessar por dentro de todas as argolas. Para que o observador não consiga deduzir qual a profundidade das argolas devido ao efeito de perspectiva, o mesmo foi desabilitado durante a realização deste teste. 
Realização: O observador movimenta a nave visando atravessar por dentro de todas as argolas. Ao atravessar a última, o sistema exibe qual foi o tempo decorrido para realizar a tarefa.

Métrica: Consistência do tempo necessário para atravessar todas as argolas.
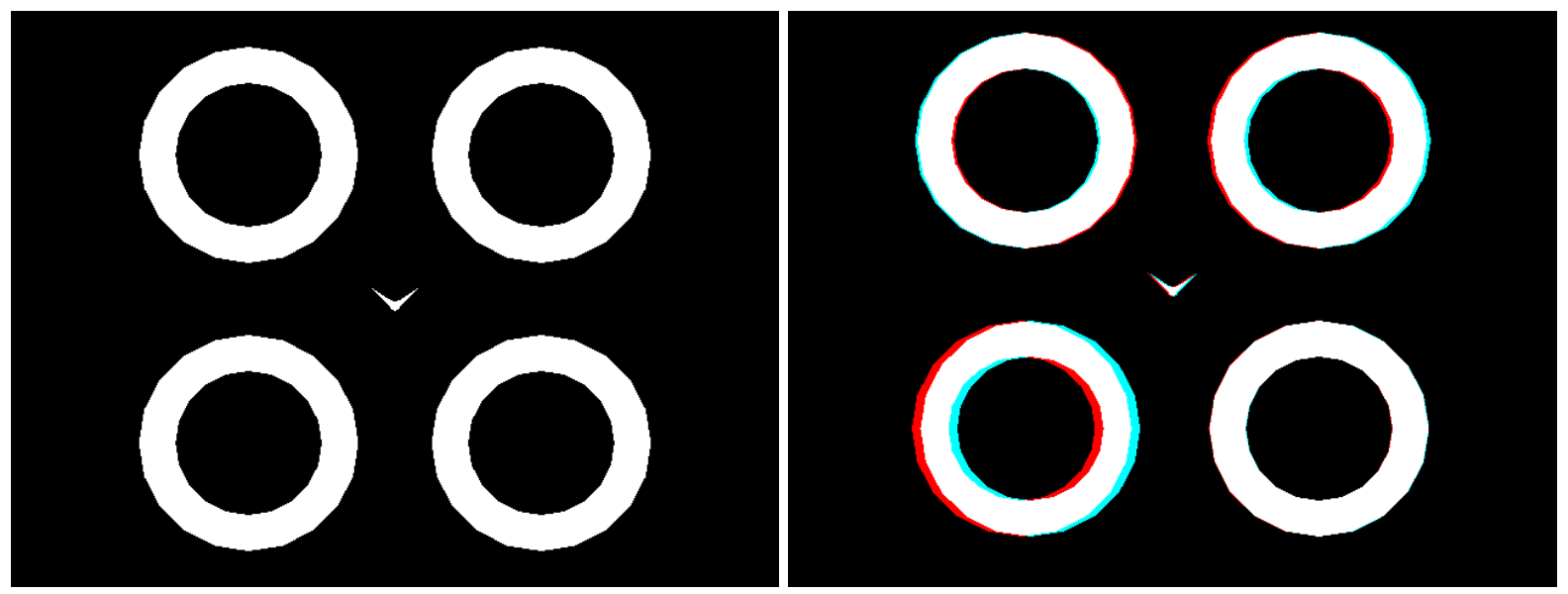

Figura 47 - Teste de Interação. Imagem sem estereoscopia (esquerda) e em anaglifos (direita)

\section{Posição Relativa (Registro)}

Uma esfera é gerada nas proximidades do centro da tela, logo acima de uma "régua" numerada de zero a cinquenta. O observador deve responder qual a posição da esfera em relação a métrica proposta pela "régua".

Realização: Após avaliar a posição relativa entre os objetos, o observador responde qual a posição da esfera na métrica proposta pela régua. Neste momento o teste é finalizado e o sistema informa a posição relativa correta.

Métrica: Erro de posição. 

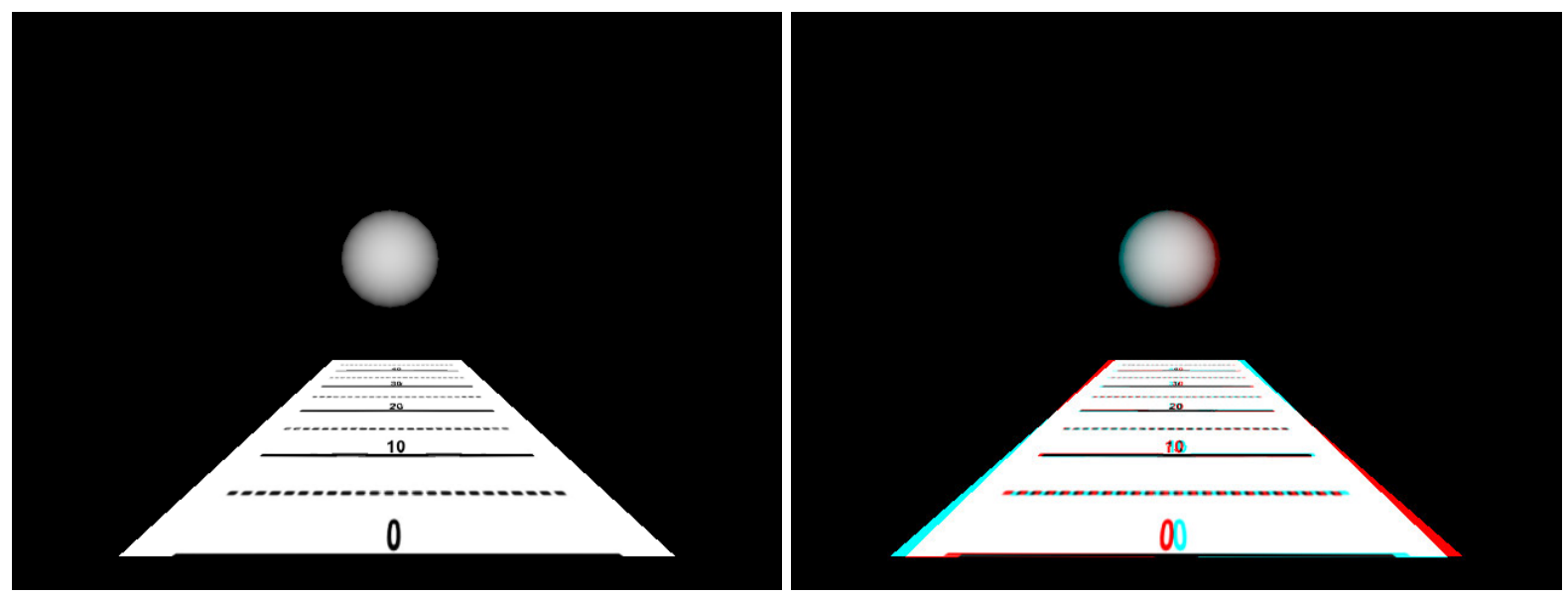

Figura 48 - Teste de Posição Relativa. Imagem sem estereoscopia (esquerda) e em anaglifos (direita)

\section{Posição no Espaço (Registro)}

Uma forma geométrica é gerada em wireframe e posicionada no centro da tela. $\mathrm{O}$ observador então aponta no espaço físico a posição que ele visualiza os vértices da forma geométrica, considerando que ele estará vendo o objeto para "fora" da tela devido ao posicionamento estereoscópico. Câmeras posicionados perpendicularmente ao lado e acima do observador estarão capturando a posição relativa entre cada um dos vértices identificados pelo obsevador.

Realização: $O$ teste é iniciado e o observador indica os vértices numa ordem prédeterminada, sempre avisando o sistema quando considera estar apontando corretamente para o vértice. O sistema então captura cada vértice indicado pelo observador e compara com os vértices da forma geométrica gerada.

Métrica: Erro entre as posições relativas de cada vértice.

\subsubsection{Específico - Qualitativo}


Um ambiente virtual aumentado com um avatar em vídeo é gerado e o observador deve julgar qual o grau de integração entre o ambiente e o avatar.

Realização: O observador deve avaliar o resultado dando uma nota de 1 a 5 .

Métrica: Nota subjetiva de 1 a 5.

\section{Coerência (Sensação Visual)}

Um ambiente virtual aumentado com um avatar em vídeo é gerado e o observador deve julgar a estabilidade na posição relativa entre os elementos virtuais e reais da cena.

Realização: O observador deve avaliar o resultado dando uma nota de 1 a 5 .

Métrica: Nota subjetiva de 1 a 5.

Fidelidade das Cores (Fidelidade Visual)

Este teste é realizado apenas para identificar as limitações de cores resultante do uso da técnica de anaglifos. São apresentadas de forma seqüencial esferas de diferentes cores que o observador deve identificar e relatar qual cor está visualizando.

Realização: $O$ teste é realizado em duas sessões, primeiro sem estereoscopia e em seguida utilizando anaglifos. A cada esfera apresentada o observador relata qual a cor vista.

Métrica: São comparados os resultados dos dois testes e contabilizados todos os erros de classificação. 


\subsubsection{Geral - Quantitativo}

\section{Overhead (Processamento)}

Este teste visa obter de forma objetiva qual 0 acréscimo de tempo de processamento ao sistema devido ao uso da técnica estereoscópica.

Realização: O tempo de processamento de um quadro para outro de um ambiente virtual aumentado é calculado para cada técnica. Depois esses valores são descritos em relação ao tempo de processamento sem nenhuma técnica.

Métrica: Acréscimo do tempo de processamento em porcentagem.

\section{Desempenho (Processamento)}

Este teste visa obter de forma objetiva qual a performance das soluções no hardware e software utilizado para os testes.

Realização: O número de quadros renderizados por segundo é calculado pelo sistema e exibido para o pesquisador.

Métrica: Número de quadros por segundo.

\subsubsection{Geral - Qualitativo}

\section{Conforto e ergonomia}


Após realizar todos os outros testes o observador avalia o nível de conforto ao utilizar a técnica estereoscópica sendo julgada.

Realização: O observador deve avaliar a solução estereoscópica.

Métrica: Avaliação subjetiva.

\subsection{Seleção dos testes}

Após uma bateria de testes preliminar de avaliação do funcionamento do sistema ficou evidente que o tempo necessário para a realização dos testes estava muito extenso. O tempo médio para um observador completar os testes estava em torno de duas horas, enquanto a ITU-R, referência para testes de qualidade visual em televisores, recomenda que a duração de uma sessão deve ser de trina minutos (ITU-R BT.500-11, 2002).

A decisão para reduzir o tempo de execução dos testes foi selecionar um grupo de testes que apresentam boa coesão e são suficientes para definição de um resultado conclusivo. Assim, os testes de resultado subjetivo foram eliminados da bateria, por não propiciarem dados que possam ser analisados de forma direta.

O grupo de testes escolhido para serem executados por observadores são apresentados no item 4.5.1. A única exceção é o teste de Posição no Espaço, que não pode ser incluído na bateria de testes pois se encontra em um estágio muito preliminar para obtenção de dados consistentes. 


\section{ANÁLISE DE RESULTADOS E CLASSIFICAÇÃO DAS TÉCNICAS}

Inicialmente foram realizados os testes de processamento no sistema, overhead e desempenho. Os valores foram mensurados através de um módulo de avaliação de processamento gráfico, incorporado ao próprio sistema. Ativando este módulo, uma anotação é exibida na tela, informando a taxa atual de quadros renderizados por segundo e o tempo médio decorrido entre um quadro e outro.

Em um segundo momento, foram realizados os testes com os observadores, seguindo o processo descrito no item 3.4. Os observadores realizaram os testes de três formas diferentes: sem o auxílio de solução estereoscópica, com óculos anaglifos vermelho/ciano e com óculos obturadores. Embora o sistema suporte também estereoscopia com HMDs e óculos polarizados, foi decidido dispensar a realização dos testes com estas soluções principalmente devido ao hardware exigido por elas. Este hardware diferenciado trás duas complicações para a realização dos testes. A primeira são as variáveis adicionais decorrentes da mudança do sistema visual, ou, em outras palavras, o observador precisaria se submeter a visualização do teste em uma tela projetada no caso dos óculos polarizados e a visualização através de reduzidos displays LCD no caso do HMD. A segunda é o tempo necessário para realização da bateria de testes, que aumentaria significativamente devido a troca de equipamento entre uma solução estereoscópica e outra. Este acréscimo no tempo estenderia ainda mais a duração da bateria de testes, que já se encontra no limiar das recomendações da ITU, conforme descrito no item 4.6.

\subsection{Resultados}

Os testes de processamento não obtiveram resultados significativos, provavelmente devido a alta capacidade do hardware disponível para realização dos testes. 
Utilizando as cenas criadas para realização dos outros testes, a diferença nos resultados obtidos entre as soluções estereoscópicas nos testes de overhead e de desempenho se confundem com as flutuações entre cada execução.

Um procedimento mais adequado para a realização dos testes de processamento é, possivelmente, a criação de uma cena especialmente para esta avaliação. A cena precisa ser projetada considerando a capacidade do hardware que será utilizado durante os testes, assim, mesmo que a diferença de processamento entre as soluções seja mínima, ainda é possível obter dados relevantes para a comparação.

Embora os testes de processamento não tenham alcançado resultados interessantes para a pesquisa, os testes com observadores geraram muito material para a comparação das soluções. Entretanto, melhor do que apresentar os dados brutos obtidos nos testes são os dados devidamente consolidados na forma do erro cometido pelos observadores. Conforme descrito no item 3.5, a análise dos dados é feita com base no desvio quadrático das respostas dos observadores com relação ao valor correto apresentado pelo sistema. No caso do teste da nave, como não existe uma resposta correta, o valor de referência utilizado é a média dos resultados do observador, assim mensurando a consistência de sua performance. A Tabela 3 a seguir apresenta o desvio das respostas dos observadores para cada um dos testes individualmente.

Com raríssimas exceções, os resultados com maior desvio foram obtidos quando os observadores estavam sem o auxílio de solução estereoscópica, o que indica a relação diretamente proporcional entre a visão estereoscópica e a performance nos testes.

Um problema identificado após a coleta dos dados foi a influência de parâmetros que são sorteados pelo sistema. Em testes que o fator aleatório tem uma forte influência na cena, a variação do desvio obtido na ausência de solução estereoscópica é também muito grande. Este fato pode ser verificado nos resultados dos testes da régua e dos blocos, nos quais o elemento aleatório influencia a posição, profundidade e tamanho dos objetos da cena. 
Tabela 3 - Desvio quadrático

\begin{tabular}{|c|c|c|c|c|c|}
\hline & & Esfera & Régua & Blocos & Nave \\
\hline \multirow{4}{*}{ Observador1 } & Normal & 140 & 2455 & 65,71 & 252,85 \\
\cline { 2 - 6 } & Anaglifo & 0 & 77 & 23,7 & 37,1 \\
\cline { 2 - 6 } & Obturador & 0 & 43 & 1,19 & 17,84 \\
\hline \multirow{4}{*}{ Observador2 } & Normal & 148 & 509 & 38,43 & 411,34 \\
\cline { 2 - 6 } & Anaglifo & 0 & 306 & 14,03 & 20,18 \\
\cline { 2 - 6 } & Obturador & 0 & 111 & 3,7 & 100,86 \\
\hline \multirow{4}{*}{ Observador4 } & Normal & 292 & 921 & 65,91 & 252,62 \\
\cline { 2 - 6 } & Anaglifo & 16 & 178 & 8,63 & 91,33 \\
\cline { 2 - 6 } & Obturador & 0 & 1127 & 4,86 & 0,66 \\
\cline { 2 - 6 } & Normal & 168 & 1228 & 19 & 485,71 \\
\hline \multirow{3}{*}{ Observador5 } & Obturador & 0 & 286 & 13,66 & 233,11 \\
\cline { 2 - 6 } & Normal & 100 & 1297 & 26,58 & 86,47 \\
\cline { 2 - 6 } & Anaglifo & 16 & 871 & 19,16 & 75,56 \\
\cline { 2 - 6 } & Obturador & 0 & 379 & 16,03 & 24,21 \\
\hline \multirow{3}{*}{ Observador6 } & Normal & 84 & 128 & 150,22 & 217,41 \\
\cline { 2 - 6 } & Anaglifo & 4 & 371 & 16,55 & 26,91 \\
\cline { 2 - 6 } & Obturador & 0 & 39 & 86,9 & 63,15 \\
\hline & Normal & 124 & 1348 & 35,07 & 158,44 \\
\cline { 2 - 6 } & Anaglifo & 136 & 1906 & 27,51 & 363,06 \\
\cline { 2 - 6 } & Obturador & 44 & 562 & 30,41 & 624,82 \\
\hline \multirow{3}{*}{ Observadory } & & & & \\
\hline & & & 715 & 34,51 & 443,28 \\
\hline
\end{tabular}

Para realizar uma análise comparativa das soluções estereoscópicas é interessante organizar estes dados de forma relativa. Assim, os valores de desvio obtidos em cada teste foram normalizados com relação ao desvio sem o uso de estereoscopia. Portanto na Tabela 4 temos os mesmos dados só que normalizados com relação ao valor Normal de referência. Porcentagens superiores a cem indicam um valor de desvio maior do que sem estereoscopia e porcentagens inferiores a cem um desvio menor. 
Tabela 4 - Desvio quadrático normalizado

\begin{tabular}{|c|c|c|c|c|c|}
\hline & & Esfera & Régua & Blocos & Nave \\
\hline \multirow{3}{*}{ Observador1 } & Normal & $100 \%$ & $100 \%$ & $100 \%$ & $100 \%$ \\
\cline { 2 - 6 } & Anaglifo & $0 \%$ & $3 \%$ & $36 \%$ & $15 \%$ \\
\cline { 2 - 6 } & Obturador & $0 \%$ & $2 \%$ & $2 \%$ & $7 \%$ \\
\hline \multirow{3}{*}{ Observador2 } & Normal & $100 \%$ & $100 \%$ & $100 \%$ & $100 \%$ \\
\cline { 2 - 6 } & Anaglifo & $0 \%$ & $60 \%$ & $37 \%$ & $5 \%$ \\
\cline { 2 - 6 } & Obturador & $0 \%$ & $22 \%$ & $10 \%$ & $25 \%$ \\
\hline \multirow{3}{*}{ Observador3 3} & Normal & $100 \%$ & $100 \%$ & $100 \%$ & $100 \%$ \\
\cline { 2 - 6 } & Anaglifo & $5 \%$ & $19 \%$ & $13 \%$ & $36 \%$ \\
\cline { 2 - 6 } & Obturador & $0 \%$ & $122 \%$ & $7 \%$ & $0 \%$ \\
\hline \multirow{3}{*}{ Observador5 } & Normal & $100 \%$ & $100 \%$ & $100 \%$ & $100 \%$ \\
\cline { 2 - 6 } & Anaglifo & $31 \%$ & $58 \%$ & $182 \%$ & $91 \%$ \\
\cline { 2 - 6 } & Obturador & $0 \%$ & $23 \%$ & $72 \%$ & $48 \%$ \\
\cline { 2 - 6 } & Normal & $100 \%$ & $100 \%$ & $100 \%$ & $100 \%$ \\
\cline { 2 - 6 } & Obturador & $0 \%$ & $29 \%$ & $60 \%$ & $28 \%$ \\
\hline \multirow{3}{*}{ Observador6 } & Normal & $100 \%$ & $100 \%$ & $100 \%$ & $100 \%$ \\
\cline { 2 - 6 } & Anaglifo & $5 \%$ & $290 \%$ & $11 \%$ & $12 \%$ \\
\cline { 2 - 6 } & Obturador & $0 \%$ & $30 \%$ & $58 \%$ & $29 \%$ \\
\hline & Normal & $100 \%$ & $100 \%$ & $100 \%$ & $100 \%$ \\
\cline { 2 - 6 } & Anaglifo & $110 \%$ & $141 \%$ & $78 \%$ & $229 \%$ \\
\cline { 2 - 6 } & Obturador & $35 \%$ & $42 \%$ & $87 \%$ & $394 \%$ \\
\hline \multirow{3}{*}{ Observadory } & $16 \%$ & $67 \%$ & $72 \%$ & $87 \%$ \\
\hline & & & & \\
\hline
\end{tabular}

A comparação dos resultados obtidos por cada observador indica que a performance ao usar óculos obturadores é consistentemente melhor em relação a óculos anaglíficos, embora a diferença não seja assintosa. Em especial o observador 4 teve muita dificuldade no uso de anaglifos, com resultados próximos ou até maiores do que sem o auxílio de nenhum óculos. Uma expeculação possível é que este observador tem dificuldades visuais com relação ao espectro de cores, do qual a solução anaglífica é muito dependente.

Um outro importante aspecto a notar é que o observador 7 é um caso excepcional, pois possui declarada dificuldade para percepção de profundidade dos objetos. Analisando os seus resultados, fica evidente que nenhuma das soluções se destacou de forma significativa com relação a Normal, sem estereoscopia. Apenas 
no teste das esferas e da régua que a solução por óculos obturadores foi razoavelmente melhor, com um desvio pouco mais de cinquenta porcento inferior ao obtido sem nenhuma solução estereoscópica.

Um comentário recorrente após os testes foi o cansaço visual e desconforto devido ao uso da solução por anaglifos. Além disso, alguns observadores também comentaram a melhora da percepção estereoscópica após um tempo de adaptação, ao se usar qualquer solução estereoscópica, embora esta informação não seja confirmada de forma evidente pelos resultados dos testes.

\subsection{Classificação}

Inicialmente o objetivo deste item do trabalho era classificar as soluções estereoscópicas conforme os dados obtidos durantes os testes, mas isso se mostrou limitado. Com base nos dados experimentais, a classificação das soluções estaria restrita, principalmente, a performance nos testes e existem diversos outros fatores que podem ser usados para comparação e classificação. Por este motivo, a proposta passou a ser uma classificação mais abrangente, incluindo também informações teóricas sobre visão estereoscópia e sobre a tecnologia envolvida em cada solução.

O primeiro ponto de discussão com relação a classificação encontrada na pesquisa literária é a separação entre estéreo ativo e estéreo passivo. Esta terminologia é usada normalmente para referenciar estereoscopia por óculos obturadores e por óculos anaglifícos ou polarizados, respectivamente. No entanto para esta classificação acomodar outras formas de estereoscopia é necessário primeiro uma redefinição mais robusta de quais fatores tornam uma solução ativa ou passiva.

No contexto deste trabalho, esta classificação das soluções estereoscópicas se refere apenas a parte do observador, com relação ao tipo de equipamento que ele precisa utilizar para que o par estéreo seja filtrado, de modo que cada olho visualize somente uma das imagens. A outra parte diz respeito ao processo de geração das 
imagens estereoscópicas, mais espeficicamente, como o par estéreo é apresentado para o observador. A primeira parte é denominada receptor e a segunda emissor de pares estéreo. Estes conceitos são melhor descritos nos dois itens a seguir (5.2.1 e 5.2.2), incluindo exemplos de soluções representando as categorias identificadas, tanto de receptores como de emissores. A Tabela 5 a seguir organiza esta classificação de forma visual, tornando mais fácil o entendimento de como cada solução se enquadra.

\subsubsection{Receptor de Par Estéreo}

Como meio de redefinir a aplicação dos termos estéreo ativo e passivo é proposta esta classificação das soluções estereoscópicas tendo em vista o receptor do par estéreo. Neste caso o termo receptor se refere ao equipamento que de alguma forma separa o par estéreo, encaminhando uma das imagens para o olho esquerdo do observador e a outra imagem para o olho direito. Esta separação do par estéreo entre os dois olhos é essencial para a obtenção de profundidade através da estereoscopia.

A seguir são apresentados os grupos de receptores estereoscópicos e como cada uma das soluções pesquisadas se enquadram nesta classificação.

\section{Dinâmico (Ativo)}

Esta categoria de receptores abrange aqueles que o estado depende do tempo, ou seja, as propriedades do receptor mudam dependendo do instante em que "fotografamos" o seu estado. O principal representante deste grupo são os óculos obturadores que, dependendo do instante, está bloqueando ou permitindo a visualização através de suas lentes. 


\section{Estático (Passivo)}

O complemento do grupo Dinâmico. Os receptores do tipo Estático tem um estado fixo, que independe do instante em que o verificamos. Existem diversos exemplos deste grupo, em especial os históricos óculos anaglíficos e os mais modernos polarizados. Ambos possuem lentes com propriedades constantes, que estão sempre no mesmo estado, livres do contexto do tempo. Um caso especial deste grupo são os HMDs, pois nestes o emissor e o receptor de par estéreo coincidem no mesmo equipamento. Os HMDs foram classificados no grupo Estático por serem equipamentos utilizados pelo observador que propiciam a separação das imagens através do isolamento óptico, limitando o campo de visão de cada olho.

\section{Ausente}

Este grupo engloba as soluções estereoscópicas que dispensam um receptor de par estéreo, devido a características do emissor. Um exemplo são as soluções autoestereoscópicas, que pela própria natureza das técnicas, dispensam o observador de utilizar um equipamento dedicado a separar o par estéreo.

\subsubsection{Emissor de Par Estéreo}

Um meio de classificação das soluções estereoscópicas é o modo como ela exibe o par estéreo para o observador. Descrevendo em outras palavras, o mecanismo de multiplexação que o emissor utiliza para que as imagens do par estéreo não se misturem, se tornando uma única imagem indistinguível. Com base neste critério de classificação, foram observados três grupos de emissores estéreo: espacial, temporal e visível. 


\section{Espacial}

Este grupo abrange os emissores que distinguem cada imagem do par estéreo através de diferenças de posição no espaço. Como exemplo trivial temos as soluções autoestereoscópicas, nas quais as imagens esquerda e direita são exibidas de posições e direções diferentes, para permitir que um observador visualize uma imagem diferente com cada olho. Outro membro são os HMDs, com displays independentes para cada imagem do par estéreo.

\section{Temporal}

Uma alternativa ao método Espacial é a apresentação de cada imagem do par estéreo em um instante diferente. Assim, temos a categoria Temporal de emissores, os quais exibem a imagem esquerda e a direita em momentos distintos. A solução por óculos obturadores utiliza esta abordagem, necessitando de monitores capazes de exibir imagens alternadas a altas frequências, de modo que seja imperceptível ao olho humano. Um membro especial desta categoria é a ténica baseada no efeito pulfrich, que se baseia na característica da visão humana de perceber luz menos intensa de forma mais lenta. Assim, a imagem visualizada por um dos olhos esta sempre alguns instantes defasada em relação ao outro.

\section{Visível}

Esta categoria de emissores engloba aqueles que se aproveitam de alguma propriedade da luz visível para proporcionar o isolamento do par estéreo. Dois bons exemplos são os anaglifos, que se aproveitam dos diferentes comprimentos de onda do espectro da luz, e a polarização, que utiliza a possibilidade de "alinhar" a luz como forma de isolar as imagens do par estéreo. 
Tabela 5 - Classificação das soluções estereoscópicas através dos tipos de emissores e receptores

\begin{tabular}{|c|c|c|c|}
\hline & Dinâmico (Ativo) & Estático (Passivo) & Ausente \\
\hline Espacial & - & $\begin{array}{c}\text { HMD } \\
\text { Estereoscópio } \\
\text { Slides Estéreo }\end{array}$ & $\begin{array}{c}\text { Autoestereoscopia } \\
\text { Visão Paralela / Cruzada } \\
\text { Estereograma }\end{array}$ \\
\hline Temporal & Óculos Obturadores & Efeito Pulfrich & Par Estéreo Alternado* \\
\hline Visível & - & $\begin{array}{l}\text { Óculos Anaglifos } \\
\text { Óculos Polarizados } \\
\text { ChromaDepth } \\
\text { ColorCode 3-D }\end{array}$ & - \\
\hline
\end{tabular}

* Conceitualmente não é uma solução estereoscópica pois ambos os olhos veem a mesma imagem 


\section{APLICAÇÃO EM REALIDADE AUMENTADA}

As pesquisas em Realidade Aumentada buscam constantemente tecnologias e soluções que possibilitem uma maior integração entre elementos reais e elementos virtuais, possivelmente como um meio de aprimorar a experiência de tele-presença dos usuários ao utilizar estes sistemas. Esta busca se distribui por diversos segmentos que envolvem a RA, começando pela capacidade e precisão da tecnologia até o design de aplicações e interfaces que explorem mais os recursos oferecidos por ela.

Um exemplo deste processo evolutivo é a tecnologia utilizada para os passos de rastreamento e registro (AZUMA, 1997). Devido aos elementos virtuais de um sistema de RA não existirem fisicamente, a sua posição no espaço precisa ser determinada a partir de pontos de referência dos objetos reais. Um meio para obter esses pontos de referência que são necessários para o rastreamento e registro é o uso de marcadores fiduciais. Este tipo de solução é muito utilizada em sistema nos quais o usuário observa cenas reais incrementadas de objetos virtuais através de HMDs ou dispositivos móveis (BILLINGHURST et. al, 2001) (SCHMALSTIEG; WAGNER, 2007).

Uma das primeiras alternativas de macadores são os detectados por uma biblioteca denominada ARToolKit (2010), desenvolvida no final da década de 90. Esta biblioteca é capaz de determinar a posição e orientação de marcadores quadrados que seguem um padrão preto e branco. Diversos grupos de pesquisa desenvolveram projetos baseados nesta biblioteca, sendo um destes projetos 0 "Magic Book" (BILLINGHURST et. al, 2001) que demonstra uma forma de incrementar um livro real com adições virtuais através da RA. Alguns anos depois, uma outra solução com nome ARTag (2010) foi desenvolvida para suprir alguns dos problemas e limitações do ARToolKit. Fiala (2004) realizou uma comparação extensiva das duas soluções, mostrando que o ARTag tem vantagens em diversas características como falsos positivos, confusão de marcadores, perda por oclusão, entre outras. Wagner e Schmalstieg (2009) apresentam uma revisão dessa 
evolução, com foco nos dispositivos móveis, e mostram como diversas técnicas foram desenvolvidas nos últimos anos para atender a este desafio da RA.

Da mesma forma que na parte da tecnologia, um outro segmento que tem exigido esforços na área de RA são as aplicações desta tecnologia, voltadas cada vez mais ao público geral. Pesquisadores da área de IHC (Interface Homem-Computador) buscam uma forma de criar interfaces que extraiam o máximo da RA (GABBARD; SWAN, 2007) enquanto outros trabalham fazendo testes diretamente com usuários, como Schmalstieg e Wagner (2007) que relatam o desenvolvimento e a experiência de alunos utilizando aplicações de RA, voltadas a educação e entretenimento, sendo executadas em dispositivos móveis.

A razão de levantar a evolução destas frontes que envolvem a Realidade Aumentada é que ambas oferecem oportunidades para a aplicação da estereoscopia. No primeiro caso, que envolve o rastreamento e registro dos elementos, não é a estereoscopia comentada neste trabalho, que resulta na sensação de profundidade por parte do observador, mas o uso matemático da disparidade entre o par estéreo. Comparando a imagem capturada por duas ou mais câmeras distintas, com posição e orientação conhecidas, é possível utilizar as imagens por elas capturadas para determinar a posição dos elementos filmados no espaço. Pintaric e Kaufmann (2007) construiram um sistema de rastreamento voltado a $R V$ e RA que se baseia justamente neste princípio estereoscópico. O sistema realiza a deteç̧ão e rastreamento de marcadores infravermelhos que são capturados por câmeras de vídeo em tempo real. As imagens obtidas pelas diferentes câmeras são processadas matematicamente seguindo o conceito de disparidade, visando determinar a posição tridimensional dos elementos nelas presentes.

No segundo caso, do ponto de vista de IHC, a estereoscopia fornece um mecanismo intuitivo de aumentar a precisão e velocidade dos usuários ao manipular sistemas de RV e RA. Por causa da natureza tridimensional desses sistemas, as soluções utilizadas para interfaces bidimensionais introduzem erro e ambiguidade decorrentes do grau adicional de liberdade. Teather e Stuerzlinger (2007) definiram um guia de boas práticas para criação de interfaces 3D e também realizaram alguns experimentos para avaliar tipos diferentes de interfaces. Uma conclusão interessante 
baseada nos resultados experimentais é que a estereoscopia proporciona um impacto significativo na precisão das ações do usuário.

\subsection{Desafios da Estereoscopia em Realidade Aumentada}

A estereoscopia e a Realidade Aumentada são linhas de pesquisa que caminham próximas, possivelmente devido a relação intrínseca entre elas de que um sistema de RA idealmente precisa ser visualizado estereoscopicamente para ser fiel ao mundo real. Nesse sentido, os desafios envolvendo as duas áreas podem ser observados em dois níveis: um mais conceitual, descobrindo formas inovadoras de unir estes tópicos, e outro mais prático, agregando a outra tecnologia a projetos e sistemas que envolvem apenas uma delas.

Um exemplo de projeto que agrega estereoscopia a um sistema de RA é apresentado por Peterson, Axholt e Ellis (2008), no qual os autores utilizam um sistema de RA que incrementa a percepção visual do usuário, mostrando anotações virtuais associadas a elementos de uma cena externa real. A adição da estereoscopia facilita a tarefa do usuário de associar uma anotação a um elemento real, inserindo a profundidade como mais uma variável que o auxilia a determinar esta relação.

\subsubsection{Vídeo-Avatar}

Um trabalho em especial que visa agregar as duas tecnologias é o Vídeo-Avatar do INTERLAB, que está inserido dentro do projeto TIDIA-AE da FAPESP. O módulo Vídeo-Avatar visa permitir que um indivíduo, no caso do projeto TIDIA-AE um professor, possa ministrar aulas remotamente com alto grau de tele-presença do 
ponto de vista dos alunos. As imagens de vídeo do professor capturadas em tempo real são incorporadas a um ambiente virtual, formando um par estéreo que então é transmitido através da internet, de modo que o aluno possa observar o professor e o ambiente com percepção de profundidade (TOKUNAGA, 2009). 


\section{APLICAÇÃO EM JOGOS}

A utilização de técnicas estereoscópicas vem se tornando uma estratégia cada vez mais comum, ainda que explorada de forma limitada no desenvolvimento de jogos eletrônicos.

Embora alguns estudos indiquem que tal tecnologia pode provocar desconforto a alguns jogadores (HÄKKINEN et al., 2006), ou pode não causar qualquer efeito em ações praticadas dentro de um ambiente imersivo (MCMAHAN et al., 2006), esse recurso tem se mostrado presente em alguns game engines (JACOBSON et al., 2005), em dispositivos gráficos para computadores pessoais (NVIDIA, 2008) e em alguns jogos de console, como o Sly3 (SLY3, 2009].

As primeiras experiências estereoscópicas na área se limitavam a oferecer algum suporte que permitia utilizar, em um pequeno número de jogos, um par de óculos 3D (STEREO3D, 2010), que aumentava a sensação de imersão do jogador. A geração seguinte, por sua vez, trazia uma extensa lista de títulos, lançados nas décadas de 1980 e 1990, que continha o recurso de forma nativa (STEREO3D, 2010).

Com o desenvolvimento de APIs como a Direct3D e o OpenGL, que fazem a comunicação direta com o driver da placa gráfica, desde que esta possua um chipset 3D, houve um crescimento do número de jogos que exploravam, de alguma forma, a visão estereoscópica (STEREO3D, 2010).

A geração atual de dispositivos gráficos foi elaborada de forma a transformar centenas de jogos em uma experiência estereoscópica, por meio da modificação do driver de vídeo do sistema operacional, mesmo que, originalmente, esses jogos não tenham sido projetados para utilização com esse tipo de recurso (NVIDIA, 2008).

Em relação aos consoles, foram lançados na década de 1990 alguns jogos utilizados com óculos 3D para o Master System, da empresa Sega, que produziam ilusão de profundidade. No Playstation 2 foi adotada a tecnologia do anaglifo, que era utilizada de forma não obrigatório em determinados momentos, dentro de alguns jogos (SLY3, 2009). 
Ainda no que se refere a consoles, em 2009, no evento Consumer Electronics Show, realizado em Las Vegas, a empresa Sony exibiu protótipos de jogos para o console Playstation 3 (Wipeout HD, Grand Turismo 5 e Motorstorm) usando efeitos de estereoscopia.

\subsection{Desafios da Estereoscopia em Jogos}

Apesar da diversidade de estilos e dos diferentes níveis de sofisticação é possível identificar nos jogos eletrônicos alguns elementos comuns, que fazem parte de sua composição. Assim como ocorre com esses elementos, é interessante primeiro classificar como a estereoscopia se encaixa nos jogos.

\subsubsection{Conceitualização}

Independentemente de gênero ou do nível de sofisticação gráfica, jogos de computador (ou executáveis em qualquer outra plataforma) possuem características em comum, com elementos que fazem parte de sua composição. Rollings e Morris (2004) classificaram esses elementos em três grupos. São eles:

- Integral - vitais para o jogo funcionar adequadamente. A ausência de um elemento desse tipo retira do jogador uma gama substancial de escolhas.

- Chrome - intensificam a diversão proporcionada pelo jogo, mas não afetam a jogabilidade. Realçam o "clima" que o jogo transmite ao jogador.

- Substituto - caracterizados por apenas proporcionar uma opção equivalente para o jogador. Agregam pouco valor adicional ao jogo. 
Tanto as primeiras experiências aplicadas a jogos eletrônicos quanto os lançamentos ligados a área exibidos recentemente em eventos trazem a estereoscopia como um acessório visual, o que a classifica como um elemento do grupo chrome, influente na estética, mas não na jogabilidade.

Um importante passo para o fortalecimento da estereoscopia no mercado de jogos é a migração desse elemento da categoria chrome para a integral, ou seja, vital para uma plena experiência de jogo. Este aspecto é melhor discutido no item 7.1.2 a seguir.

\subsubsection{Tendencias}

A evolução dos jogos eletrônicos pode ser melhor compreendida quando se observa, entre outras características, a qualidade gráfica e as diversas formas de interação proporcionadas pelos jogos atuais. $\mathrm{O}$ aumento exponencial do poder de processamento dos computadores domésticos, aliado ao barateamento de dispositivos menos convencionais tem possibilitado aos fabricantes a exploração do limite dessa tecnologia, agregando aos seus jogos uma infinidade de recursos, com o objetivo de serem mais atrativos aos consumidores.

Nesse sentido, grande parte dos esforços de pesquisadores da área visa buscar meios de aumentar o nível de imersão dos jogadores através da qualidade visual. Recursos como a visão estereoscópica, que permite visualizar diferentes níveis de profundidade entre os elementos que compõem o cenário do jogo, tem se mostrado uma alternativa interessante. No entanto, independentemente da técnica adotada, a estereoscopia tem sido um meio de simplesmente aprimorar a visualização do cenário virtual do jogo, utilizado em momentos específicos e de maneira opcional.

Esta é uma abordagem limitada do potencial da estereoscopia. Considerando que os jogos eletrônicos são cenas interativas incrementadas com regras que a tornam um jogo, qualquer recurso que adicione graus de liberdade na interação entre o jogador e a cena pode ser explorado diretamente na jogabilidade, não somente como um 
adereço visual. O artigo de Tomoyose et al. (2009) apresenta mais detalhadamente esta abordagem da utilização da estereoscopia nos jogos.

\subsection{Implementação da Estereoscopia em Game Engine}

As restrições para implementação da estereoscopia estão fortemente relacionadas ao hardware, software e solução estereoscópica escolhidos. Como meio de organizar as opções disponíveis a descrição é apresentada por solução estereoscópica.

\section{Anaglifos}

Uma das técnicas de mais simples implementação, a plataforma escolhida influencia apenas na performance resultante, mas nenhum recurso especial é necessário. Esta é uma opção interessante para ser implementada em um protótipo para testes, pois os óculos anaglifos são fáceis de se obter.

\section{HMD e Obturadores}

A implementação desta técnica é altamente vinculada ao hardware e software utilizados, assim a plataforma precisa dar suporte explícito a este tipo de solução. No caso dos computadores da linha PC existem basicamente duas opções, através do hardware de vídeo, o que exige uma placa de vídeo com recurso de quad-buffer, ou através dos drivers da Nvidia, que embora permita estereoscopia transparente ao desenvolvedor, impede que este tenha o controle da renderização estereoscópica.

\section{Polarizado}


Considerando o método de praxe para implementação desta solução, com dois projetores cada um com um filtro polarizador diferente, a principal exigencia é um hardware com duas saídas de vídeo independentes. O software deve renderizar o par estéreo e direcionar cada imagem do par a uma saída de vídeo diferente. Apenas como observação, a tela na qual as imagens são projetadas também precisa de atenção especial, pois deve ser de um material que mantém a polarização da luz.

\subsubsection{Caso EnJine}

A implementação de um módulo estereoscópico no EnJine impõem fortes restrições com relação ao software adotado, que segue a tecnologia Java. A biblioteca Java3D tem o problema citado no item 4.1 de limitar o controle que o desenvolvedor tem do processo de renderização e inclusive apresenta alguns problemas para incorporar imagens capturadas por câmeras de vídeo como textura em tempo real. Mesmo com estas considerações, um módulo estereoscópico para o EnJine é factível, lembrando sempre das limitações de performance impostas por uma linguagem de mais alto nível e interpretada, como é o caso do Java.

Um caminho interessante para criação de um módulo estereoscópico é definir uma classe abstrata ou interface que rege o padrão a ser seguido na implementação de uma técnica. Seguindo este formato, cada solução estereoscópica se torna um componente diferente que pode ser invocado quando necessário, permitindo alterar o modo de renderização em tempo de execução, conforme a solução desejada.

Aprofundando em detalhes mais técnicos de implementação, a experiência com o primeiro protótipo (item 4.1.1) resultou em um conhecimento melhor de como desenvolver o componente correspondente a cada solução estereoscópica. No caso de anaglifos, por exemplo, uma forma interessante de obter o par estéreo é "cobrir" as duas câmeras virtuais com esferas transparentes que fazem o papel de lentes. A esfera ao redor da câmera da esquerda permite apenas a passagem de luz 
vermelha e a esfera posicionada na câmera direita permite a passagem de luz ciana. Com este procedimento obtemos o par anaglífico sem precisar manipular individualmente as imagens renderizadas em memória.

O desenvolvimento de um módulo para óculos obturadores e HMDs exige apenas a utilização do recurso de stereo presente na documentação do Java3D. Note que a habilitação desta opção só é possível se o hardware de vídeo suportar o recurso de quad-buffer. Por fim, um componente estereoscópico para óculos polarizados com uso de projetores necessita o controle das saídas de vídeo do computador, de modo que a imagem obtida pela câmera esquerda seja direcionada para uma saída e a obtida pela direita para outra saída. O código para realizar esta tarefa também pode ser encontrado na documentação do Java3D. 


\section{CONCLUSÕES}

Como foi possível reconhecer através da pesquisa teórica, a estereoscopia é uma área do conhecimento muito abrangente que envolve diversos outros campos nos quais é possível explorar o efeito estereoscópico, dentre os quais podemos citar a arte, medicina e computação gráfica. Neste trabalho, foi decidido concentrar os esforços nas soluções estereoscópicas que permitem a visualização, com sensação de profundidade, de imagens geradas por computação gráfica.

Inicialmente, a pesquisa literária, que é a base deste projeto, forneceu os recursos para uma importante contribuição: a criação de uma referência consolidada e concisa sobre os conceitos, técnicas e equipamentos utilizados para visualização estereoscópica, materializada no item 2 deste trabalho.

Investigando o ponto de vista da indústria é possível notar que, devido ao histórico da estereoscopia, começando pelas artes, através da fotografia e vídeo, até alcançar a computação, por diversas vezes a estereoscopia se propagou como produto de nicho. A indústria do entretenimento tenta uma nova onda estereoscópica para firmar esta tecnologia no mercado. O número de cinemas 3D e de jogos com suporte estereoscópico cresce a cada dia, mas um fator importante é que estão se tornando cada vez mais populares. Este é o grande diferencial desta nova onda com relação as anteriores, os produtos são voltados ao grande público, não apenas um acessório para "excêntricos". Grandes produções de hollywood como o filme Avatar e jogos das maiores produtoras como a Sony e seu Playstation 3 são exemplos desse esforço da indústria em popularizar a estereoscopia.

Embora a indústria faça um grande esforço para emplacar um novo salto visual através da estereoscopia, pesquisas em torno da qualidade das técnicas estereoscópicas e a real sensação dos observadores são escassos, bem como o estudo de outras características, como a precisão da profundidade observada.

Como contribuição voltada a esta lacuna e principal tópico deste trabalho foi proposto e desenvolvido um sistema em direção a suprir esta necessidade. Este sistema permite realizar testes diversos, executados com diferentes soluções 
estereoscópicas. Embora, inicialmente, apenas alguns módulos de testes e soluções tenham sido implementados, a arquitetura do sistema facilita a criação de módulos adicionais. Embora tenha sido necessário superar algumas barreiras, como a obtenção do hardware adequado e a migração da proposta inicial de utilizar tecnologia Java e Java3D para $\mathrm{C}++$ e OpenGL, o sistema foi implementado com sucesso, exibindo boa performance e a flexibilidade necessária para expansões.

Uma bateria de testes foi realizada com alguns observadores especialistas, também como forma de validar o sistema e a metodologia de criação dos testes. Os resultados obtidos confirmaram experimentalmente dois aspectos essenciais da pesquisa: a possibilidade de criar testes que avaliam o efeito estereoscópico e o fato de um observador ter resultados diferentes com soluções estereoscópicas distintas.

Em um plano mais conceitual, o trabalho busca contribuir com uma forma mais adequada de classificação das soluções estereoscópicas. Ao invés de se limitar a terminologia comum e ambígua de estéreo ativo e passivo, a proposta é separar em dois subsistemas: o emissor e o receptor de pares estéreo. O emissor é o componente responsável pela exibição das imagens estereoscópicas e foram definidas três categorias: Espacial, Temporal e Visível. O receptor é o componente utilizado pelo observador que é responsável por separar as imagens esquerda e direita para o respectivo olho. Foram propostas três categorias de receptores: Dinâmico (Ativo), Estático (Passivo) e Ausente.

Finalmente, como contribuições adicionais, são apresentadas discussões do estado atual e tendências da estereoscopia aplicada a área de RA e de jogos. Com relação a RA, a discussão busca demonstrar como a estereoscopia pode contribuir em diversos desafios e objetivos desta área, além de ser simplesmente um recurso adicional disponível para alcançar uma sensação maior de tele-presença. Tendo em vista os jogos, com foco naqueles que envolvem computação gráfica, a principal direção da argumentação é o uso da estereoscopia como um elemento integral da mecânica do jogo, não apenas um adereço visual. 


\subsection{Trabalhos Futuros}

Esta pesquisa abre a oportunidade de algumas frentes para trabalhos futuros, tanto teóricos como prático. No plano teórico, ainda é necessário um maior esforço para o projeto de testes que sofram reduzida influência de fatores imprevisíveis, de preferência formando um conjunto que, independente dos observadores, quando executado sem o auxílio da estereoscopia resulte em valores semelhantes. Ainda no escopo conceitual, a metodologia do processo de execução da bateria de testes precisa ser consolidada, para elevar sua robustez e confiabilidade.

De um ponto de vista mais prático, existe a possibilidade de expandir o sistema de testes, sendo com a incorporação de novos módulos estereoscópicos ou a implementação de novos testes. Uma tarefa mais imediata é a execução experimental de soluções estereoscópicas já implementadas mas que ficaram de fora da bateria de testes, como os HMDs e óculos polarizados.

Outras frentes para trabalhos futuros é a aplicação da estereoscopia em outras áreas, em especial RA e jogos, que fizeram parte da discussão dessa pesquisa. No campo da RA, uma tendência interessante é a utilização da estereoscopia para o aumento da sensação de tele-presença, ressaltando o uso em video-avatares. Uma das frentes de pesquisa mais interessantes é com relação ao uso da estereoscopia nos jogos, que precisa atravessar a fronteira do simples visual para ser parte da mecânica dos jogos. 


\section{REFERÊNCIAS}

3D EXPERIENCE. 3D Experience - A Thrilling Experience. 2006. Disponível em: $<$ http://www.freewebs.com/thrillzonein3d/3dpicturestosee.htm>. Aceso em nov. 2008.

ADAMS, G. Um Balanço Bibliográfico e de Fontes da Estereoscopia. Anais do Museu Paulista, São Paulo, v.6/7, n.7, pp. 207-226, 2003.

ADOROCINEMA.COM. Space Jam. 2007. Disponível em: $<$ http://www.adorocinema.com/filmes/space-jam/space-jam.asp $>$. Acesso em nov.2008.

AMAZON. Linear Polarized 3D Glasses for IMAX movies and 3D Display. Disponível em: <http://www.amazon.com/Linear-Polarized-3D-GlassesDisplay/dp/B001BG3A86>. Acesso em nov.2008.

APO - American Paper Optics. 3D Glasses Online. Disponível em: $<$ http://www.3dglassesonline.com/>. Acesso em out.2008.

ARTOOLKIT. ARToolKit Home Page. Disponível em: $<$ http://www.hitl.washington.edu/artoolkit/ > . Acesso em fev.2010.

ARTAG. ARTag Home Page. Disponível em: < http://www.artag.net/>. Acesso em fev.2010.

AWN SHOWCASE. Who Framed Roger Rabbit. 2005. Disponível em: $<$ http://showcase.awn.com/showphoto.php?photo=1260\&si=toon $>$. Acesso em nov.2008.

AZUMA, R.T. A Survey of Augmented Reality. Presence: Teleoperators and Virtual Environments. vol. 6. pp 355-385, 1997.

BEENE, G. Stereogram Overview. Stereograms Information Center. Disponível em: $<$ http://www.garybeene.com/stereo/rds-over.htm>. Acesso em out.2008.

BELTRÃO, L. Uma Abordagem para a Estereoscopia via Funções de Green de Equações de Casamento. 2007. 84p. Dissertação (Mestrado) - Universidade Federal Fluminense, Niterói, 2007. 
BILLINGHURST, M., KATO, H., POUPYREV, I. The MagicBook: A Transitional AR Interface. Elsevier Computers and Graphics, v.25, n.5, p. 745-753, novembro 2001.

BRITANNICA. Louis Ducos du Hauron. In: Encyclopædia Britannica. Disponível em: <http://www.britannica.com/EBchecked/topic/172961/Louis-Ducos-du-Hauron>. Acesso em out.2008.

BURDER, D. 3D Images Ltd. 2005. Disponível em: $<$ http://www.stereoscopy.com/3d-images/photography.html>. Acesso em nov.2008.

BWH VENTURES. Creating Custom Stereograms. Disponível em: $<$ http://www.eyetricks.com/stereograms/custom.htm>. Acesso em nov.2008.

CALIFE, D., TOMOYOSE, A., SPINOLA, D., BERNARDES JR, J., TORI, R. Robot ARena: infrastructure for applications involving spatial augmented reality and robots. In: SYMPOSIUM ON VIRTUAL AND AUGMENTED REALITY, 9., 2007, Petropolis. Proceedings of the Symposium on Virtual and Augmented Reality. Porto Alegre: SBC, 2007. p. 92-99.

COLLIER, I. Stereo-Pair Images. lam Collier 3D Photographs 1993. Disponível em: $<$ http://users.comlab.ox.ac.uk/ian.collier/3d/stereo.html>. Acesso em out.2008.

COLORCODE. ColorCode 3-D. Disponível em: $<$ http://www.colorcode3d.com/whatis/index.htm>. Acesso em nov.2008.

COMBS, D. A Walk Through the Roses of Reynolda Gardens in Pulfrich 3-D. Combs Music. Disponível em: <http://www.combsmusic.com/RosesVideo.html>. Acesso em out.2008.

DAVY JONES LOCKER. Dive Expeditions. 2007. Disponível em: $<$ http://www.techdivethailand.com/wreck-diving-photos.htm>. Acesso em nov.2008.

DEEB, S.; MOTULSKY, A. Red-Green Color Vision Defects. GeneReviews. 2005. Disponível em: $<$ http://www.ncbi.nlm.nih.gov/bookshelf/br.fcgi?book=gene\&part=rgcb $>$. Acesso em out.2008.

ENGDAHL, T. 3D Glasses and Other 3D Display Devices. EPanorama.net. 1999. Disponível em: <http://www.epanorama.net/documents/pc/3dglass.html $>$. Acesso em out.2008. 
ENJINE. Engine para Jogos em Java. enJine. 2007. Disponível em: $<$ http://enjine.incubadora.fapesp.br>. Acesso em fev.2010.

FEHN, C. 3D TV Broadcasting. In: SCHREER, O. KAUFF, P. SIKORA, T. 3D Videocommunication. Chichester: John Wiley and Sons, 2005, p.23-38.

FIALA, M. ARTag Revision 1: A Fiducial Marker System Using Digital Techniques. National Research Council of Canada. 2004. Disponível em: <http://ecl.incheon.ac.kr/courses/ar7/articles/>. Acesso em fev.2010.

FOSTER, G. Understanding and Implementing Scene Graphs. Gamedev.net. Disponível em: $<$ http://www.gamedev.net/reference/programming/features/scenegraph/>. Acesso em fev.2010.

FRITSCH, D.; KADA, M. Visualisation Using Game Engines. In: ISPRS CONGRESS, 20., Istanbul, 2004. Istanbul: 2004. Commission 5, p. 621-625.

GABBARD, J.L., SWAN, J.E. Usability Engineering for Augmented Reality: Employing User-based Studies to Inform Design. IEEE Transactions on Visualization and Computer Graphics, USA, v.14, n.3, p.513-525, 2007.

GASPERINI, J. Time For Space Wiggle. OCC Panoram. 2003. Disponível em: $<$ http://3dculture.com/occ/Panoram time4space wiggle.htm>. Acesso em out.2008.

GESHWIND, D. Inventor of 2D-to-3D Conversion Used for "Superman Returns" Unveils Improved 'Super-Fast' Technology for Next Time. 2D-to-3D-Conversion: The Next Generation. 2006. Disponível em: <http://www.unipat.org/3dmg/PR2.htm>. Acesso em fev.2010.

GLM. GLM: an Alias Wavefront OBJ file library. Frederic Devernay website, 2010. Disponível em: <http://devernay.free.fr/hacks/glm/>. Acesso em fev.2010.

GLUT. GLUT - The OpenGL Utility Toolkit. OpenGL website, 2010. Disponível em: $<$ http://www.opengl.org/resources/libraries/glut/>. Acesso em fev.2010.

GRINBERG, V.; PODNAR, G.; SIEGEL, E.M. Geometry of Binocular Imaging, 1994. Disponível em: <http://citeseer.ist.psu.edu/grinberg94geometry.html>. Acesso em out.2008. 
HALLE, M. Autostereoscopic displays and computer graphics. Computer Graphics, ACM SIGGRAPH, v.31, n.2, pp. 58-62, May 1997. Disponível em: $<$ http://web.media.mit.edu/ halazar/autostereo/autostereo.html $>$. Acesso em nov.2008.

HÄKKINEN, J., PÖLÖNEN, M., TAKATALO, J. AND NYMAN, G. Simulator sickness in virtual display gaming: a comparison of stereoscopic and non-stereoscopic situations. Proceedings of the 8th conference on Human-computer interaction with mobile devices and services. Helsing. New York: ACM Press, 227-230. 2006.

HOLLIMAN, N. S. 3D Display Systems. 2002. Disponível em: $<$ http://citeseerx.ist.psu.edu/viewdoc/summary?doi=10.1.1.15.2146>. Acesso em nov.2008.

HOM, J. The Usability Methods Toolbox Handbook. 1998. Disponível em: $<$ http://www.idemployee.id.tue.nl/g.w.m.rauterberg/lecturenotes/UsabilityMethodsToo lboxHandbook.pdf>. Acesso em fev.2010.

IMDB. Avatar. Box Office Mojo. Disponível em: $<$ http://boxofficemojo.com/movies/?id=avatar.htm $>$. Acesso em fev.2010.

INITION. Trivisio AR-vision Goggles/HMD. Disponível em: $<$ http://www.inition.co.uk/inition/product.php?URL =product hmd trivisio hmd seeth rough\&SubCatID $=16>$. Acesso em nov.2008.

ITU-R BT.500-1. Methodology for the subjective assessment of the quality of television pictures. The ITU Radiocommunication Assembly. 2002. Disponível em: $<$ http://www.dii.unisi.it/ menegaz/DoctoralSchool2004/papers/ITU-R BT.500-

11.pdf>. Acesso em: mar.2010.

JACOBSON, J., LE RENARD, M., LUGRIN, J.L. AND CAVAZZA, M. The CaveUT system: immersive entertainment based on a game engine. Proceedings of the 2005 ACM SIGCHI International Conference on Advances in computer entertainment technology. Valencia. New York: ACM Press, 184-187. 2005.

JAVA3D. Java 3D Parent Project. Java.net, 2010. Disponível em: $<$ https://java3d.dev.java.net/>. Acesso em fev.2010.

JMF. Java SE Desktop Technologies - Java Media Framework API (JMF). ORACLE Sun Developer Network, 2010. Disponível em: $<$ http://java.sun.com/javase/technologies/desktop/media/jmf/>. Acesso em fev.2010. 
JNI. JDK 5.0 Java Native Interface-related APIs \& Developer Guides. Sun Microsystems, 2004. Disponível em: <http:/java.sun.com/j2se/1.5.0/docs/guide/jini/>. Acesso em fev.2010.

JONES, A.; MCDOWALL, I.; YAMADA, H.; BOLAS, M.; DEBEVEC, P. Rendering for an Interactive 360 Light Field Display. Computer Graphics, ACM SIGGRAPH 2007 Papers Proceedings, 2007. Disponível em: $<$ http://gl.ict.usc.edu/Research/3DDisplay/>. Acesso em nov.2008.

KITAMURA, Y.; KONISHI, T.; YAMAMOTO, S.; KISHINO, F. Interactive Stereoscopic Display for Three or More Users. In: INTERNATIONAL CONFERENCE ON COMPUTER GRAPHICS AND INTERACTIVE TECHNIQUES, 2001, New York. Proceedings of the 28th annual conference on Computer graphics and interactive techniques. New York: ACM, 2001. pp. 231-240. Disponível em: $<$ http://portal.acm.org/citation.cfm?id=383259.383285 >. Acesso em: 23 mar.2008.

KLEIN, A. Stereoscopy.com - The Gallery. Stereoscopy.com, 2008. Disponível em: $<$ http://www.stereoscopy.com/gallery/index.html $>$. Acesso em out.2008.

KONDO, T.; SHIBASAKI, J.; ARITA-KIKUTANI, H.; MANABE, M.; INABA, R.; MIZUKI, A. Mixed Reality Technology at a Natural History Museum. 2007. Disponível em: <http://www.archimuse.com/mw2007/papers/kondo/kondo.html>. Acesso em nov.2008.

LPI. Stereo Imagery: Anaglyphs. Lunar Planetary Institute, Houston, Texas. 1999. Disponível em: <http://www.lpi.usra.edu/education/MarsMillennium/3dlesson.pdf>. Acesso em out.2008.

MCMAHAN, R.P., GORTON, D., GRESOCK, J., MCCONNELL, W. AND BOWMAN, D.A. Separating the effects of level of immersion and 3D interaction techniques. Proceedings of the ACM symposium on Virtual reality software and technology, Limassol New York: ACM Press, 108-111. 2006.

MILGRAM, P. et al. Augmented reality: a class of displays on the realityvirtuality continuum. Telemanipulator and Telepresence Technologies. 1994. Disponível em: <http://link.aip.org/link/?PSI/2351/282/1>. Acesso em: out.2008.

MINH, S.; FAZEKAS, K.; GSCHWINDT, A. The Presentation of Three-Dimensional Objects with Single Image Stereogram. IEEE Transactions on Instrumentation and Measurement, v. 51, n.5, p.955-961, 2002. 
NAKAMURA, R., BERNARDES JR, J., TORI, R. enJine: Architecture and Application of an Open-Source Didactic Game Engine. In: BRAZILIAN SYMPOSIUM ON COMPUTER GAMES AND DIGITAL ENTERTAINMENT, 5., 2006, Recife. Digital Proceedings of the V Brazilian Symposium on Computer Games and Digital Entertainment. Porto Alegre: SBC, 2006 p.1-7.

NAVE, C.R. HyperPhysics. Georgia State University. 2006. Disponível em: $<$ http://hyperphysics.phy-astr.gsu.edu/hbase/HFrame.html>. Acesso em: out.2008.

NVIDIA. NVIDIA 3D Stereo. NVIDIA website. Disponível em: $<$ http://www.nvidia.com/object/3d stereo.html>. Acesso em: out.2008.

O'BRIEN, D. Fog Day. 2008. Disponível em: <http://gct13.com/e/20080224/fog-day1>. Acesso em: out.2008.

OPENCV. Open Source Computer Vision. OpenCV Wiki, 2010. Disponível em: $<$ http://opencv.willowgarage.com/wiki/>. Acesso em: fev.2010.

OPENGL. OpenGL - The Industry Standard for High Performance Graphics. OpenGL website, 2010. Disponível em: <http://www.opengl.org/>. Acesso em: fev.2010.

PETTIGREW, J. D. The Evolution of Binocular Vision. In: Visual Neuroscience. Cambridge: Cambridge University Press, 1986, p. 208-222.

PETERSON, S.D., AXHOLT, M., ELLIS, S.R. Comparing Disparity Based Label Segregation in Augmented and Virtual Reality. In: VIRTUAL REALITY SOFTWARE AND TECHNOLOGY, 15., 2008, Bordeaux. Proceedings of the ACM Symposium on Virtual Reality Software and Technology. New York: ACM, 2008, p.285-286.

PHOENIX TROPICALS. Growing Bermuda and Rye Grass in Phoenix Arizona. Disponível em: <http://www.phoenixtropicals.com/grass.html>. Acesso em: nov.2008.

PIEKARSKI, W. Interactive 3D Modelling in Outdoor Augmented Reality Worlds. 2004. Disponível em: <http://www.tinmith.net/wayne/thesis/piekarski-thesis.htm>. Acesso em nov.2008.

PINTARIC, T., KAUFMANN, H. Affordable Infrared-Optical Pose-Tracking for Virtual and Augmented Reality. In: IEEE VR WORKSHOP ON TRENDS AND ISSUES IN TRACKING FOR VIRTUAL ENVIRONMENTS, 2007, Charlotte. Proceedings of 
Trends and Issues in Tracking for Virtual Environments Workshop. Charlotte: IEEE, 2007, p.44-51.

RAINBOW SYMPHONY. Proview Professional 3D Glasses. 2000. Disponível em: <http://www.rainbowsymphony.com/pro3d.html>. Acesso em: nov.2008.

RASKAR, R., WELCH, G. \& FUCHS, H. Spatially augmented reality. In: INTERNATIONAL WORKSHOP ON AUGMENTED REALITY, 1., 1998, San Francisco. Proceedings of the international workshop on Augmented Reality : placing artificial objects in real scenes. Natick: A. K. Peters, 1998, p. 63-72.

REEL 3D. 3-D Slide Viewers. Disponível em: $<$ http://www.stereoscopy.com/reel3d/slide-viewers-realist.html>. Acesso em: nov.2008.

RMM. An Illustrated Guide to Stereo Slide Mounting. Rocky Mountain Memories $2001 . \quad$ Disponível em: $<$ http://www.rmm3d.com/3d.encyclopedia/mounting/section3.html>. Acesso em: nov.2008.

ROBERTS, D. History of Lenticular and Related Autostereoscopic Methods. Leap Hechnologies, Hillsboro, $2003 . \quad$ Disponível em: $<$ http://www.microlens.com/pdfs/history of lenticular.pdf $>$. Acesso em: nov.2008.

ROOLLINGS, A. AND MORRIS, D. Game Architecture and Design: A New Edition. New Riders, 43-45. 2004.

SANTOS, A.D.; MACHADO, L. S. Visualização Tridimensional de Baixo Custo para o Desenvolvimento de Aplicações em Medicina. In: SYMPOSIUM ON VIRTUAL AND AUGMENTED REALITY, 10., 2008, João Pessoa. Proceedings X Symposium on Virtual and Augmented Reality, João Pessoa, 2008, p.179-182.

SCHMALSTIEG, D., WAGNER, D. Experiences with Handheld Augmented Reality. In: SYMPOSIUM ON MIXED AND AUGMENTED REALITY, 6., 2007, Washington. Proceedings of the 2007 6th IEEE and ACM International Symposium on Mixed and Augmented Reality. Washington: IEEE Computer Society, 2007. p.1-13.

SCHRECK, F. Colograms - a simple way to create stereoscopic images. Colograms. Disponível em: $<$ http://george.ph.utexas.edu/ schreck/schreck/cologram/>. Acesso em: out.2008. 
SCREENDIGEST. Digital Cinema building momentum as 3D drives market.. Disponível em: $<$ http://www.screendigest.com/press/releases/pr 0303 2010/view.html>. Acesso em mar.2010.

SILVA, R. Optical See-Through HMD. 2003. Disponível em: $<$ http://virtual.Incc.br/ rodrigo/links/AR/node7.html>. Acesso em: nov.2008.

SISCOUTTO, R.A. Proposta de Arquitetura para Teleconferência Tridimensional Baseada na Integração de Vídeo Avatar Estereoscópico em Ambiente Virtual Tridimensional. 2003. 192p. Tese (Doutorado) - Escola Politécnica da Universidade de São Paulo, São Paulo, 2003.

SISCOUTTO, R. A. SZENBERG, F. TORI, R. RAPOSO, A. B. CELES, W. GATTAS, M. Estereoscopia. In: TORI, R. KIRNER, C. SISCOUTTO, R. Fundamentos e Tecnologia de Realidade Virtual e Aumentada - Livro do Pré-Simpósio, VIII Symposium on Virtual Reality. Porto Alegre: SBC, 2006. c.13, p. 221-245.

SLY3, 2009. SLY3: Honor Among Thieves. Playstation. Disponível em: $<$ http://www.us. playstation.com/ Sly3/>. Acesso em: mai.2009.

STARKS, M. Stereoscopic Imaging Technology. Stereoscopic Imaging Technology, 3DTV Corporation. Disponível em: $<$ http://www.3dmagic.com/articles/sit.html $>$. Acesso em out.2008.

STEREO3D.COM. The independent 3D and Virtual Reality resource!. Disponível em: <http://www.stereo3d.com/3dhome.htm>. Acesso em: mar.2010.

STEREOSCOPY.COM. The World of 3D-Imaging. Disponível em: $<$ http://www.stereoscopy.com/>. Acesso em: mar.2010.

STEUER, J. Defining Virtual Reality: Dimensions Determining Telepresence. The Journal of Communication, v.42, n.4, p.73-93, 1992.

TEATHER, R.J., STUERZLINGER, W. Guidelines for 3D Positioning Techniques. In: CONFERENCE ON FUTURE PLAY, Toronto, 2007. Proceedings of the 2007 Conference on Future Play. Toronto, Canada. 2007.

TOMOYOSE, A.N., SANCHES, S.R., TORI, R. Integração da Estereoscopia à Mecânica dos Jogos. Proceedings: VIII Brazilian Symposium on Games and Digital Entertainment. Rio de Janeiro, RJ, Brazil, 2009. 
TOKUNAGA, D.M., SANCHES, R.R.S., TRIAS, P.L., BERNARDES J.A.L., NAKAMURA, R., TORI, R. Video-based microfacet-billboard avatar for educational immersive teleconference systems. In: SYMPOSIUM ON VIRTUAL AND AUGMENTED REALITY, 11., Porto Alegre, 2009. Proceedings of XI Symposium on Virtual and Augmented Reality. Porto Alegre, 2009.

TORI, R.; BERNARDES J.; NAKAMURA, R. Teaching Introductory Computer Graphics Using Java 3D, Games, and Customized Software: A Brazilian Experience. In: INTERNATIONAL CONFERENCE AND EXHIBITION ON COMPUTER GRAPHICS AND INTERACTIVE TECHNIQUES, 33., 2006, Boston. Proceedings of XXXIII International Conference and Exhibition on Computer Graphics and Interactive Techniques, Boston, 2006.

US PATENT 5524188. Viewing three dimensional objects by rotational wobble about multiple axes. Free Patents Online. Disponível em: $<$ http://www.freepatentsonline.com/6687003.html>. Acesso em: out.2008.

US PATENT 6687003. Method for Recording and Viewing Stereoscopic Images in Color Using Multichrome Filters. Free Patents Online. Disponível em: <http://www.freepatentsonline.com/6687003.html>. Acesso em out.2008.

VILELA, A.L.M. Anatomia \& Fisiologia Humanas. Disponível em: $<$ http://www.afh.bio.br/sentidos/sentidos1.asp $>$. Acesso em: set.2009.

WAACK, F. Stereo Photography. 2004. Disponível em: <http://www.stereoscopy.com/library/waack-ch-5.html>. Acesso em: nov.2008.

WAGNER, D., SCHMALSTIEG, D. History and Future of Tracking for Mobile Phone Augmented Reality. In: INTERNATIONAL SYMPOSIUM ON UBIQUITOUS VIRTUAL REALITY, 0., 2009. Proceedings of International Symposium on Ubiquitous Virtual Reality 2009, pp. 7-10.

WEINAND, L. 3D Shutter Glasses. 3D Stereo Technology: Is it Ready for Prime Time? 2005. Disponível em: <http://www.tomshardware.com/reviews/3d-stereotechnology, 1023-5.html>. Acesso em: nov.2008.

WEINAND, L. Autostereoscopic Displays. 3D Stereo Technology: Is it Ready for Prime Time? 2005. Disponível em: <http://www.tomshardware.com/reviews/3dstereo-technology, 1023-5.html>. Acesso em: nov.2008. 
WIKIPEDIA. Volumetric Display. Volumetric Display - Wikipedia the free encyclopedia. 2008. Disponível em: <http://en.wikipedia.org/wiki/Volumetric display>. Acesso em: out.2008.

WOLFGANG, C.; DANCY, M. Polarization Exploration. WebPhysics. Disponível em:<http://webphysics.davidson.edu/physlet resources/dav optics/examples/polariz ation.html>. Acesso em: out.2008.

WOODS, A. 3D on Your PC. Stereoscopic (3D) Imaging. 2005. Disponível em: <http://www.3d.curtin.edu.au/3D-PC/>. Acesso em: out.2008.

WOODS, A. Stereoscopic Displays and Applications. Stereoscopic Displays and Applications Conference Website. Disponível em: <http://www.stereoscopic.org/3dcinema/index.html>. Acesso em: out.2008.

WOODS, A. The Illustrated 3D Movie List. 3D Movie Website. Disponível em: <http://www.3dmovielist.com/list.html>. Acesso em: out.2008.

ZALMAN. Trimon 2D/3D Convertible LCD Monitor. Zalman, leading the world of Quiet Computing Solutions. Disponivel em: <http://www.zalman.co.kr/ENG/product/Product Read.asp?idx=219>. Acesso em: nov.2008.

ZYDA, M. From Visual Simulation to Virtual Reality to Games. Disponível em: $<$ http://csdl2.computer.org/persagen/DLAbsToc.jsp?resourcePath=/dl $/ \mathrm{mags} / \mathrm{co} /$ \&toc= comp/mags/co/2005/09/r9toc.xml\&DOl=10.1109/MC.2005.297>. Acesso em: 21 ago.2008.

ZYGMUNT, P. YUNFENG, L. GREGORY, F. A New Look at Binocular Stereopsis. Vision Research, v.45, n.17, p.2244-2255, 2005. 
ANEXO A

\begin{tabular}{|c|c|c|c|c|c|c|}
\hline & & 1 & 2 & 3 & 4 & 5 \\
\hline \multirow{2}{*}{ Esferas } & resultado & & & & & \\
\hline & solução & \multicolumn{5}{|c|}{$1-2-3-4$} \\
\hline \multirow{2}{*}{ Regua } & resultado & & & & & \\
\hline & solução & & & & & \\
\hline \multirow{2}{*}{ Blocos } & resultado & & & & & \\
\hline & solução & \multicolumn{5}{|c|}{10,0} \\
\hline Nave & resultado & & & & & \\
\hline
\end{tabular}

\begin{tabular}{|c|c|c|c|c|c|c|}
\hline \multirow{2}{*}{ Esferas } & $\mathbf{1}$ & $\mathbf{2}$ & $\mathbf{3}$ & $\mathbf{4}$ & $\mathbf{5}$ \\
\hline \multirow{2}{*}{ Regua } & resultado & solução & \multicolumn{5}{|c|}{$1-2-3-4$} & & \\
\hline \multirow{2}{*}{ Blocos } & resultado & & & & & \\
\cline { 2 - 7 } & solução & & & & & \\
\hline & resultado & solução & & & & \\
\hline \multirow{2}{*}{ Nave } & resultado & & & & & \\
\hline
\end{tabular}

\begin{tabular}{|c|c|c|c|c|c|c|}
\hline & & 1 & 2 & 3 & 4 & 5 \\
\hline \multirow{2}{*}{ Esferas } & resultado & & & & & \\
\hline & solução & \multicolumn{5}{|c|}{$1-2-3-4$} \\
\hline \multirow{2}{*}{ Regua } & resultado & & & & & \\
\hline & solução & & & & & \\
\hline \multirow{2}{*}{ Blocos } & resultado & & & & & \\
\hline & solução & \multicolumn{5}{|c|}{10,0} \\
\hline Nave & resultado & & & & & \\
\hline
\end{tabular}

